\title{
The empirical probability of integrating CSP and its cost optimal configuration in a low carbon energy system of EUMENA
}

\author{
Author: Denis Hess ${ }^{1 *}$
}

Ongoing cost reduction of low carbon energies allows an increasing implementation of such technologies for climate protection targets. How decreasing cost develop in the future is high-grade uncertain. Thus cost sensitivities analyses of an expert based cost-range are needed to show if specific technologies can be cost advantageous for an energy system. In this paper a low carbon and cost-optimal energy system of Europe, Middle East and North Africa (EUMENA) in the year 2050 is analysed with regard to concentrating solar power (CSP). Cost sensitivity analyses show how frequently an integration of CSP in the energy system is. This frequency is defined as empirical probability of technological integration (EPTI). An energy system model allows a suitable analysis framework with tangible competitive technologies such as renewable energies, nuclear power plants and carbon capture and storage (CCS). As a highlight the EPTI of an export of CSP from MENA to EU via point-to-point high voltage direct current (HVDC) transmission lines is analysed. Such CSP-HVDC power plants show an EPTI of up to 66\%. CSP in MENA and southern EU show an average EPTI of $85 \%$, nuclear power plants of $32 \%$ and CCS of $50 \%$. The cost sensitivity analysis shows additionally the cost optimal configuration of CSP and CSP-HVDC. This clarifies the role of CSP and CSP-HVDC for the energy system as a dispatchable base and medium load power plant depending on the region inside EUMENA.

Keywords: CSP-HVDC, optimization, energy system model, renewable dispatchable energies, cost-optimal CSP configuration, DESERTEC

\section{Introduction}

\subsection{State of science}

Research activities of the DLR and other institutions depict the potential use of CSP in MENA and the transmission of CSP to Europe [1], [2], [3], [4]. They found out that the use of CSP in MENA and an export of CSP electricity from MENA to Europe via specific high voltage direct

\footnotetext{
${ }^{1}$ Energy Systems Analysis, German Aerospace Center (DLR), D-70569 Stuttgart, Germany. Corresponding author e-mail: denis.hess@dlr.de
} 
Post-print - Please quote as: Hess, D. The empirical probability of integrating CSP and its cost optimal configuration in a low carbon energy system of EUMENA. Solar Energy, 2018 (accepted)

current transmission lines (HVDC) can supplement the energy mix by balancing domestic energies such as wind turbines and photovoltaic. The progress of a worldwide CSP implementation and its potential role is shown in [5] and [6]. The authors emphasise the system value of CSP as a potential backbone of a low carbon energy system. CSP combined with thermal storage and co-firing option can provide electricity according to demand. Therefore CSP is a valuable dispatchable energy technology [7]. This distinguishes CSP from other fluctuating renewable energies in its energy quality. However, the system advantage of CSP related to cost is high-grade uncertain for a future energy system in the year 2050. Especially, with its current worldwide installed capacity of $5 \mathrm{GW}$ a cost reduction is possible due to learning effects with higher installation capacities but uncertain how its cost develops in competition to other technologies. This provokes the question if a further integration of CSP can be cost advantageous on the long term perspective? Here we show with an energy system model the empirical probability of technological integration (EPTI) of CSP in a low carbon energy system in the year 2050. Energy system models are today's methods to approximate optimal future energy systems. Often they follow the target function of minimal system cost, perfect foresight and linear programming (REMix, PLEXOS, TIMES, ReEDS, etc. [8]). These numerical models are bottom-up models using detailed technology modules building up a simulation of an energy system. The minimization of system cost as objective function results in potential exclusions of specific technologies. Due to small and quite fortuitous cost difference among technologies, some technologies can be excluded automatically by the optimization model due to a small cost difference. This so-called "penny flip" effect is a major barrier in optimizing energy systems because it leads to unrealistic results. To solve this barrier as well as the uncertainty of specific technological cost, a comprehensive cost sensitivity analysis is applied.

\subsection{Novelty and scientific contribution}

The present paper considers a broad range of techno-economic expert assumptions. With such data a frequency of an integration of a certain technology compared to all other used technologies is possible. This empirical probability of technological integration analysis includes uncertainty and high spatio-temporal resolution applying a numerical energy system model. As a major novelty in energy system modelling and CSP analysis, this approach allows assessing the potential of an integration of a technology in a cost-optimized and low carbon energy system. Additionally, the cost-optimal configuration of CSP with its thermal storage, solar field and co-firing option is shown. Such configuration values are important for the design of this technology in an entire energy system under a least-cost assumption. As a novel highlight, CSP power plants are considered that transfer dispatchable energy from 
Post-print - Please quote as: Hess, D. The empirical probability of integrating CSP and its cost optimal configuration in a low carbon energy system of EUMENA. Solar Energy, 2018 (accepted)

MENA to EU via point-to-point HVDC from a CSP hotspot to a potential centre of demand in the EU.

\section{Methodology and key assumptions}

\subsection{Hypothesis}

An empirical probability of technological integration analysis can show how probable an integration of a certain technology is in a cost-optimal framework of an energy system. For this purpose an energy system model is applied with cost sensitivity scenarios of the analysed technology and tangible alternative technologies using expert cost assumptions. For CSP a learning curve approach of cost reduction is applied based on scenarios of worldwide installed capacity in the year 2050 (see appendix Table 18). Having a more detailed look on potential competitive and tangible low carbon dispatchable technologies to CSP, the EPTI of nuclear power plants and CCS technologies is calculated.

In the last part of this paper the CSP-HVDC and CSP configuration values out of the sensitivity scenarios are analysed identifying the role of the technology for the energy system in different regions.

The objective of the analysis is to model CSP relative conservatively compared to other technologies. This facilitates a conservative examination of this technology to analyse its EPTI strictly avoiding an overestimation of this technology.

\subsection{Modelling framework}

\subsubsection{Examination area EUMENA}

Calculating the EPTI for CSP the examination area EUMENA is applied. This geographical region consists of geographical subregions: Europe, Middle East and North Africa [9]. As a region with about $15 \%$ of global population in 2050 [10], EUMENA influences global climate targets significantly and therefore needs careful considerations on the composition of its future energy systems.

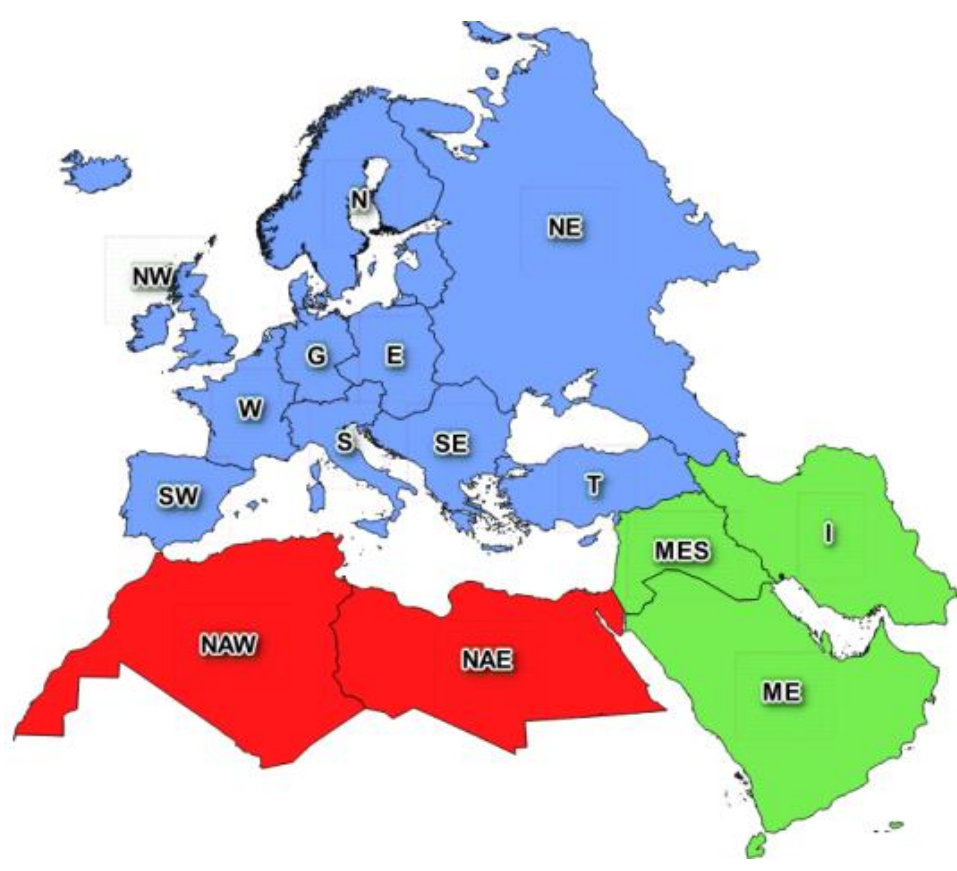

Figure 1: EUMENA geographical map 
Post-print - Please quote as: Hess, D. The empirical probability of integrating CSP and its cost optimal configuration in a low carbon energy system of EUMENA. Solar Energy, 2018 (accepted)

In Figure 1 the 15 analysed regions inside EUMENA are illustrated. The blue area represents geographical Europe, the green area Middle East and the red area North Africa. An aggregation inside such regions is made due to computational constraints of the used energy system model. In the following Table 1 the spatial aggregation for the model regions of the nodes in Figure 1 and the assumed annual electrical net demand is shown. The definition and abbreviation of the nodes in Table 1 is essential to better understand the results in Figure 4, Figure 5 and Figure 6 . The spatial focus of the analysis is not only on the entire EUMENA region but also on sub-regions and nations, wherefore Germany is used as a national example.

An aggregation of separate nations can lead to a smoothing of their demand and resource characteristic. To reduce such falsification an aggregation is at first made according to a similar distribution of demand. Secondly the aggregation is made to limit the east-west expansion of a region avoiding an excessive smoothing of solar resources. Depending on the spatial proximity of a model region to Germany, the model regions close to Germany have a smaller spatial area than the distant model regions. This allows a better model framework to cope with a higher influence of the surrounding regions for Germany. The annual electrical net demand in 2050 follows a demand model which includes electricity demand of the heat and mobility sector and is described in the appendix in section 8.1.2 and Table 9. 
Post-print - Please quote as: Hess, D. The empirical probability of integrating CSP and its cost optimal configuration in a low carbon energy system of EUMENA. Solar Energy, 2018 (accepted)

Table 1: Aggregation of countries to 15 model regions in the examination area EUMENA

\begin{tabular}{|c|c|c|c|}
\hline $\begin{array}{l}\text { Model region } \\
\text { / Node }\end{array}$ & Alias & Country or region & $\begin{array}{c}\text { Annual } \\
\text { electrical net } \\
\text { demand [TWh] } \\
\text { in } 2050\end{array}$ \\
\hline $\mathbf{G}$ & Germany & Germany & 706 \\
\hline $\mathbf{N}$ & North & $\begin{array}{l}\text { Denmark, Norway, Sweden, Finland, Lithuania, } \\
\text { Latvia, Estonia }\end{array}$ & 571 \\
\hline $\mathbf{E}$ & East & Poland, Czech Republic, Slovakia, Hungary & 429 \\
\hline $\mathbf{S}$ & South & $\begin{array}{l}\text { Switzerland, Austria, Liechtenstein, Italy, } \\
\text { Slovenia }\end{array}$ & 689 \\
\hline $\mathbf{W}$ & West & France, Belgium, Netherlands, Luxemburg & 920 \\
\hline NW & North West & United Kingdom, Ireland, Iceland & 785 \\
\hline NE & North East & $\begin{array}{l}\text { Ukraine, Moldova, Belarus, Russia until Ural } \\
\text { mountains, Azerbaijan, Armenia, Georgia }\end{array}$ & 1037 \\
\hline SE & South East & $\begin{array}{l}\text { Greece, Croatia, Rumania, Serbia, Kosovo, } \\
\text { Albania, Macedonia, Bulgaria, Bosnia- } \\
\text { Herzegovina, Montenegro }\end{array}$ & 321 \\
\hline SW & South West & Portugal, Spain & 342 \\
\hline $\mathbf{T}$ & $\begin{array}{l}\text { Turkey, } \\
\text { Cyprus }\end{array}$ & Turkey, Cyprus & 613 \\
\hline MES & Mesopotamia & Israel, Jordan, Palestine, Lebanon, Syria, Iraq & 950 \\
\hline I & Iran & Iran & 874 \\
\hline ME & Middle East & $\begin{array}{l}\text { Djibouti, Yemen, Oman, Saudi Arabia, UAE, } \\
\text { Qatar, Bahrain, Kuwait }\end{array}$ & 974 \\
\hline NAE & $\begin{array}{l}\text { North Africa } \\
\text { East }\end{array}$ & Libya, Egypt & 1178 \\
\hline NAW & $\begin{array}{l}\text { North Africa } \\
\text { West }\end{array}$ & Morocco, Algeria, Tunisia & 674 \\
\hline
\end{tabular}


Post-print - Please quote as: Hess, D. The empirical probability of integrating CSP and its cost optimal configuration in a low carbon energy system of EUMENA. Solar Energy, 2018 (accepted)

\subsubsection{The concept of a CSP transfer from MENA to EU}

Figure 2 illustrates the concept of point-to-point transmission lines from potential CSP hotspots in MENA to centres of demand in EUMENA. The point-to-point lines from potential CSP power plants in MENA to centres of demand in EU are configured as HVDC keeping transmission losses low. A CSP-HVDC power plant is a dispatchable solar thermal power plant combined with thermal storage, co-firing option and a HVDC point-to-point transmission line. The combined and enclosed use of CSP and HVDC is defined as CSP-HVDC power plant in the following. This technology is ready for use and its elements are in operation worldwide for many years so far. The important point of view is that such a power plant includes the HVDC transmission line and is therefore projectable as a possible business case. CSP-HVDC has to be considered as a power plant in distance, just with a longer line from the generator to the feed-in point into the grid.

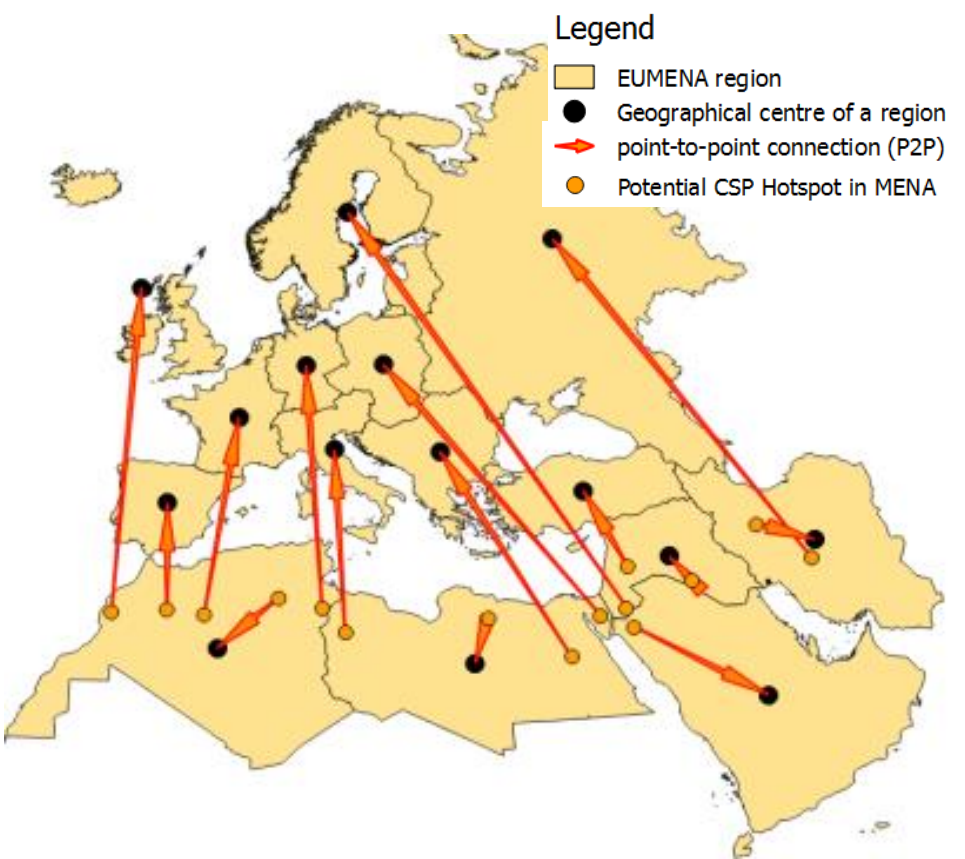

Figure 2: Scheme of CSP and point-to-point transmission lines

The total average length of such point-to-point HVDC lines to one model region is between $1200 \mathrm{~km}$ and $3800 \mathrm{~km}$ and is listed in Table 2. For the sensitivity analysis two pathways are used: predominant overhead lines $(\mathrm{OHL})$ and predominant sea and underground cables (UGC). The pathways are calculated with a line laying model which is described in the appendix. 
Post-print - Please quote as: Hess, D. The empirical probability of integrating CSP and its cost optimal configuration in a low carbon energy system of EUMENA. Solar Energy, 2018 (accepted)

Table 2: CSP-HVDC transmission line lengths to model regions as potential offtakers

\begin{tabular}{|c|c|c|c|c|c|}
\hline \multirow{2}{*}{$\begin{array}{l}\text { Model } \\
\text { region }\end{array}$} & \multicolumn{2}{|c|}{$\begin{array}{l}\text { Predominant } \mathrm{OHL} \\
\text { configuration }\end{array}$} & \multicolumn{2}{|c|}{$\begin{array}{l}\text { Predominant sea and } \\
\text { UGC configuration }\end{array}$} & \multirow{2}{*}{$\begin{array}{c}\text { Total average } \\
\text { length of point-to- } \\
\text { point line }\end{array}$} \\
\hline & $\begin{array}{l}\text { Length line } \\
\text { land }\end{array}$ & $\begin{array}{l}\text { Length line } \\
\text { sea }\end{array}$ & $\begin{array}{l}\text { Length line } \\
\text { land }\end{array}$ & $\begin{array}{l}\text { Length line } \\
\text { sea }\end{array}$ & \\
\hline$\overline{\mathbf{G}}$ & 2343 & 249 & 1212 & 1403 & 2604 \\
\hline $\mathbf{N}$ & 3461 & 331 & 1675 & 1915 & 3691 \\
\hline$E$ & 2549 & 356 & 1104 & 1626 & 2818 \\
\hline S & 1540 & 366 & 568 & 1321 & 1898 \\
\hline $\mathbf{W}$ & 2178 & 214 & 1012 & 1318 & 2361 \\
\hline NW & 2747 & 930 & 645 & 3291 & 3807 \\
\hline NE & 2502 & 109 & 1342 & 1129 & 2541 \\
\hline SE & 1928 & 441 & 587 & 1604 & 2280 \\
\hline NAE & 0 & 0 & 0 & 0 & 0 \\
\hline NAW & 0 & 0 & 0 & 0 & 0 \\
\hline SW & 1206 & 88 & 521 & 846 & 1331 \\
\hline$T$ & 899 & 255 & 406 & 838 & 1199 \\
\hline MES & 0 & 0 & 0 & 0 & 0 \\
\hline I & 0 & 0 & 0 & 0 & 0 \\
\hline ME & 0 & 0 & 0 & 0 & 0 \\
\hline
\end{tabular}

\subsubsection{Energy system model REMix}

As a numerical energy system model REMix (sustainable Renewable Energy Mix) [11], [12] and [13] is applied. This bottom-up model has the target function of minimizing system cost (total cost) using linear programming under perfect foresight. System cost include the annuities of investment and the cost of operation and maintenance (O\&M), fuel and emission cost for energy relevant technologies (power plants, storage and grid) shown in Eq. (1). REMix consists of two models: REMix-EnDAT (Energy Data Analysis Tool) and REMixOptiMo (Energy System Optimization). REMix-EnDAT uses climate and weather data to calculate potentials and technological time series of PV, Wind, CSP and hydro power plants. By regarding the cost of technologies, REMix-OptiMo can decide upon configuration and operation of the energy system. This means a quantitative decision about which capacity is built and which dispatch is used. Such an optimization can be performed based on a "greenfield" (model endogenous optimization), a "partial greenfield" (model endogenous 
Post-print - Please quote as: Hess, D. The empirical probability of integrating CSP and its cost optimal configuration in a low carbon energy system of EUMENA. Solar Energy, 2018 (accepted)

optimization under exogenously given capacities) or just a dispatch optimization with only exogenously given capacities. REMix-OptiMo performs the following output data: capacity, generation, system operation, cost as well as emission data. The model structure is illustrated in Figure 3. REMix is built in the algebraic language GAMS using the CPLEX solver. A detailed overview of the model methods is available in the references [11], [12] and [13]. Due to worldwide available meteorological data, calculated and complied by the German Aerospace Centre, REMix is worldwide applicable. The basic modelling assumptions including the CSP model and all applied and tangible technologies such as renewable energies, nuclear power plants, CCS, coal power plants and gas turbines are explained and characterised in the appendix.

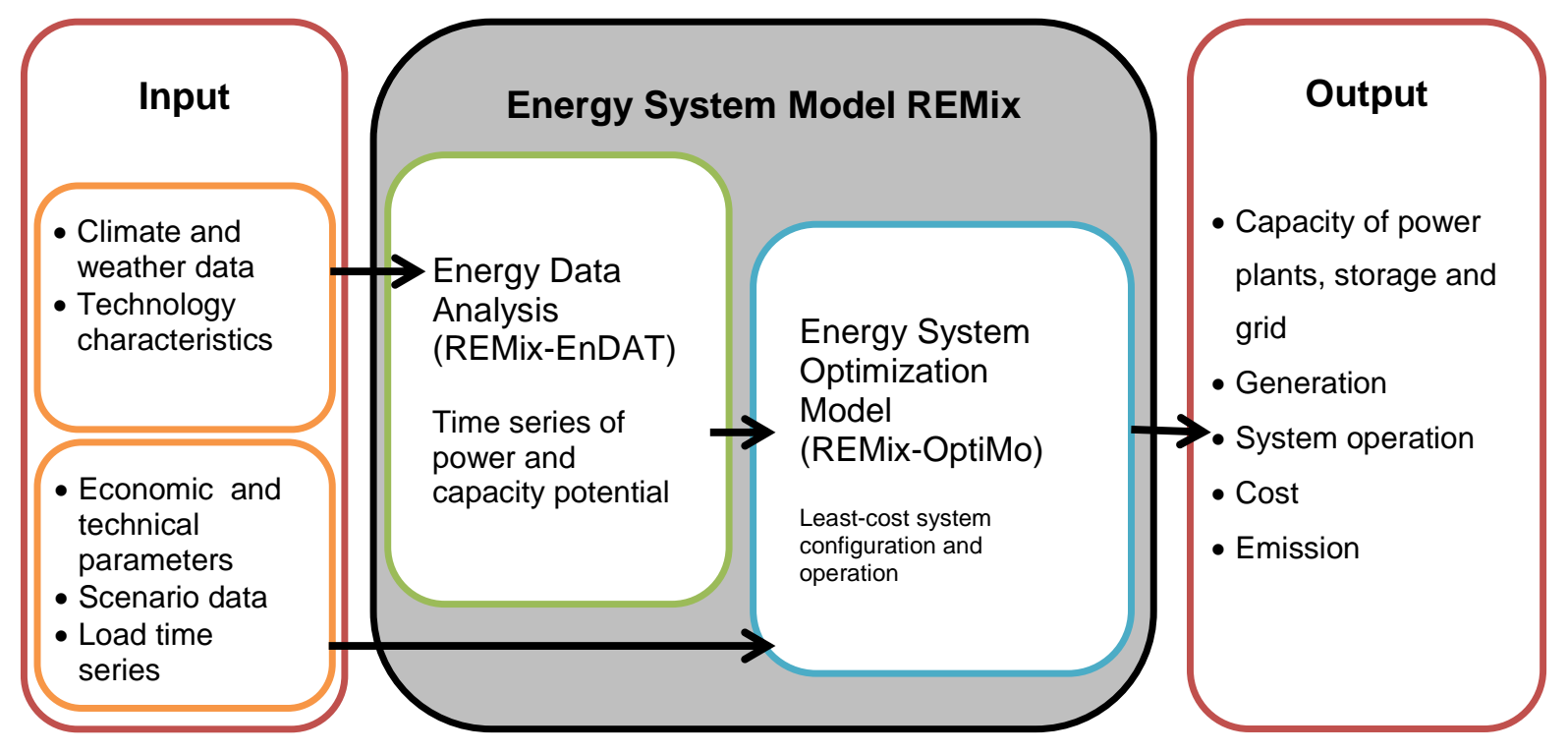

Figure 3: Model structure of REMix-EnDAT and REMix-OptiMo, input and output data based on [13]

Objective function in the linear program framework to be minimized:

$$
\sum \text { System cost }[k €] \rightarrow \text { minimize }
$$

The following equations concretise the system cost and calculation method. REMix, can optimize the variables which are written in bold. System cost is the sum of capital cost $\boldsymbol{C}_{\text {capital }}$ and operation cost $\boldsymbol{C}_{\text {operation }}$ described in Eq.(2). For the calculation of capital cost the annuity method is used including endogenous capacity $\boldsymbol{P}_{\text {addedcap }}$ and exogenous capacity $P_{\text {existCap }}$ according to Eq. (3) and (4), which are multiplied with specific $\operatorname{cost} c_{\text {specinv }}\left[\frac{\% \text { of investment }}{\text { year }}\right]$. The operation cost of the power plant park is calculated using fix 
Post-print - Please quote as: Hess, D. The empirical probability of integrating CSP and its cost optimal configuration in a low carbon energy system of EUMENA. Solar Energy, 2018 (accepted)

and variable O\&M as well as fuels and emission cost according to Eq. (5). All cost assumptions in the paper are given in constant monetary value of the year 2015.

$$
\begin{gathered}
\text { System Cost }[k €]=\boldsymbol{C}_{\text {capital }}+\boldsymbol{C}_{\text {operation }} \\
=\text { Capital Cost }+ \text { Fix O\&M Cost }+ \text { Variable O\&M Cost }+ \text { Fuel Cost }+ \text { Emission Cost } \\
\boldsymbol{C}_{\text {capital }}=\left(\boldsymbol{P}_{\text {addedCap }}+P_{\text {existCap }}\right) \cdot c_{\text {specInv }} \cdot f_{\text {annuity }} \\
f_{\text {annuity }}=\frac{i \cdot(1+i)^{t_{y}}}{(1+i)^{t_{y}}-1} \\
\boldsymbol{C}_{\text {operation }}=\left(\boldsymbol{P}_{\text {addedCap }}+P_{\text {existCap }}\right) \cdot c_{\text {specInv }} \cdot c_{\text {O\&M Fix }} \\
+\sum_{t} \boldsymbol{P}_{\text {gen }}(t) \cdot\left(c_{\text {O\&M Variable }}+c_{\text {Fuel }}+c_{\text {Emission }}\right)
\end{gathered}
$$

The used parameters for Eq. (2)-(5) are available in the appendix in Table 12 to Table 16.

\subsection{Empirical probability analysis within an energy system model}

The empirical probability of CSP-HVDC, CSP and other dispatchable energies, such as nuclear power plants and CCS technologies is determined by cost sensitivity scenarios. Because of their low carbon emission and possible competition of dispatchability to CSPHVDC and CSP, nuclear and CCS are considered. Hereby, each region in EUMENA is analysed separately in a modelling framework of isolated regions without grid interconnection to allow an analysis for each region separately. The analysis is performed in a "greenfield" approach. The transmission and distribution grid inside a region is considered according to [14] with specific grid values available in Table 19. 
Post-print - Please quote as: Hess, D. The empirical probability of integrating CSP and its cost optimal configuration in a low carbon energy system of EUMENA. Solar Energy, 2018 (accepted)

The use of an optimization model considering minimal cost as target function leads to a socalled "penny flip" effect which causes an exclusion of technologies. This exclusion can be based on minimal cost differences of technologies. To avoid this effect in the following, different cost relations of technologies are required. Table 3 shows the possible combination of cost assumptions of technologies. These cost relation combinations arise 9 different scenarios. In addition to the described sensitivity framework in Table 3, two transmission line technologies (OHL and UGC) are analysed. Consequently, the complete sensitivity includes $2 \times 9=18$ scenarios.
Table 3: Sensitivity analysis of a single technology in REMix using different technological cost relations

\begin{tabular}{|c|c|}
\hline $\begin{array}{c}\text { Cost assumption } \\
\text { of all } \\
\text { technologies }\end{array}$ & $\begin{array}{c}\text { Cost assumption } \\
\text { of examined } \\
\text { technology }\end{array}$ \\
\hline \multirow{3}{*}{$\max _{\text {all }}$} & $\max _{\text {tech }}$ \\
\hline & mean $_{\text {tech }}$ \\
\hline & $\min _{\text {tech }}$ \\
\hline \multirow{3}{*}{ mean $_{\text {all }}$} & $\max _{\text {tech }}$ \\
\hline & mean $_{\text {tech }}$ \\
\hline & $\min _{\text {tech }}$ \\
\hline \multirow{3}{*}{$\min _{\text {all }}$} & $\max _{\text {tech }}$ \\
\hline & meantech $_{\text {tech }}$ \\
\hline & $\min _{\text {tech }}$ \\
\hline
\end{tabular}

The integration frequency or relative empirical probability of technology integration (EPTI) of these 18 scenarios is defined in Eq.(6).

$$
\operatorname{EPTI}_{18}=\frac{\left|E_{P T I_{18}}\right|(\text { capacity }>1 G W)}{18}
$$

The absolute empirical probability |EPTI| includes the integration of a technology if a

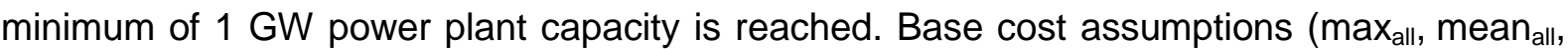
$\min _{\text {all }}$ ) are set constant for all technologies. Only the examined technology (here: CSP-

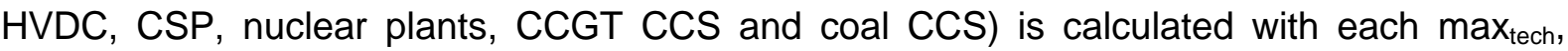
mean $_{\text {tech }}$ and $\min _{\text {tech }}$ cost combination to the base cost assumptions of all other technologies. Thus, the probability of each cost assumption is assumed to be equal.

The aim of this analysis is to quantify the relative empirical probability of the above mentioned technologies in each model region. Showing also EPTI depending on $\mathrm{CO}_{2}$ emission, two different $\mathrm{CO}_{2}$ emission limits with 0 and $16 \mathrm{~g} \mathrm{CO}_{2} / \mathrm{kWh}_{\text {demand }}$ (" $0 \mathrm{CO}_{2}$ Emission" and "Small $\mathrm{CO}_{2}$ Emission") are used. This amounts to an overall sum of $36(18 \times 2)$ 
Post-print - Please quote as: Hess, D. The empirical probability of integrating CSP and its cost optimal configuration in a low carbon energy system of EUMENA. Solar Energy, 2018 (accepted)

scenarios. CCS technologies are excluded in the first step due to their existing $\mathrm{CO}_{2}$ emission and incompatible comparability in this framework. In an excursion in section 3.2 CCS is included showing its EPTI (emission scenario "Small $\mathrm{CO}_{2}$ Emission with CCS"). The small $\mathrm{CO}_{2}$ emission limit is in the range trying to reach the below $2^{\circ} \mathrm{C}$ goal [15].

\section{Results of the empirical probability analysis}

\subsection{The empirical probability of CSP-HVDC, CSP and nuclear power plants}

The results in Figure 4 exhibit the integrated capacity of the analysed technologies as dots and capacity bandwidth. The boxplots show the data using quartiles. The technologies are CSP-HVDC (Figure 4a, d), CSP (Figure 4b, e) and nuclear energy (Figure 4c, f) in each model region. The spread of the bandwidth depends on the input cost assumptions and the regional resource and demand profile. Regions which are not listed e.g. in Figure 4 exclude the technology per definition. This is the case for CSP-HVDC which is only defined for EU and for CSP which is only cost efficient in MENA southern EU regions. It is recognizable that the empirical probability of CSP-HVDC and CSP increase with a lower allowed $\mathrm{CO}_{2}$ emission limit in some model regions while the empirical probability of nuclear plants does not change (Table 4). A lower $\mathrm{CO}_{2}$ emission limit benefits therefore the integration of CSP-HVDC and CSP. Based on the results it can be concluded that CSP-HVDC and CSP can substitute carbon emitting technologies, while in this context nuclear power does not.

Table 4: Model region average EPTI considering the $\mathrm{CO}_{2}$ emission limit reduction from 16 to $0 \mathrm{~g} \mathrm{CO}_{2} / \mathrm{kWh}_{\text {demand }}$

\begin{tabular}{l|l|l}
\hline $\begin{array}{l}\text { CSP-HVDC } \\
\text { from } 37.7 \% \text { to } 43.3 \% \Delta\end{array}$ & $\begin{array}{l}\text { CSP } \\
\text { from } 85.0 \% \text { to } 87.2 \% \Delta\end{array}$ & $\begin{array}{l}\text { Nuclear power plants } \\
\text { no change of } 32.2 \%\end{array}$ \\
\hline
\end{tabular}

The average EPTI for all model regions in Table 4 shows that an integration of CSP-HVDC is more supposable than nuclear power plants. CSP has with $85 \%$ and above the highest integration probability. An integration of CSP in MENA regions, Iberia and Turkey is therefore highly probable according to cost.

In Germany the EPTI of CSP-HVDC is $50 \%$. An integration of this technology according to cost is therefore just as probable as improbable. The analysis of the integration probability therefore leads to the statement that CSP-HVDC can be integrated but also that it can't. Table 5 helps to clarify in more depth which cost and transmission infrastructure combinations lead to an integration of CSP-HVDC capacity in Germany and which don't. In the case of "UGC" the EPTI of CSP-HVDC is $33 \%$ whereas in the case of "OHL" the EPTI is $67 \%$. The use of underground cable makes CSP-HVDC more expensive in relation to other 
Post-print - Please quote as: Hess, D. The empirical probability of integrating CSP and its cost optimal configuration in a low carbon energy system of EUMENA. Solar Energy, 2018 (accepted)

options and therefore decreases the likelihood of an integration in the cost minimizing approach. The cost combination of $\max _{\text {all }}$ and mean all shows that CSP-HVDC is more frequently integrated than in the cost combination $\min _{\text {all. }}$. The cost input parameters are therefore more favourable for CSP-HVDC when other energy technologies are in the same high or medium cost scenario.

Table 5: Results of cost and transmission infrastructure combination for the integration of CSP-HVDC capacity in Germany

\begin{tabular}{|c|c|c|c|}
\hline $\begin{array}{l}\text { Cost assumption } \\
\text { of all technologies }\end{array}$ & $\begin{array}{c}\text { Cost assumption } \\
\text { of examined } \\
\text { technology }\end{array}$ & $\begin{array}{c}\text { CSP-HVDC } \\
\text { capacity [GW] in } \\
\text { Germany "UGC" }\end{array}$ & $\begin{array}{c}\text { CSP-HVDC } \\
\text { capacity [GW] in } \\
\text { Germany "OHL" }\end{array}$ \\
\hline \multirow{3}{*}{$\max _{\text {all }}$} & max $_{\text {tech }}$ & 0 & 13 \\
\hline & mean $_{\text {tech }}$ & 59 & 80 \\
\hline & $\min _{\text {tech }}$ & 98 & 111 \\
\hline \multirow{3}{*}{ mean $_{\text {all }}$} & max $_{\text {tech }}$ & 0 & 10 \\
\hline & mean $_{\text {tech }}$ & 0 & 0 \\
\hline & $\min _{\text {tech }}$ & 74 & 85 \\
\hline \multirow{3}{*}{$\min _{\text {all }}$} & max $_{\text {tech }}$ & 0 & 0 \\
\hline & mean $_{\text {tech }}$ & 0 & 0 \\
\hline & $\min _{\text {tech }}$ & 0 & 5 \\
\hline
\end{tabular}

Capacity of CSP-HVDC is the net capacity of the power block. The colours show in green a high capacity and in yellow a small capacity. 

system of EUMENA. Solar Energy, 2018 (accepted)
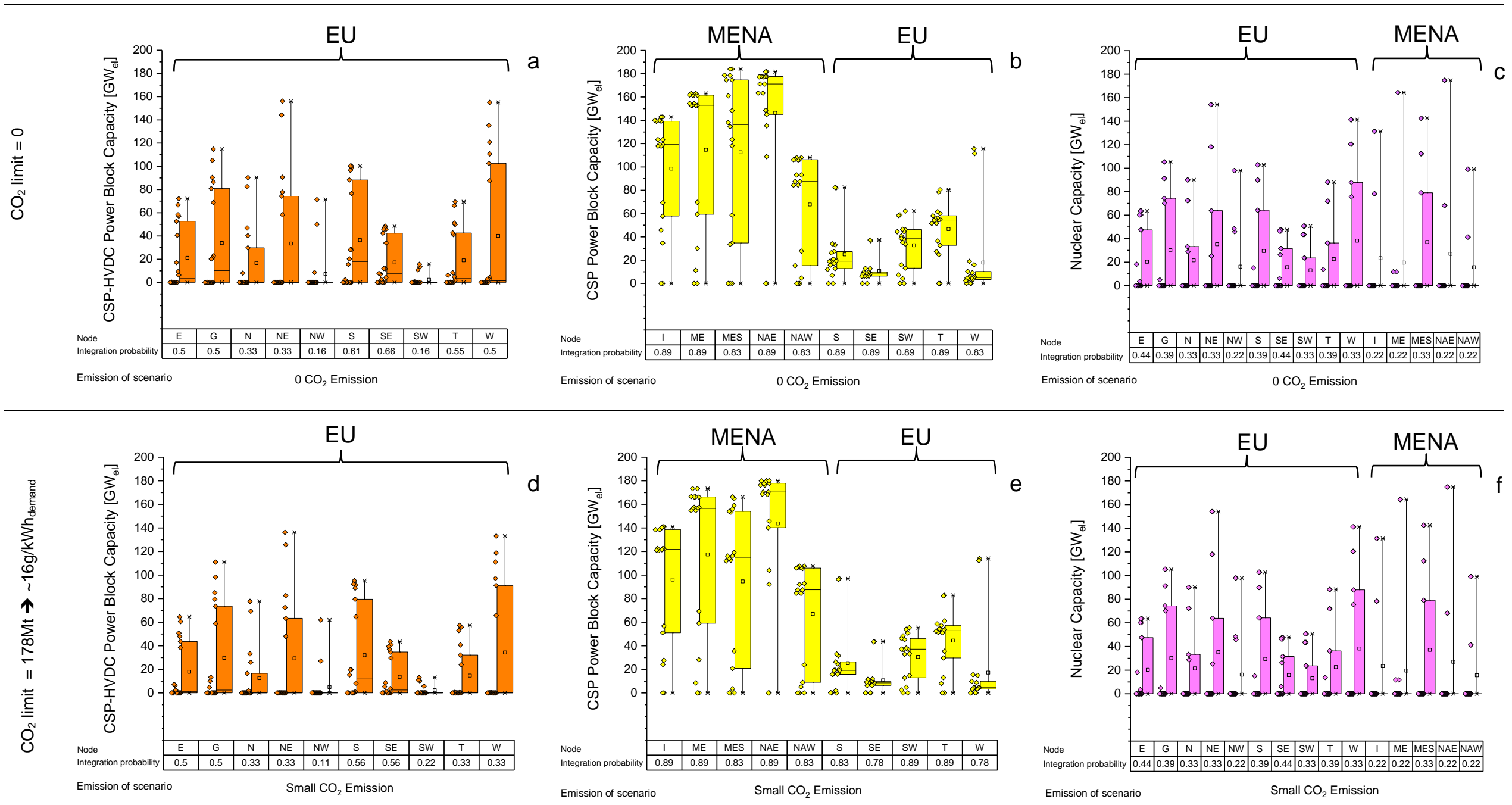

\footnotetext{
Figure 4: EPTI of CSP-HVDC, CSP and nuclear power plants - no CCS allowed
} 
Post-print - Please quote as: Hess, D. The empirical probability of integrating CSP and its cost optimal configuration in a low carbon energy system of EUMENA. Solar Energy, 2018 (accepted)

\subsection{Excursion: empirical probability of CCS}

In this excursion CCGT CCS and coal CCS are included, showing the EPTI in Figure 5 of CSP-HVDC (a), CSP (b), nuclear power (c), CCGT CCS (d) and coal CCS (e). Figure 5 displays the EPTI of CSP-HVDC, CSP and nuclear plants without and with CCS. The results in Figure 5 reason that the inclusion of CCS decreases the EPTI of CSP-HVDC and nuclear plants while values of CSP don't change. This leads to the conclusion that CCS may partially replace CSP-HVDC in EU, but it is still probable that CSP-HVDC may be integrated.

Table 6: Comparing average EPTI of CSP-HVDC, CSP and nuclear power plants in a scenario without CCS with a scenario allowing CCS

\begin{tabular}{l|l|l}
\hline $\begin{array}{l}\text { CSP-HVDC } \\
\text { from } 37.7 \% \text { to } 35.6 \% \nabla\end{array}$ & $\begin{array}{l}\text { CSP } \\
\text { no change of } 85 \%\end{array}$ & $\begin{array}{l}\text { nuclear power plants } \\
\text { from 32.2\% to } 30.7 \% \nabla\end{array}$ \\
\hline
\end{tabular}

First values are the average EPTI in the scenario without CCS from Table 4.

The average EPTI of CCGT CCS is $50.7 \%$ and of coal CCS is $7.0 \%$. Coal CCS is not very probable to be integrated in a low carbon energy scenario due to better alternatives. A low $\mathrm{CO}_{2}$ emission limit leads to the use of low specific $\mathrm{CO}_{2}$ emitting CCS technologies. An analysis of CCS technologies was also performed by [16]. In this paper lower specific $\mathrm{CO}_{2}$ emitting CCS technologies are preferred with rising $\mathrm{CO}_{2}$ certificate cost. CCS technologies are thus influenced by an emission limit and $\mathrm{CO}_{2}$ cost.

Yet, it must be noted that the modelling of CCS and other technologies does not include unit commitment constraints e.g. ramping cost, minimal load and part-load behaviour or minimal downtime hours. The result is that the energy system would need more flexibility options than the model suggests. The flexibility of nuclear, coal and gas fired power plants and CCS is overestimated whereby the storage demand is underestimated [17]. In contrast, the flexibility of CSP is not underestimated because its components are designed to cover the demand flexible [18]. The EPTI of CCS is seen as non-dominant because of the missing unit commitment constraints. Thus, CCS can be neglected. 

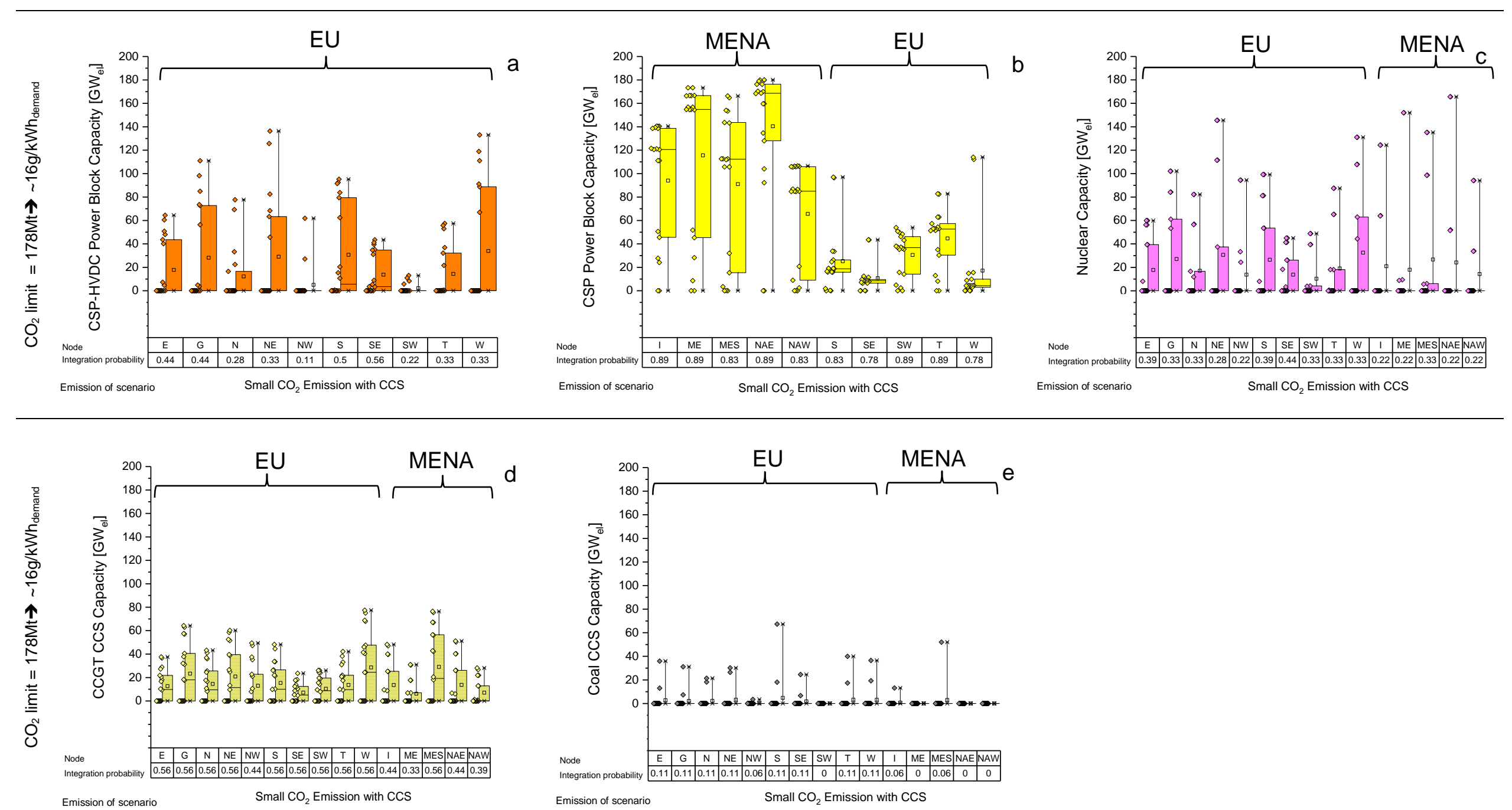

Figure 5: EPTI of CSP-HVDC, CSP, nuclear power plants, CCGT CCS, Coal CCS and the value of CCS 
Post-print - Please quote as: Hess, D. The empirical probability of integrating CSP and its cost optimal configuration in a low carbon energy system of EUMENA. Solar Energy, 2018 (accepted)

\section{The role of CSP-HVDC and CSP for the energy system}

Taking a more detailed look on CSP-HVDC and CSP, this section depicts their optimized configuration of the emission scenario "Small $\mathrm{CO}_{2}$ Emission". The configuration criteria solar multiple (Figure 6a, b) and thermal energy storage full load hours (Figure 6c, d), are chosen to clarify the role of the technologies in the energy system and the potential differences of the cost optimal configurations of CSP-HVDC for EU, domestic CSP in MENA and domestic CSP in EU.

\subsection{Solar Multiple}

The solar multiple is an indicator of full load hour hours, availability and therefore also dispatchability of the renewable energy share of CSP. The higher the solar multiple the more full load hours a CSP power plant has. The solar multiple is defined as ratio of solar field capacity $P_{S F, C S P}$ and power block capacity $P_{P B, C S P}$ according to equation (7). The efficiency of the power block $\eta_{\text {generator }}$ is the product of the thermal and electrical efficiency. A solar multiple of 1 describes a system with a solar field which is large enough to provide nominal capacity for the power block under nominal irradiance (here $800 \mathrm{~W} / \mathrm{m}^{2}$ ). A solar multiple of 2 characterises a system with a solar field twice as large as with a solar multiple of 1 (with the same power block capacity). This solar field can provide energy for the power block and for a thermal storage. Thus, one solar field will directly drive the turbine while the other solar field will serve to fill the storage for night time operation [3].

$$
\text { Solar Multiple: } \quad S M=\frac{P_{S F, C S P}\left[G W_{t h}\right]}{P_{P B, C S P}\left[G W_{e l}\right] \cdot \eta_{\text {generator }}}
$$

Figure $6 \mathrm{a}$ and $\mathrm{b}$ shows that CSP-HVDC has a higher solar multiple than CSP. This result occurs because CSP is in competition with more cost-efficient use of PV in MENA compared to $\mathrm{PV}$ in EU. PV in MENA leads therefore to a reduced solar multiple of CSP in MENA in a cost-optimized framework. CSP-HVDC has with its high solar multiple a flexible base load characteristic, providing dispatchable energy according to demand.

Another effect is that CSP has a small solar multiple in southern EU regions like in S, SE, T and $\mathbf{W}$ because it is more efficient to use other technologies than building a larger solar field in such regions with a seasonal lack of DNI irradiance. The absolute configuration values of CSP in these EU regions are also comparably small. Thus, CSP can be used efficiently in southern EU but only in a small scale compared to CSP in MENA. An exception is the EU region SW in which the solar multiple can also achieve higher values but also comparable small values. 
Post-print - Please quote as: Hess, D. The empirical probability of integrating CSP and its cost optimal configuration in a low carbon energy system of EUMENA. Solar Energy, 2018 (accepted)

\subsection{Thermal Energy Storage}

The thermal energy storage (TES) for the analysed regions is described in Figure $6 c, d$ with full load hours of the storage. These full load hours can be calculated according to Eq. (8) with a ration of TES capacity. $P_{T E S, C S P}$ and power block capacity $P_{P B, C S P}$.

$$
\text { TES full load hours }=\frac{P_{T E S, C S P}\left[G W h_{t h}\right]}{P_{P B, C S P}\left[G W_{e l}\right]} \cdot \eta_{\text {generator }}
$$

The results in Figure $6 \mathrm{c}$ reveal that the thermal energy storage of CSP-HVDC has about 13 full load hours and is thus considered as medium-term storage. The thermal energy storage of CSP has about the same range of full load hours (Figure 6d). However, CSP thermal energy storage full load hours are lower than for CSP-HVDC. The lower full load hour is attended by the lower solar multiple for CSP.

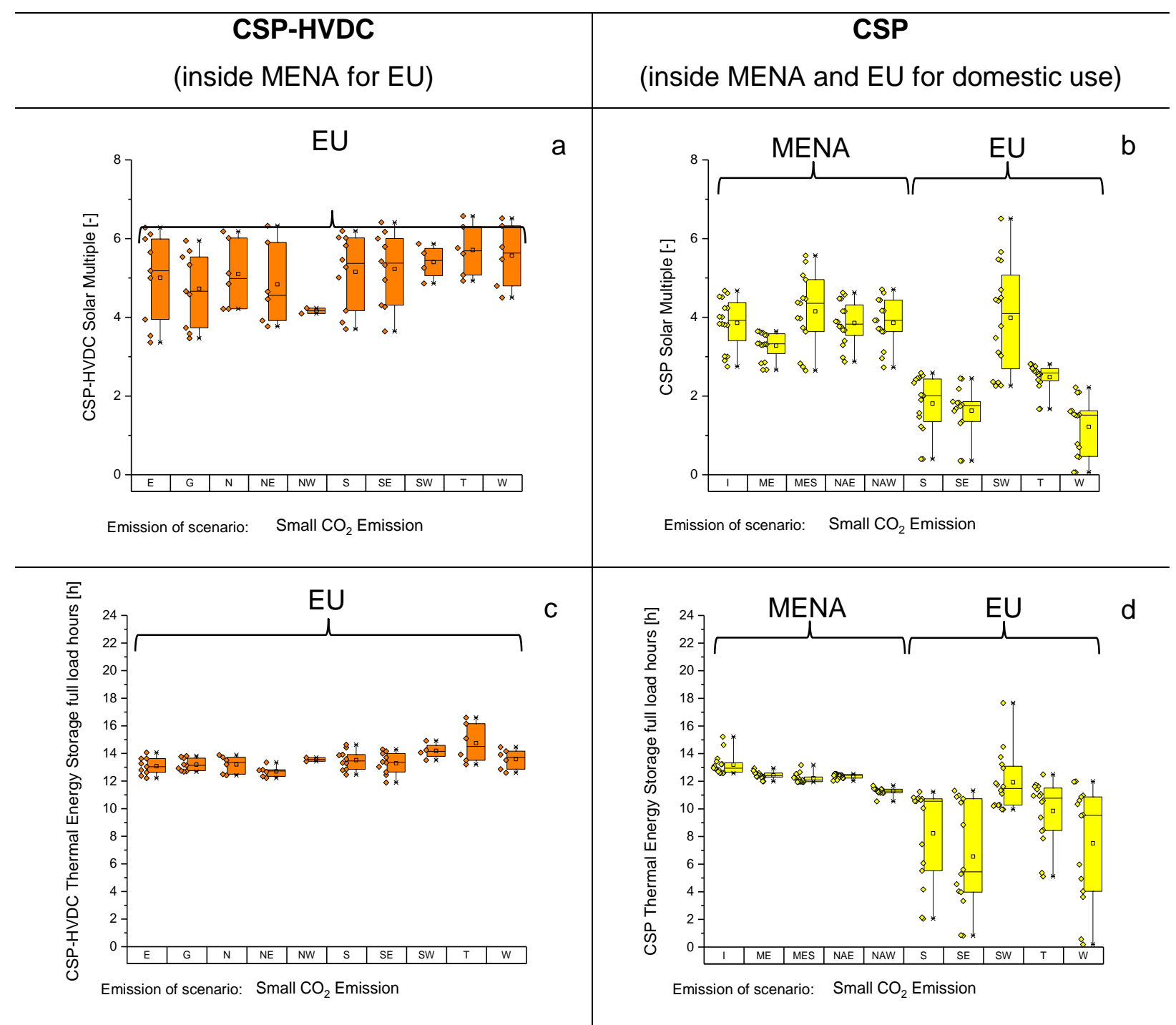

Figure 6: Solar Multiple (a, b) and Thermal Energy Storage full load hours (c, d) of CSPHVDC (in MENA for EU) and CSP (in MENA and southern EU) 
Post-print - Please quote as: Hess, D. The empirical probability of integrating CSP and its cost optimal configuration in a low carbon energy system of EUMENA. Solar Energy, 2018 (accepted)

\subsection{Demand for land}

The demand for land of the power plant can be calculated by the solar field capacity of CSPHVDC and CSP. Equation (9) shows how the needed area of the solar field can be calculated. This indicates how much space in desert regions is needed or in other words how much space can be used and cultivated.

$$
\text { power plant size }\left[\mathrm{km}^{2}\right]=\frac{P_{S F, C S P}\left[G W_{t h}\right]}{0.1762}
$$

Figure 7 reveals the resulting CSP and CSP-HVDC demand for land of the EPTI analysis in this section. The boxplots in Figure 7 show the data using quartiles. It is remarkable that the median of the demand for land of CSP-HVDC is quite similar compared to the domestic use of CSP inside the MENA region. In other words: "one mirror for MENA, one mirror for EU". However, the resulting median demand for land of CSP-HVDC is a little lower than CSP inside MENA. The median value of the demand of land for CSP inside MENA for its regional use is in the scale of the area of Switzerland $\left(41.285 \mathrm{~km}^{2}\right)$. The accumulation of the values for CSP inside MENA for MENA demonstrates that its median demand for land is more robust than the median value of CSP-HVDC. An accumulation of the demand for land for CSP-HVDC is visible in the under scale of the bar. Based on the large bandwidth of CSPHVDC, a specific statement of how much area might be used for CSP-HVDC in MENA can't be done with these results.

The area of CSP inside EU for EU is comparable small with a median value of $5000 \mathrm{~km}^{2}$ which equates twice the German federal state of the Saarland $\left(2570 \mathrm{~km}^{2}\right)$.

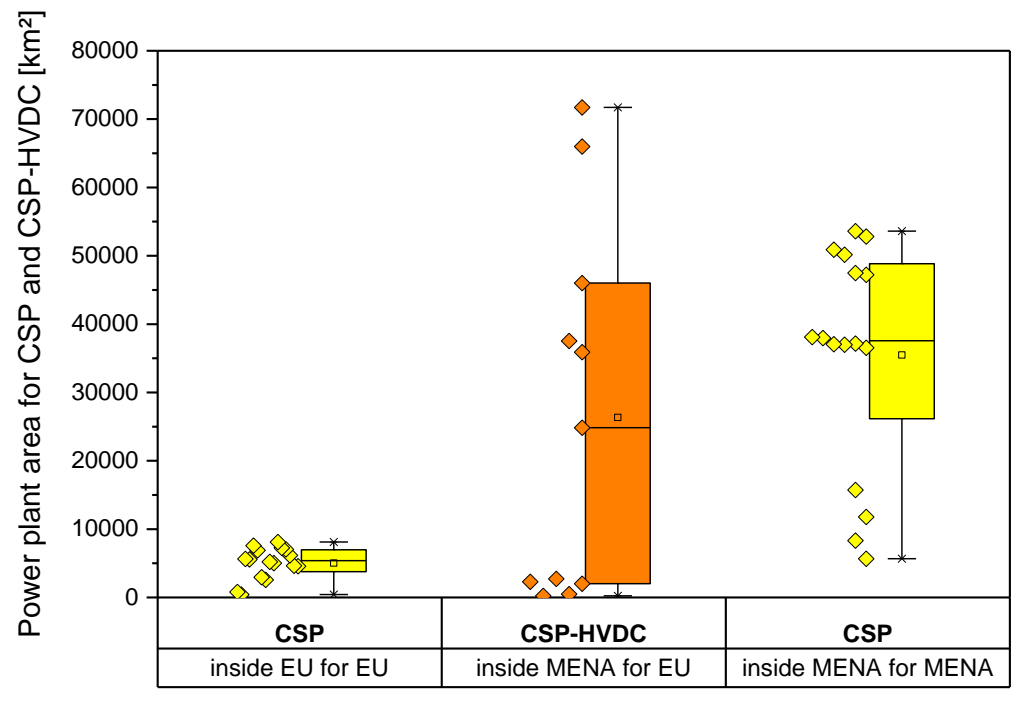

Emission of scenario: Small $\mathrm{CO}_{2}$ Emission

Figure 7: Bandwidth of possible area use [ $\left.\mathrm{km}^{2}\right]$ of CSP and CSP-HVDC in EU and MENA 
Post-print - Please quote as: Hess, D. The empirical probability of integrating CSP and its cost optimal configuration in a low carbon energy system of EUMENA. Solar Energy, 2018 (accepted)

Table 7 supplements the configuration criteria of Figure 6 with the power block capacity, net electrical generation and the co-firing. Compared to CSP the average power block capacity and net electrical generation for CSP-HVDC are smaller. Thus, CSP in MENA has a dominant use while CSP-HVDC is more seen as a supplement for EU. Whereas CSP use a co-firing in small shares, CSP-HVDC provides energy without co-firing usage.

Table 7: CSP-HVDC and CSP configuration in sensitivity scenario of Figure 4 with small $\mathrm{CO}_{2}$ emissions ( $\left.16 \mathrm{~g} \mathrm{CO}_{2} / \mathrm{kWh}_{\text {demand }}\right)$

\begin{tabular}{|c|c|c|c|c|}
\hline \multirow{2}{*}{ Configuration } & \multicolumn{2}{|c|}{ CSP-HVDC } & \multicolumn{2}{|c|}{ CSP } \\
\hline & $\min -\max$ & average & $\min -\max$ & average \\
\hline $\begin{array}{l}\text { Solar multiple } \\
{[-]}\end{array}$ & $3.4-6.6$ & 5.1 & $0.1-6.5$ & 3.0 \\
\hline $\begin{array}{l}\text { Solar field size } \\
{\left[\mathrm{km}^{2}\right]}\end{array}$ & $73.7-12899.6$ & 4261.9 & $76.3-13684.5$ & 4236.8 \\
\hline $\begin{array}{l}\text { Solar field } \\
{\left[\mathrm{GW}_{\mathrm{th}}\right]}\end{array}$ & $12.8-2272.7$ & 751.0 & $13.4-2411.2$ & 746.5 \\
\hline $\begin{array}{l}\text { Thermal energy storage } \\
\text { full load hours [h] }\end{array}$ & $11.9-16.6$ & 13.4 & $0.2-17.7$ & 10.6 \\
\hline $\begin{array}{l}\text { Thermal energy storage } \\
{\left[\mathrm{GWh}_{\mathrm{th}}\right]}\end{array}$ & $41.8-5091.6$ & 1854.6 & $55.4-6044.4$ & 2366.9 \\
\hline $\begin{array}{l}\text { Power block capacity } \\
\text { [GW] }\end{array}$ & $1.3-136.3$ & 50.5 & $1.9-180.0$ & 76.1 \\
\hline $\begin{array}{l}\text { Net electrical generation } \\
{[\mathrm{TWh} / \mathrm{y}]}\end{array}$ & $7.5-842.9$ & 321.7 & $9.0-1256.2$ & 444.3 \\
\hline $\begin{array}{l}\text { Co-firing with natural gas } \\
{[\mathrm{TWh} / \mathrm{y}]}\end{array}$ & 0 & - & $0.2-20.5$ & 3.6 \\
\hline
\end{tabular}

Average values are calculated considering all regions equally. The values (in grey) reflect the relative configuration of the power plants. The other values show the absolute dimension in a possible bandwidth.

Detailed regional configuration values of CSP-HVDC and CSP with the frame conditions of 0 and $16 \mathrm{~g} \mathrm{CO}_{2} / \mathrm{kWh}_{\text {demand }}$ also with CCS are shown in the appendix Figure 28 to Figure 31.

\section{Conclusion, suggestion for improvements and outlook}

In this paper the empirical probability of CSP-HVDC, CSP, nuclear power and CCS are introduced. It can be concluded that the empirical probability of CSP-HVDC implies a possible integration of this technology. It should be noted that the cost assumptions of CSP 
Post-print - Please quote as: Hess, D. The empirical probability of integrating CSP and its cost optimal configuration in a low carbon energy system of EUMENA. Solar Energy, 2018 (accepted)

and the pathway of HVDC are assumed as relative conservative and that CSP still renders a cost reduction till 2050 due to its advancing learning curve. Therefore CSP-HVDC is rather underestimated than overrated and it has therefore a high potential to be integrated. Nuclear plants and CCS are also possibly integrated yet with a lower EPTI of nuclear plants than CSP-HVDC or under the very optimistic modelling conditions for CCS.

The results are achieved using a simplified technological model. A detailed technological CSP model regarding the resulting configuration is needed. Modelling improvements can consider a higher spatio-temporal resolution showing more details. Other energy system evaluation criteria such as infrastructural need, curtailment, grid stress are important to show the value of CSP-HVDC for a holistic energy system analysis. The model doesn't consider scale effects such as higher internal demand with a rising solar multiple so-called parasitic losses. A combination of CSP and PV may attenuate such losses with the use of costefficient PV. The use of the thermal storage as a medium term storage by the entire energy system can be also a promising possibility for CSP because surplus electricity of the system can be stored in the thermal storage of CSP to avoid otherwise higher electrical storage capacity and curtailment of the energy system. The high solar multiple of CSP-HVDC (4-6) leads to potential constructional questions especially regarding parasitics in a large solar field size. Transforming desert areas in arable land raises the question which of the CSP technologies (tower, trough or Fresnel) is favourable to be used for this purpose and at the same time efficient for an export via HVDC. Conceptual technological alternatives to CSPHVDC have a low technology readiness level such as Wind or PV combined with a thermal/electrical storage, heat pump and co-firing option, or nuclear fusion and are therefore intangible. Technological breakthroughs are uncertain from today's point of view. Such technological concepts are important for further research activities but should be definitely no obstacles to concretise technically functioning CSP-HVDC reaching climate protection targets as soon as possible.

As a result of the configuration values of CSP-HVDC and CSP it is concluded that the two technologies fulfil different roles in the analysed regions. CSP-HVDC has a high solar multiple and a base load characteristic. CSP in MENA has a lower solar multiple due to efficient combination of CSP and PV in the domestic energy mix. Based on comparable high thermal energy storage full load hours, the medium-term thermal storage of CSP in MENA is frequented like in the CSP-HVDC configuration. Thus, CSP in MENA has also a baseload characteristic but a lower use of the solar field than CSP-HVDC. The CSP power plants in the EU for domestic use have a lower solar multiple and lower thermal energy storage full 
Post-print - Please quote as: Hess, D. The empirical probability of integrating CSP and its cost optimal configuration in a low carbon energy system of EUMENA. Solar Energy, 2018 (accepted)

load hours due to other more efficient technologies and the drastic reduction of DNI in winter. CSP in EU for domestic use shows therefore a commitment to medium load levels.

It is remarkable that the median of the demand for land of CSP-HVDC is quite similar compared to the domestic use of CSP inside the MENA region. In other words: "one mirror for MENA, one mirror for EU". Thus, CSP power plants can be built hand in hand for the domestic use in MENA and with separate power plants for an export to EU. 
Post-print - Please quote as: Hess, D. The empirical probability of integrating CSP and its cost optimal configuration in a low carbon energy system of EUMENA. Solar Energy, 2018 (accepted)

\section{Abbreviations}

\begin{tabular}{|c|c|}
\hline CCGT & Combined cycle gas turbine \\
\hline CCS & Carbon capture and storage \\
\hline CSP & Concentrating Solar Power \\
\hline CSP-HVDC & $\begin{array}{l}\text { Concentrating solar power with point-to-point high voltage direct } \\
\text { current line }\end{array}$ \\
\hline$D C$ & Direct Current \\
\hline EPTI & relative Empirical Probability of Technological Integration \\
\hline$E U$ & geographical Europe \\
\hline EUMENA & Europe, Middle East and North Africa \\
\hline$H V D C$ & high voltage direct current line \\
\hline max, mean, $\min$ & Cost sensitivities \\
\hline ME & Middle East \\
\hline$N A$ & North Africa \\
\hline$O \& M$ & Operation and maintenance cost \\
\hline $\mathrm{OHL}$ & Overhead Line \\
\hline$P 2 P$ & Point-to-Point transmission line \\
\hline$P V$ & Photovoltaic \\
\hline REMix-EnDAT & Renewable Energy Mix Energy Data Analysis Tool \\
\hline REMix-OptiMo & Renewable Energy Mix Optimization Model \\
\hline UGC & Underground Cable \\
\hline
\end{tabular}


Post-print - Please quote as: Hess, D. The empirical probability of integrating CSP and its cost optimal configuration in a low carbon energy system of EUMENA. Solar Energy, 2018 (accepted)

\section{Parameters}

\begin{tabular}{|c|c|c|}
\hline$C_{\text {Emission }}$ & {$[k \in / G W h]$} & specific emission cost \\
\hline$C_{\text {Fuel }}$ & {$[\mathrm{k} \in / \mathrm{GWh}]$} & specific fuel cost \\
\hline$C_{O \& M}$ Fix & {$[\% / y]$} & specific operation and maintenance fix costs \\
\hline$C_{\text {speclnv }}$ & {$[\mathrm{k} \in / \mathrm{MW}]$} & specific investment cost \\
\hline$e p_{18}$ & {$[-]$} & relative empirical probability using 18 scenarios \\
\hline$E P_{18}$ & {$[-]$} & absolute empirical probability using 18 scenarios \\
\hline$f_{\text {annuity }}$ & {$[-]$} & Annuity factor \\
\hline$i$ & [\%] & Interest and discount rate \\
\hline$P_{\text {existCap }}$ & {$\left[\mathrm{GW}_{e l}\right]$} & Capacity of existing power plants \\
\hline$P_{H V D C, \text { gross }}$ & {$\left[G W_{e}\right]$} & Gross capacity of the HVDC transmission line \\
\hline$P_{P B, C S P}$ & {$\left[\mathrm{GW}_{e l}\right]$} & Capacity of the CSP power block \\
\hline$P_{S F, C S P}$ & {$\left[\mathrm{GW}_{t h}\right]$} & Capacity of the CSP solar field \\
\hline$P_{T E S, C S P}$ & {$\left[\mathrm{GWh}_{t h}\right]$} & Thermal energy storage capacity of the CSP \\
\hline$\eta_{\text {generator }}$ & [\%] & $\begin{array}{l}\text { Efficiency of the generator as product of the thermal and } \\
\text { electrical efficiency }\end{array}$ \\
\hline$\eta_{\text {charge }}$ & {$[\%]$} & Charging efficiency of the storage \\
\hline$\eta_{\text {discharge }}$ & [\%] & Discharging efficiency of the storage \\
\hline$\eta_{\text {self }}$ & {$[\% / h]$} & Self-discharging rate of the storage per hour \\
\hline$s_{g e n}(t)$ & {$[-]$} & Normalised generation time series of fluctuating energy \\
\hline$S M$ & {$[-]$} & Solar Multiple \\
\hline$\Delta t$ & {$[\mathrm{~h}]$} & Calculation time interval \\
\hline$t_{y}$ & [y] & Amortization time \\
\hline$y$ & [year] & year \\
\hline
\end{tabular}

Variables

$\begin{array}{ll}\boldsymbol{C}_{\text {capital }} & {[\mathrm{k} \in / \mathrm{y}]} \\ \boldsymbol{C}_{\text {operation }} & {[\mathrm{k} \in / \mathrm{y}]} \\ \boldsymbol{P}_{\text {addedCap }} & {\left[\mathrm{GW}_{e l}\right]} \\ \boldsymbol{P}_{\text {gen }}(t) & {\left[\mathrm{GW}_{e l}\right]} \\ \boldsymbol{Q}_{\text {addedCap }}(t) & {\left[\mathrm{GW}_{t h}\right]} \\ \boldsymbol{Q}_{\text {BuS }}(t) & {\left[\mathrm{GW}_{t h}\right]} \\ \boldsymbol{Q}_{\text {charge }}(t) & {\left[\mathrm{GW}_{t h}\right]} \\ \boldsymbol{Q}_{\text {curtail }}(t) & {\left[\mathrm{GW}_{t h}\right]} \\ \boldsymbol{Q}_{\text {disharge }}(t) & {\left[\mathrm{GW}_{t h}\right]} \\ \boldsymbol{Q}_{S F}(t) & {\left[\mathrm{GW}_{t h}\right]} \\ \boldsymbol{U}_{\text {level }}(t) & {\left[\mathrm{GWh}_{t h}\right]}\end{array}$

Annual depreciation of capital expenditure

Annual operation and maintenance costs

Capacity of additional power plants

Power generation

Capacity of model endogenous CSP solar field

Thermal output of the CSP co-firing system

Thermal energy storage input

Thermal curtailment of the solar field

Thermal energy storage output

Thermal output of the solar field

Thermal energy storage level 
Post-print - Please quote as: Hess, D. The empirical probability of integrating CSP and its cost optimal configuration in a low carbon energy system of EUMENA. Solar Energy, 2018 (accepted)

This paper is part of the dissertation "The Value of Concentrating Solar Power for a Sustainable Electricity Supply in Europe, Middle East and North Africa" http://elib.dlr.de/114683/ .

\section{Acknowledgement}

While research only lives due to discussions, reflections and continuous exchange, we would like to thank Franz Trieb, Karl-Kiên Cao, Felix Cebulla, Tobias Fichter and Manuel Wetzel for their long-time discussion about sustainable energy systems.

\section{References}

[1] DLR, "Concentrating Solar Power for the Mediterranean Region (Med-CSP)," 2005.

[2] DLR, "Trans-Mediterranean interconnection for Concentrating Solar Power (TRANSCSP)," 2006.

[3] F. Trieb, C. Schillings, T. Pregger and M. O'Sullivan, "Solar electricity imports from the Middle East and North Africa to Europe," Energy Policy, vol. 42, 2012.

[4] BETTER, "Bringing Europe and Third countries closer together through renewable Energies," 2015.

[5] P. Gauché, J. Rudman, M. Mabaso, W. A. Landman, T. W. v. Backström and A. C. Brent, "System value and progress of CSP," Solar Energy, vol. 152, pp. 106-139, 2017.

[6] F. Trieb, T. Fichter and M. Moser, "Concentrating solar power in a sustainable future electricity mix," Sustainability Science, vol. 9, p. 47-60, 2014.

[7] S. Pfenninger, P. Gauché, J. Lilliestam, K. Damerau, F. Wagner and A. Patt, "Potential for concentrating solar power to provide baseload and dispatchable power," Nature Climate Change, vol. 4, p. 689-692, 2014.

[8] IRENA, "Planning for the Renewable Future: Long-term modelling and tools to expand variable renewable power in emerging economies," International Renewable Energy Agency, Abu Dhabi, 2017.

[9] G. Knies and A. Bennouna, "Nordafrikanisch - Europäischer Solarenergie Verbund. Workshop des Hamburger Klimaschutz-Fonds HKF am 9.4. 1997 an der TU Hamburg Harburg," 1997.

[10] United Nations, "World Population Prospects: The 2015 Revision," 2015. 
Post-print - Please quote as: Hess, D. The empirical probability of integrating CSP and its cost optimal configuration in a low carbon energy system of EUMENA. Solar Energy, 2018 (accepted)

[11] Y. Scholz, Renewable energy based electricity supply at low costs : development of the REMix model and application for Europe, Stuttgart: University Library of the University of Stuttgart, 2012.

[12] D. Stetter, Enhancement of the REMix energy system model : global renewable energy potentials, optimized power plant siting and scenario validation, Stuttgart: University Library of the University of Stuttgart, 2012.

[13] H. Gils, Y. Scholz, T. Pregger and D. Luca de Tena, "Integrated modelling of variable renewable energy-based power supply in Europe," Energy, vol. 123, p. 173-188, 2017.

[14] D. Hess, M. Wetzel and K.-K. Cao, "Representing node-internal transmission and distribution grids in energy system models," Renewable Energy, 2018.

[15] J. Rogelj, G. Luderer, R. C. Pietzcker, E. Kriegler, M. Schaeffer, V. Krey and K. Riahi, "Energy system transformations for limiting end-of-century warming to below $1.5^{\circ} \mathrm{C}$," Nature Climate Change, vol. 5, p. 519-527, 2015.

[16] Y. Scholz, H. C. Gils and R. C. Pietzcker, "Application of a high-detail energy system model to derive power sector characteristics at high wind and solar shares," Energy Economics, vol. 64, pp. 568-582, 2017.

[17] F. Cebulla and T. Fichter, "Merit order or unit-commitment: How does thermal power plant modeling affect storage demand in energy system models?," Renewable Energy, vol. 105, pp. 117-132, 2017.

[18] T. Fichter, Long-term Capacity Expansion Planning with Variable Renewable Energies Enhancement of the REMix Energy System Modelling Framework, Stuttgart: Universität Stuttgart, 2017.

[19] IEA, "International Energy Agency Statistics," 2017. [Online]. Available: http://www.iea.org/statistics/. [Accessed 1402 2015].

[20] F. Trieb and U. Klann, "Modeling the Future Electricity Demand of Europe, Middle East and North Africa," Stuttgart, 2006.

[21] IPCC, "Mitigation of Climate Change," 2014.

[22] IPCC, "Mitigation of Climate Change," 2014.

[23] IIASA, "Shared Socioeconomic Pathways Database," 03 2013. [Online]. [Accessed 03 08 2015].

[24] L. Gruber, “Synthese globaler, elektrischer Lastganglinien,” Berlin, 2012.

[25] G. Pleßmann, M. Erdmann, M. Hlusiak and C. Breyer, "Global Energy Storage Demand for a 100\% Renewable Electricity Supply," Energy Procedia, vol. 46, pp. 22-31, 2014. 
Post-print - Please quote as: Hess, D. The empirical probability of integrating CSP and its cost optimal configuration in a low carbon energy system of EUMENA. Solar Energy, 2018 (accepted)

[26] S. Kühnel, Investigation of the variability of solar and wind electricity generation potentials in Europe and North Africa, Oldenburg: Karl von Ossietzky University, 2013.

[27] H. Gils, "Economic Potential for Future Demand Response in Germany - Modelling Approach and Case Study. doi:10.1016/j.apenergy.2015.10.083," Applied Energy, vol. 162, p. 401-415, 2016.

[28] H. Gils, "Assessment of the theoretical demand response potential in Europe. doi:10.1016/j.energy.2014.02.019," Energy, vol. 67, pp. 1-18, 2014.

[29] N. May, "Eco-balance of a Solar Electricity Transmission from North Africa to Europe," Braunschweig, 2005.

[30] G.-G. Marcos and L.-A. Roberto, "Assessment of the European potential for pumped hydropower energy storage: A GIS-based assessment of pumped hydropower storage potential," 2013.

[31] A. Moser, "Unterstützung der Energiewende in Deutschland durch einen Pumpspeicherausbau," 2014.

[32] FIAS, 2017. [Online]. Available: https://github.com/FRESNA/powerplantmatching. [Accessed 0305 2016].

[33] R. Jung, S. Röhling, N. Ochmann, S. Rogge, R. Schellschmidt, R. Schulz and T. Thielemann, "Abschätzung des technischen Potenzials der geothermischen Stromerzeugung und der geothermischen Kraft-Wärmekopplung (KWK) in Deutschland," 2002.

[34] M. Tum, I. M. Kurt P. Günther, G. Kindermann and E. Schmid, "Sustainable Bioenergy Potentials for Europe and the Globe," Geoinformatics \& Geostatistics: An Overview, pp. 1-10, 2013.

[35] IEA, “Technology Roadmap: Solar Photovoltaic Energy,” 2010.

[36] IEA, "Data from Market Allocation (MARKAL) model, International Energy Agency and Brookhaven National Laboratory," 2009.

[37] OPENEI NREL, "The data below was downloaded from the Transparent Cost Database at http://en.openei.org/apps/TCDB/".

[38] Environmental Protection Agency, Data from Integrated Power Model (IPM), ICF International., 2010.

[39] IRENA, “IRENA Hydro Power," 2012. [Online]. Available:

http://www.irena.org/documentdownloads/publications/re_technologies_cost_analysishydropower.pdf.

[40] J. Nitsch and et al., "Long-term scenarios and strategies for the deployment of 
Post-print - Please quote as: Hess, D. The empirical probability of integrating CSP and its cost optimal configuration in a low carbon energy system of EUMENA. Solar Energy, 2018 (accepted)

renewable energies in Germany in view of European and global developments," 2012.

[41] Pregger, "Vergleichende Bewertung der Integration einer zentralen versus einer dezentralen Wasserstofferzeugung in die zukünftige Stromversorgung Deutschlands," 2015.

[42] U. Albrecht, M. Altmann, J. Michalski, T. Raksha and W. Weindorf, "Analyse der Kosten erneuerbarer Gase," BWE, 2013.

[43] D. Fürstenwerth and et al., "Stromspeicher in der Energiewende," Agora, 2014.

[44] J. Nitsch and T. Pregger, "Kostenbilanz des Ausbaus erneuerbarer Energien in der Stromerzeugung bei unterschiedlichen Preisbildungen am Strommarkt," Vierteljahrshefte zur Wirtschaftsföderung, vol. 82, pp. 45-59, 2013.

[45] E. S. Rubin, C. Chen and A. B. Rao, "Cost and performance of fossil fuel power plants with CO2 capture and storage," Energy Policy, vol. 35, p. 4444-4454, 2007.

[46] European Commission, "Press releases database," 0810 2014. [Online]. Available: http://europa.eu/rapid/press-release_IP-14-1093_de.htm. [Accessed 2003 2015].

[47] G. v. Goerne, CO2-Abscheidung und -Lagerung(CCS) in Deutschland, Germanwatch Nord-Süd Initiative e.V., 2009.

[48] H. Brakelmann, "Netzverstärkungs-Trassen zur Übertragung von Windenergie: Freileitung oder Kabel ?," Rheinberg, 2004.

[49] D. Hess, FERNÜBERTRAGUNG REGELBARER SOLARENERGIE VON NORDAFRIKA NACH MITTELEUROPA, Stuttgart: University Library of the University of Stuttgart, 2013.

[50] L. Neij, "Cost development of future technologies for power generation-A study based on experience curves and complementary bottom-up assessments," Energy Policy 36, p. $2200-2211,2008$.

[51] CSP-Today, "CSP-Today," 1502 2016. [Online]. Available: http://www.csptoday.com/.

[52] P. Viehbahn and et al., "EU-NEEDS scenario pesimistic," 2008.

[53] Greenpeace, "Global Concentrating Solar Power Outlook (scenario optimistic)," 2009. 
Post-print - Please quote as: Hess, D. The empirical probability of integrating CSP and its cost optimal configuration in a low carbon energy system of EUMENA. Solar Energy, 2018 (accepted)

\section{Appendix}

\subsection{Basic modelling assumptions}

\subsubsection{Supply technologies}

The REMix model includes weather dependent technologies such as photovoltaic, wind onshore, wind offshore and hydro run-of-river so-called fluctuating renewable energies and non-weather dependent technologies such as biomass, geothermal energy, nuclear, gas, coal fired power plants (also CCS) and CSP with co-firing so-called dispatchable energies. Biomass, geothermal and CSP with thermal energy storage and co-firing are defined as renewable dispatchable technologies. Dispatchable energies can provide electricity according to the demand and offer firm capacity. The electricity generating renewable technologies applied in the paper are listed in Table 8. These technologies are available today and they are functioning. Contrarily, technologies with a low technological readiness level such as nuclear fusion or a hydrogen turbine are not considered. This allows a pragmatic and robust energy system analysis without speculation of technological breakthroughs from today's point of view. Non-renewable technologies such as nuclear, gas, coal fired power plants (also CCS) are characterised in Table 14 on page 60. Defining the characteristic of a technology, a representative example out of a technology group is selected, but not the whole bandwidth of all specific occurrences of one technology is examined. The examples are representative for the general characteristic of a chosen technology. However, a simplification makes sense comparing only the technology groups in competition to each other. Other applied technologies defined as flexibility options such as electrical storages and the electrical grid. Potentials of pump storage, hydro run-of-river, hydro reservoir, geothermal energy, solid biomass and CSP are limited and are made available in the appendix Table 10. 
Post-print - Please quote as: Hess, D. The empirical probability of integrating CSP and its cost optimal configuration in a low carbon energy system of EUMENA. Solar Energy, 2018 (accepted)

Table 8: Classification and characteristic of used renewable energies for electricity generation based on [11] - hydro reservoir is considered neither as fluctuating nor as dispatchable but as long term storage with additional natural inflow.

\begin{tabular}{|c|c|c|c|}
\hline \multicolumn{2}{|c|}{$\begin{array}{l}\text { Technology class of electricity } \\
\text { generating power plants }\end{array}$} & Characteristics & Range of validity \\
\hline \multirow{3}{*}{ 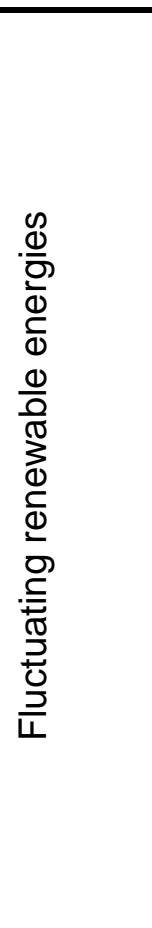 } & Photovoltaic & $\begin{array}{l}\text { Silicon cells with a } \\
\text { module efficiency of } \\
18 \%\end{array}$ & $\begin{array}{l}\text { Standard test conditions: } \\
25^{\circ} \mathrm{C} \text { module } \\
\text { temperature, } 1000 \mathrm{~W} / \mathrm{m}^{2} \\
\text { irradiance }\end{array}$ \\
\hline & Wind Offshore & $\begin{array}{l}\text { Rotor diameter: } 130 \mathrm{~m} \\
\text { Hub height: } 132 \mathrm{~m} \\
\text { Rotor diameter: } 140 \mathrm{~m} \\
\text { Hub height: } 192 \mathrm{~m}\end{array}$ & $\begin{array}{l}\text { Start-up wind speed: } 2 \\
\mathrm{~m} / \mathrm{s}, \text { nominal power output } \\
\text { is reached at } 12 \mathrm{~m} / \mathrm{s} \text {. Cut- } \\
\text { off was set to start at } 25 \\
\mathrm{~m} / \mathrm{s} \text { and to end at } 35 \mathrm{~m} / \mathrm{s} \text {. }\end{array}$ \\
\hline & $\begin{array}{l}\text { Hydro run-of-river } \\
\text { (here fluctuating } \\
\text { because of fluctuating } \\
\text { water level and no co- } \\
\text { firing option) }\end{array}$ & $\begin{array}{l}\text { No power plant model - } \\
\text { analysis is based on } \\
\text { empirical time series }\end{array}$ & $\begin{array}{l}\text { Power plants in operation, } \\
\text { annual generation and } \\
\text { generation potentials in } \\
\text { Germany }\end{array}$ \\
\hline \multirow{3}{*}{ 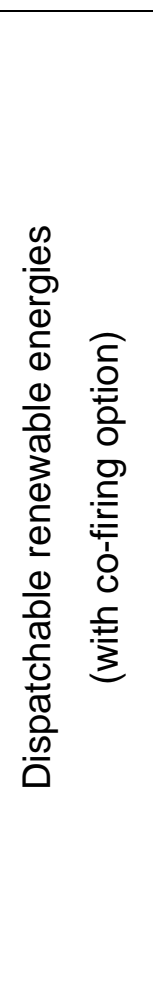 } & Biomass & $\begin{array}{l}\text { Power plant with steam } \\
\text { turbine - } 35 \% \text { electric } \\
\text { efficiency - using forest } \\
\text { wood, waste wood, } \\
\text { straw and energy crops }\end{array}$ & $\begin{array}{l}\text { Domestic share of net } \\
\text { primary production } \\
\text { potential, yields and } \\
\text { competing use scenarios } \\
\text { per country for forestry, } \\
\text { agriculture and other } \\
\text { sectors - agricultural } \\
\text { statistics. }\end{array}$ \\
\hline & Geothermal power & $\begin{array}{l}\text { Enhanced geothermal } \\
\text { system (EGS) }\end{array}$ & $\begin{array}{l}\text { Depth range } 2000-5000 \\
\mathrm{~m}\end{array}$ \\
\hline & $\begin{array}{l}\text { Concentrating Solar } \\
\text { power }\end{array}$ & $\begin{array}{l}\text { Parabolic trough power } \\
\text { plant with molten salt } \\
\text { storage - 37\% power } \\
\text { block efficiency and 95\% } \\
\text { storage efficiency - }\end{array}$ & $\begin{array}{l}\text { Reference irradiance - } \\
\text { direct normal irradiance } \\
\text { (DNI) - with } 800 \mathrm{~W} / \mathrm{m}^{2} \text {, } \\
\text { tracking the sun along the } \\
\text { north south axis }\end{array}$ \\
\hline
\end{tabular}

Other characteristic of power plant and storage are available with technological an economic data in Table 12 to Table 16. 
Post-print - Please quote as: Hess, D. The empirical probability of integrating CSP and its cost optimal configuration in a low carbon energy system of EUMENA. Solar Energy, 2018 (accepted)

\subsubsection{Demand model}

The analysis considers only the electricity demand. However, the demand model includes an electricity share of heat and mobility. The occurring electricity demand of these two sectors is added to the conventional electricity demand. In the following the assumptions of the demand until the year 2050 are explained showing the data that build the basis of the assumption in the demand model. The historical data of electricity, heat and mobility in the used model start in the year 2010 and are taken form IEA database [19].

- Electricity: net electricity demand (electricity, final consumption)

- Heat: residential and commercial heat demand (from coal, oil and gas)

- Mobility: transport demand (from oil)

The development of the electricity sector is derived from the GDP according to DLR [20]. This reference uses a scenario for the development of the GDP per capita growth rate. The used GDP per capita growth rate in the scenario "closing the gap" assumes to reduce the difference of GDP per capita of a given country to $50 \%$ compared with the GDP per capita of the USA in the year 2050. Population data are taken from the UN medium scenario [10]. For the development of the electricity share of the heat sector a $60 \%$ electricity share of global buildings final energy demand until 2050 is used and a demand reduction per capita and year (2010 to 2050 ) of $0.65 \%$ in OECD, $0.39 \%$ in Middle East and Africa and $0.28 \%$ in Eastern Europe and Russia is assumed [21]. The conversion factor using final energy of heat from oil, gas or coal is $90 \%$. For the development of the electricity share of the mobility sector outgoing from 2020 a 15\% electricity share of final energy demand until 2050 is used and a demand reduction per capita and year (2010 to 2050) of $1.08 \%$ in OECD, $-0.45 \%$ in Middle East and Africa and $-0.82 \%$ in reforming countries is assumed [22], [23]. The conversion factor using final energy from oil for mobility is $30 \%$. For heat and mobility there is still a higher share of carbon resource than in the electricity sector in 2050. However, the assumption considers low carbon emission trying to reach the $2^{\circ} \mathrm{C}$ target [15].

The resulting electricity demand in Table 9 of heat and mobility is added to the electrical load curve with the same profile because today's load curve already includes heat and mobility shares. The hourly profile of the electrical load curve is taken from ENTSO-e in 2006, Arab Union of Electricity (AUE) in 2012 and a synthetic load profile from [24], [25] and thus represent historical demand curve. It is assumed that these load curves do not have another characteristic than in the year 2050. 
Post-print - Please quote as: Hess, D. The empirical probability of integrating CSP and its cost optimal configuration in a low carbon energy system of EUMENA. Solar Energy, 2018 (accepted)

Table 9: Annual electrical demand of electricity, heat and mobility sector in 2010 and 2050

\begin{tabular}{|c|c|c|c|c|c|c|}
\hline \multirow{2}{*}{$\begin{array}{l}\text { Model } \\
\text { region } \\
\text { year }\end{array}$} & \multicolumn{2}{|c|}{$\begin{array}{l}\text { Electricity demand } \\
\text { [TWh] }\end{array}$} & \multirow{2}{*}{$\begin{array}{c}\begin{array}{c}\text { Electrical heat } \\
\text { demand [TWh] }\end{array} \\
2050\end{array}$} & \multirow{2}{*}{$\begin{array}{l}\text { Electrical mobility } \\
\text { demand [TWh }]^{*}\end{array}$} & \multicolumn{2}{|c|}{$\begin{array}{l}\text { Total electrical } \\
\text { demand [TWh] }\end{array}$} \\
\hline & 2010 & 2050 & & & 2010 & 2050 \\
\hline G & 532 & 510 & 173 & 22 & 532 & 706 \\
\hline $\mathrm{N}$ & 382 & 541 & 13 & 17 & 382 & 571 \\
\hline$E$ & 235 & 337 & 82 & 11 & 235 & 429 \\
\hline$S$ & 436 & 522 & 141 & 27 & 436 & 689 \\
\hline $\mathrm{W}$ & 641 & 673 & 205 & 42 & 641 & 920 \\
\hline NW & 370 & 552 & 201 & 32 & 370 & 785 \\
\hline $\mathrm{NE}$ & 608 & 839 & 170 & 27 & 608 & 1037 \\
\hline SE & 195 & 298 & 15 & 8 & 195 & 321 \\
\hline NAE & 151 & 1127 & 19 & 31 & 151 & 1178 \\
\hline NAW & 71 & 582 & 74 & 19 & 71 & 674 \\
\hline SW & 295 & 315 & 9 & 18 & 295 & 342 \\
\hline $\mathrm{T}$ & 175 & 509 & 90 & 14 & 175 & 613 \\
\hline MES & 150 & 796 & 99 & 56 & 150 & 950 \\
\hline I & 186 & 484 & 362 & 28 & 186 & 874 \\
\hline $\mathrm{ME}$ & 393 & 869 & 18 & 87 & 393 & 974 \\
\hline Sum & 4819 & 8953 & 1672 & 439 & 4819 & 11064 \\
\hline
\end{tabular}

${ }^{\star}$ Additional electrical heat and mobility demand are assumed to be 0 in the year 2010 .

The rising electrical demand in EUMENA, which more than doubles from 4819 TWh in 2010 to 11064 TWh in 2050, leads to a capacity expansion and higher demand of resources. Thus, in Europe dispatchable renewable energies such as biomass and geothermal energy can reach their techno-economic limit. Solving this lack, Wind, PV, storage and CSP inside Europe and from MENA can provide renewable energy. It can be expected that a rising electrical demand may lead to a rising demand of renewable dispatchable energy and therefore to a rising demand of a transfer of CSP generated electricity from MENA to Europe.

\subsubsection{Technological time series and electrical load curve}

The time series of CSP, photovoltaic, wind onshore, wind offshore, hydro run-of-river power plants and hydro reservoir natural inflow are country-wide averages calculated with REMixEnDAT based on bottom-up power plant models (see Table 8) [11], [12]. This calculation includes exclusion areas for renewable energies which define with technology parameters the potential of each renewable energy technology. For each grid box, the approach yields 
Post-print - Please quote as: Hess, D. The empirical probability of integrating CSP and its cost optimal configuration in a low carbon energy system of EUMENA. Solar Energy, 2018 (accepted)

hourly power generation based on technology parameters and resource availability. The hourly time series are available of the years 1984-2004 on global level (resolution $0.045^{\circ} \mathrm{x}$ $0.045^{\circ}$ or $\sim 50 \mathrm{~km} \times 50 \mathrm{~km}$ at equator) [12] and of the years 2006 - today on European level (resolution $0.083^{\circ} \times 0.083^{\circ}, \sim 10 \mathrm{~km} \times 10 \mathrm{~km}$ ) [11]. For the analysis a typical meteorological year is considered, which is the year 2006 in Europe [11] and the year 2002 in MENA [12]. Two different years can be chosen due to relative low meteorological differences. On European level the output of the time series deviate in the available years of about $15 \%$ max. [26]. Possible changes of the renewable resource availability due to climate change are an uncertainty which is not considered in the analysis. Peak load of demand and average resource full load hours of the model regions are available in Table 11. These input data are important for a reproducibility of the results showing key characteristics of annual input values as well as temporal intensity and temporal availability. Figure 8 serves as an example of the electrical load and technological time series of one year for Germany (country average). Here isopleth diagrams are used to illustrate such time series over the day of the year (y-axis) and over the hour of the day series (x-axis). They show in (a) the electrical load as share of peak load, in (b) the normalised availability of generated electricity by PV capacity, in (c) by wind turbines offshore, in (d) by wind turbines onshore, in (e) by hydro run of river power plants, in (f) the normalised availability of natural inflow by hydro reservoir power plants, in (g) by imports of hydro reservoir power plants from Norway, in (h) the normalised availability of generated thermal energy by the solar field of CSP in MENA for Germany and are related to the design point of $800 \mathrm{~W} / \mathrm{m}^{2}$. The hydro reservoir time series are derived from hydro run of river [11]. The CSP time series is an average of selected CSP hotspots.

The temporal profiles reveal the intensity and availability of the demand and the resources. Characteristic for the time series is the time period of regularly and unregularly low and high availability. For example the wind resources show irregular monthly and seasonal lacks (green colour Figure 8c, d) of wind compared to solar resources (black in Figure 8b,h). Solar resources are more periodical available during a year than wind or hydro resources. The availability of the solar resources PV (GHI) is smoother than the scattered resource of CSP (DNI). Comparing PV in Germany and CSP in MENA, it is visible that in winter PV drops in Germany while CSP in MENA stays in its availability nearly constant. Hydro time series are seasonally less fluctuating than wind or solar but not always such intensively available. The load curve shows a peak demand in winter which is typical in northern European regions. All isopleth diagrams of the used model regions refer to one year, start in the lower left corner $(0,0)$ on January $1^{\text {st }}$ and are shown in Figure 8 to Figure 22.

Europe: 
Post-print - Please quote as: Hess, D. The empirical probability of integrating CSP and its cost optimal configuration in a low carbon energy system of EUMENA. Solar Energy, 2018 (accepted)

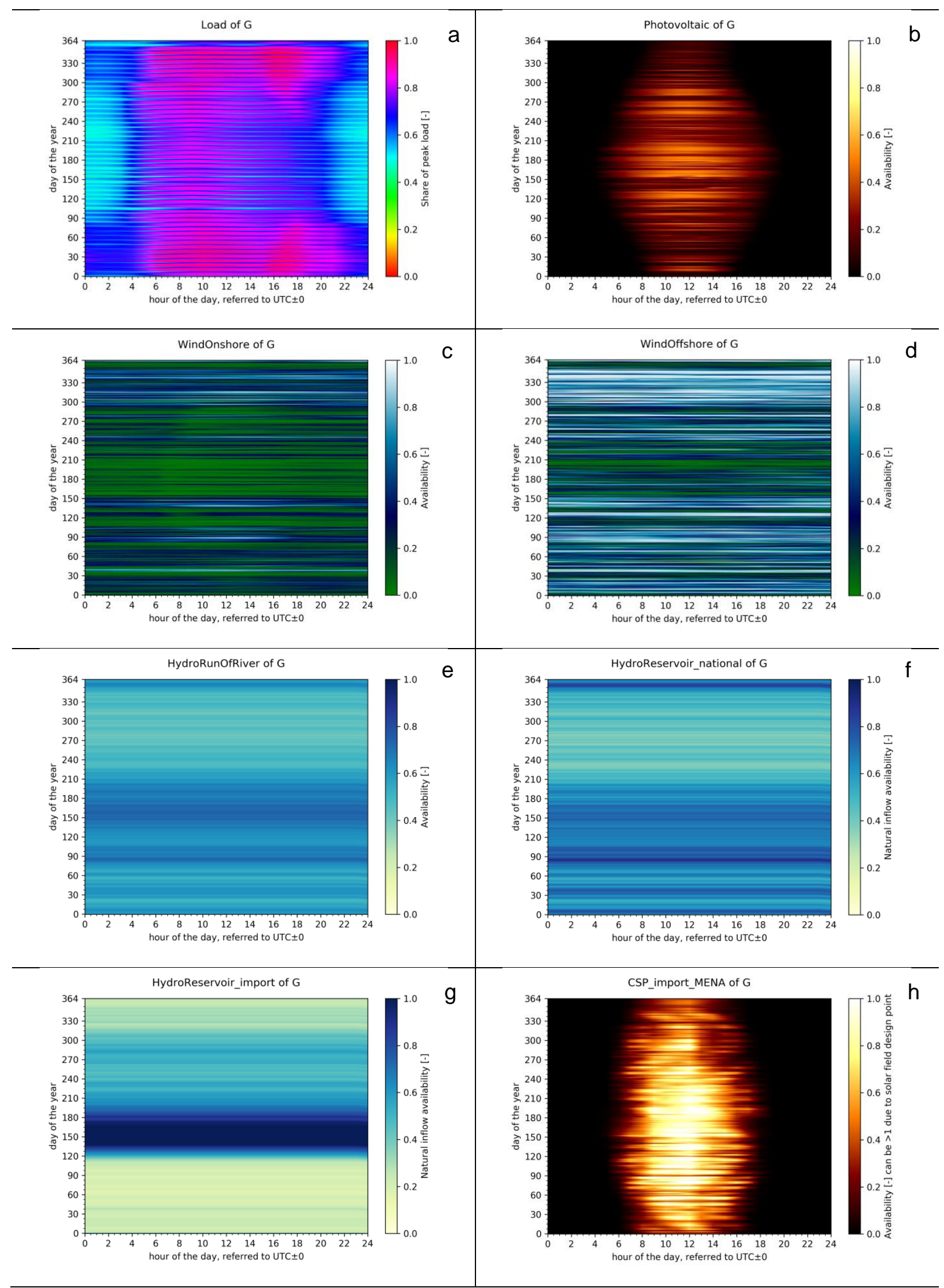

Figure 8: Load and technological time series of model region $\mathrm{G}$ 
Post-print - Please quote as: Hess, D. The empirical probability of integrating CSP and its cost optimal configuration in a low carbon energy system of EUMENA. Solar Energy, 2018 (accepted)

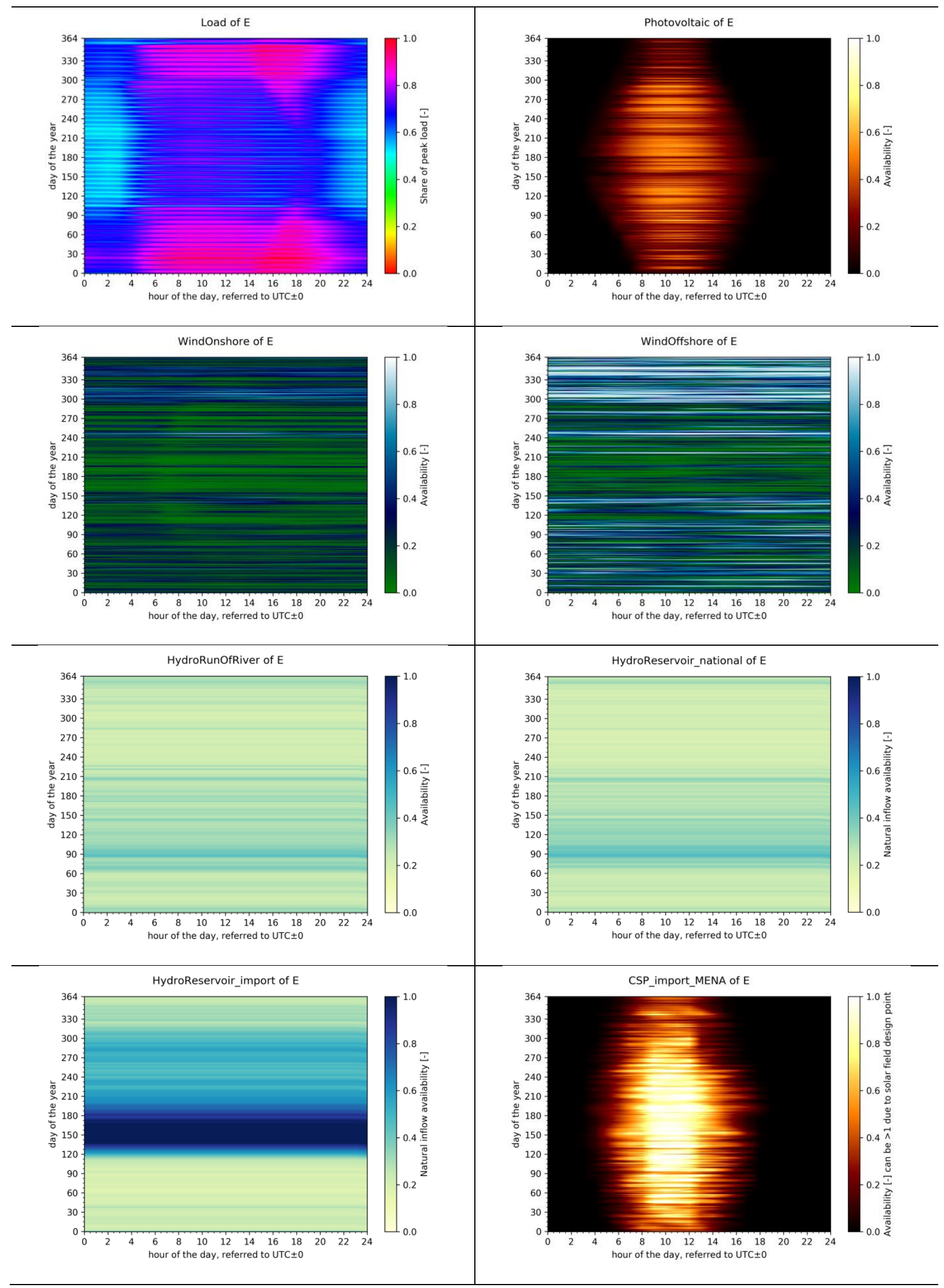

Figure 9: Load and technological time series of model region $\mathrm{E}$ 
Post-print - Please quote as: Hess, D. The empirical probability of integrating CSP and its cost optimal configuration in a low carbon energy system of EUMENA. Solar Energy, 2018 (accepted)

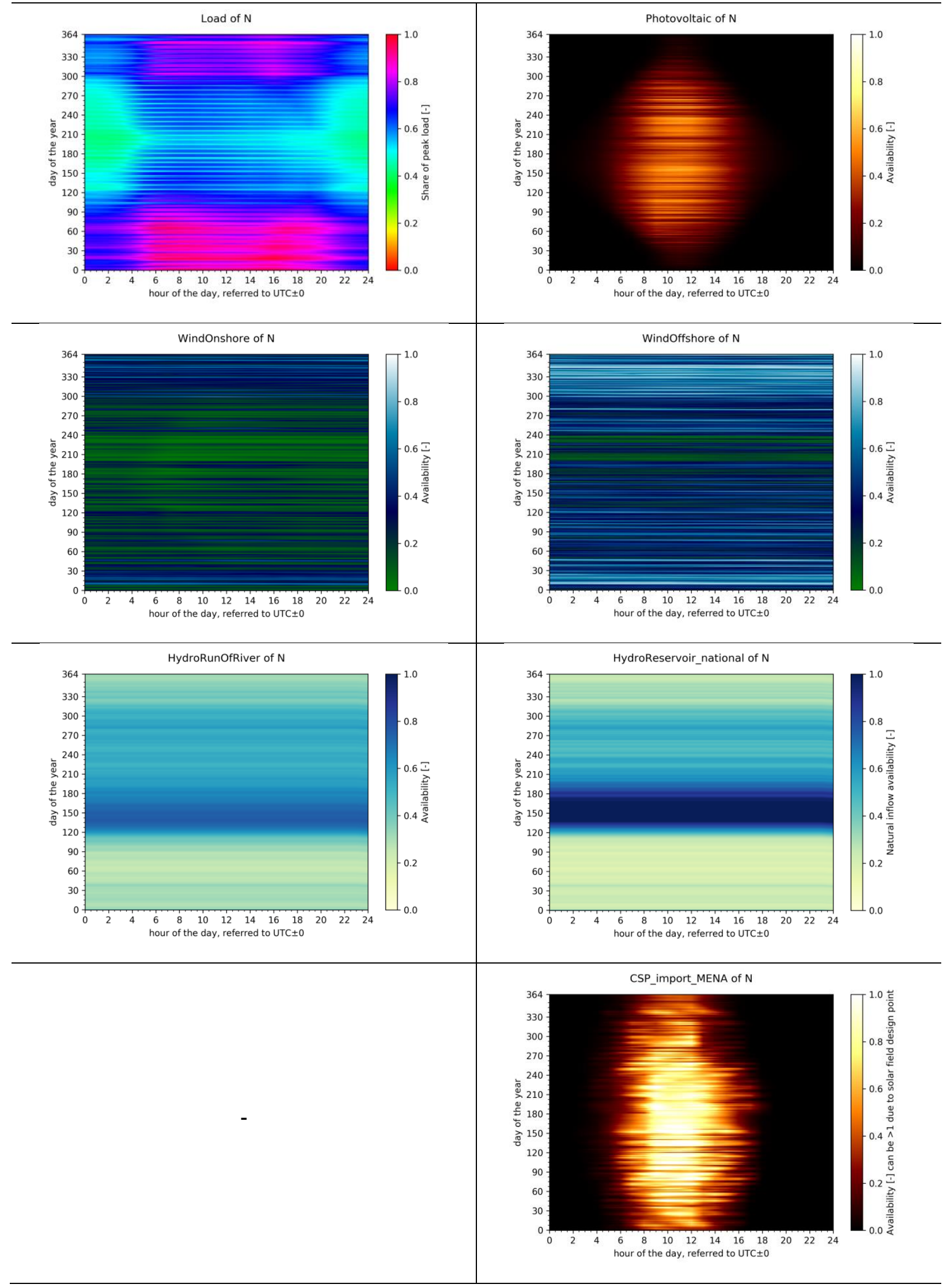

Figure 10: Load and technological time series of model region $\mathrm{N}$ 
Post-print - Please quote as: Hess, D. The empirical probability of integrating CSP and its cost optimal configuration in a low carbon energy system of EUMENA. Solar Energy, 2018 (accepted)

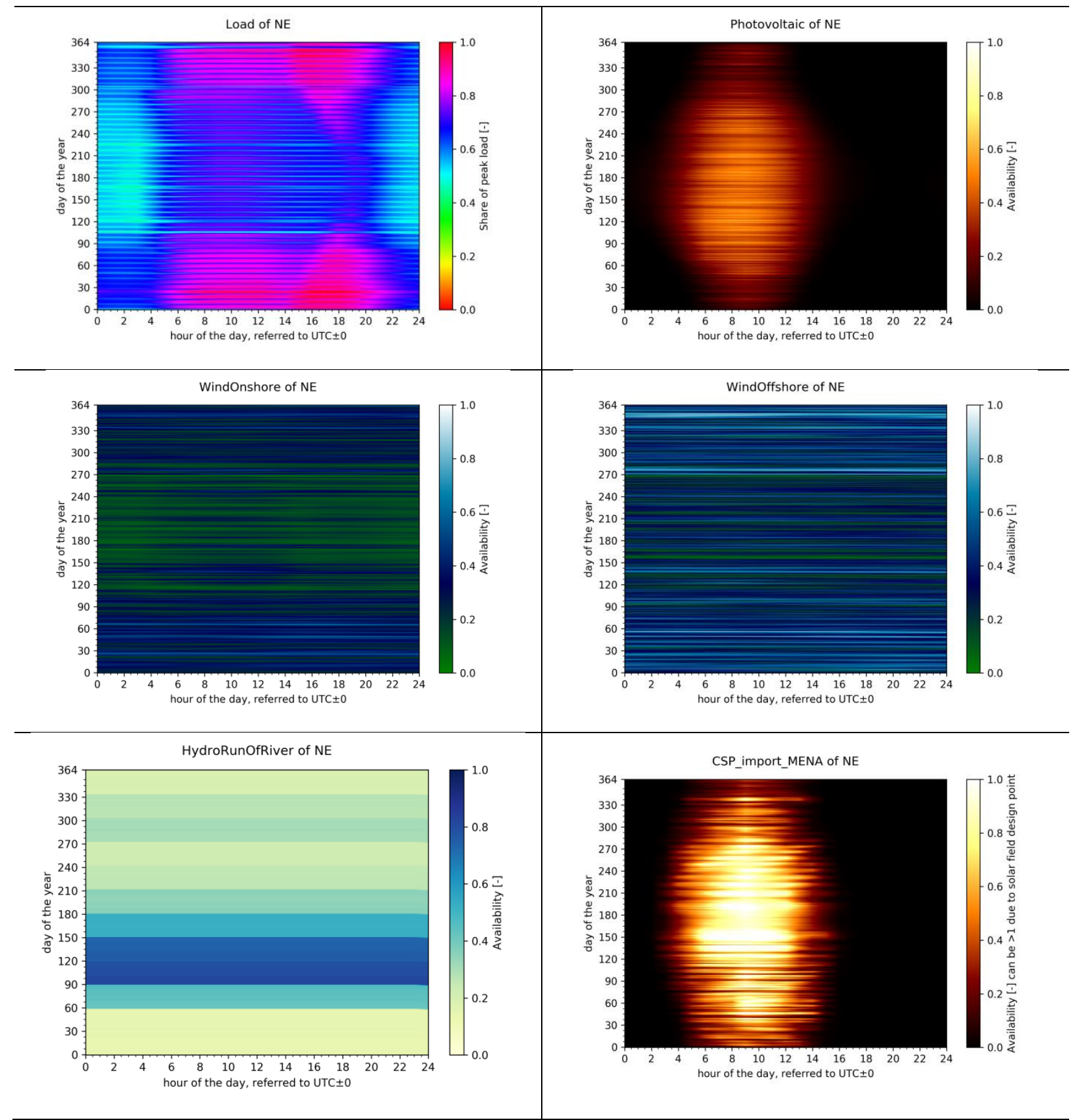

Figure 11: Load and technological time series of model region NE 
Post-print - Please quote as: Hess, D. The empirical probability of integrating CSP and its cost optimal configuration in a low carbon energy system of EUMENA. Solar Energy, 2018 (accepted)

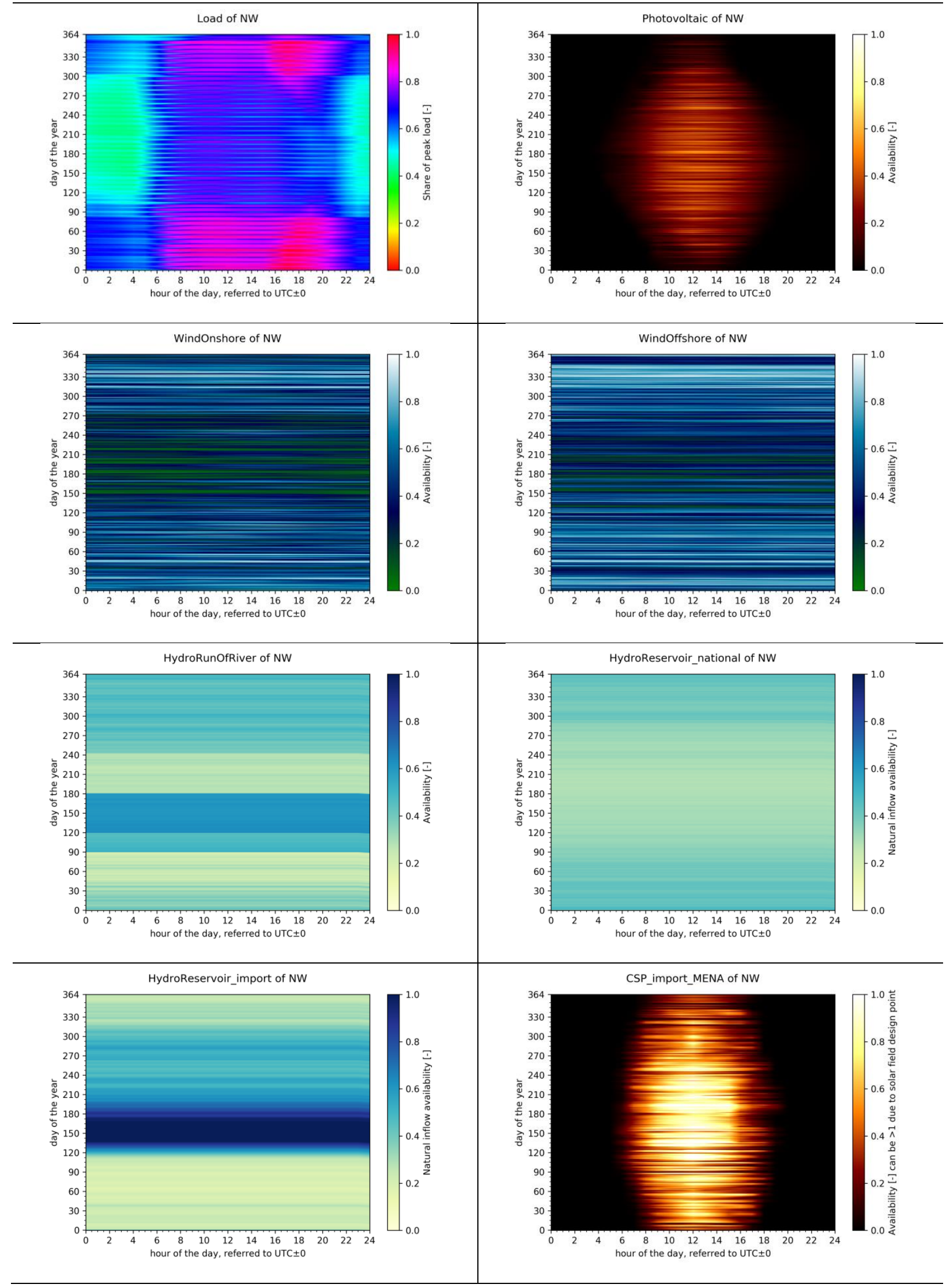

Figure 12: Load and technological time series of model region NW 
Post-print - Please quote as: Hess, D. The empirical probability of integrating CSP and its cost optimal configuration in a low carbon energy system of EUMENA. Solar Energy, 2018 (accepted)

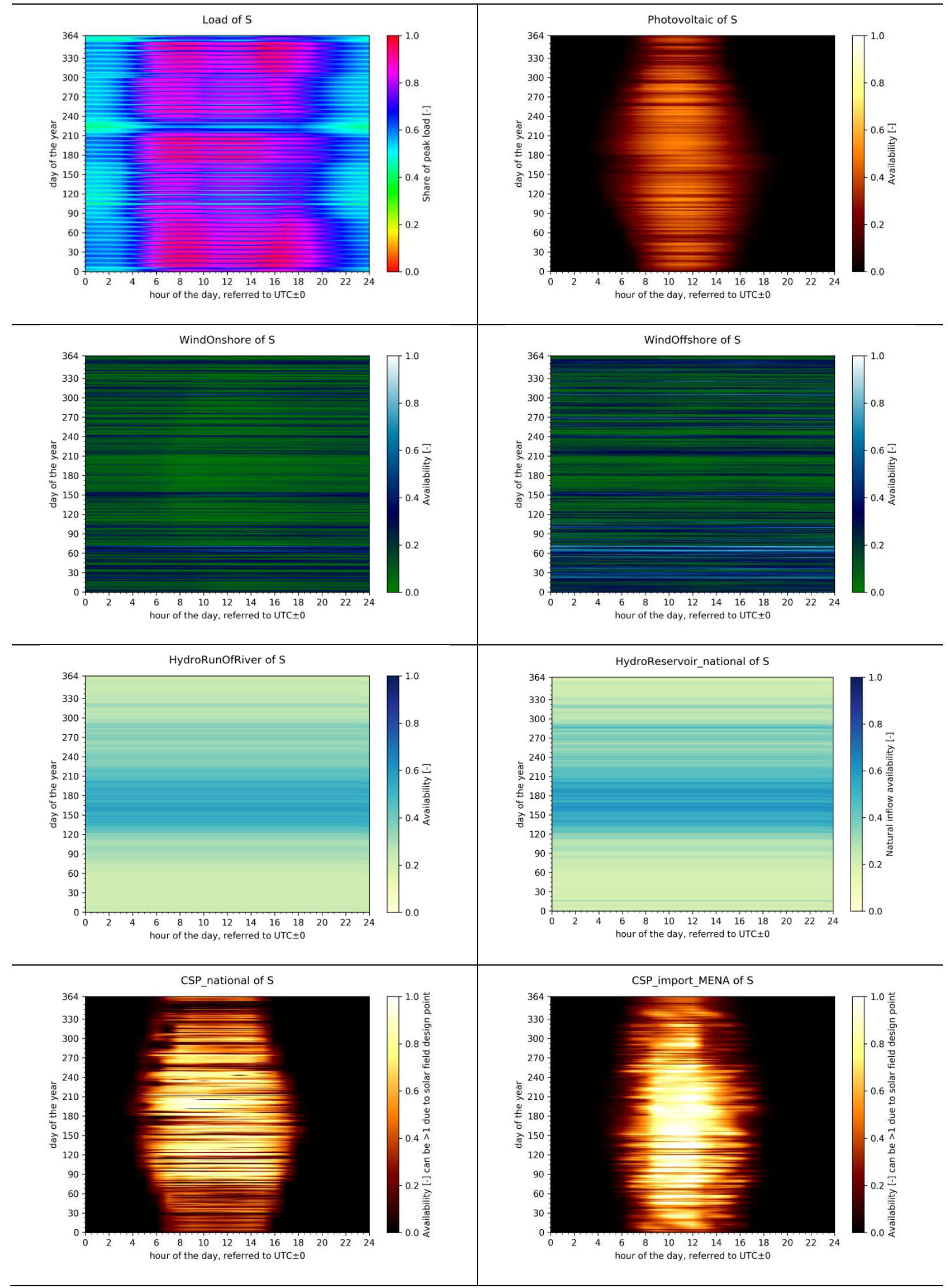

Figure 13: Load and technological time series of model region S 
Post-print - Please quote as: Hess, D. The empirical probability of integrating CSP and its cost optimal configuration in a low carbon energy system of EUMENA. Solar Energy, 2018 (accepted)

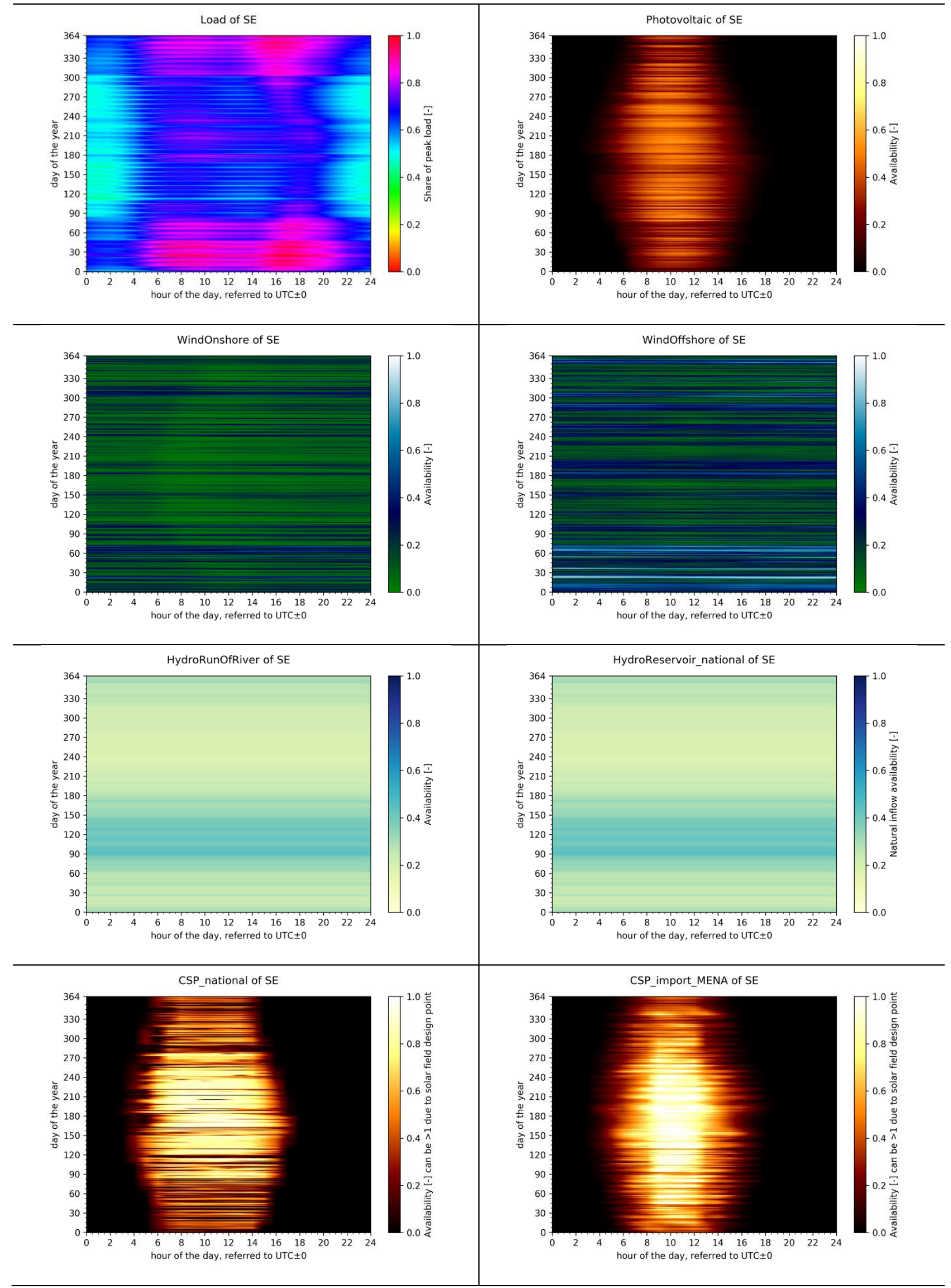

Figure 14: Load and technological time series of model region SE 
Post-print - Please quote as: Hess, D. The empirical probability of integrating CSP and its cost optimal configuration in a low carbon energy system of EUMENA. Solar Energy, 2018 (accepted)

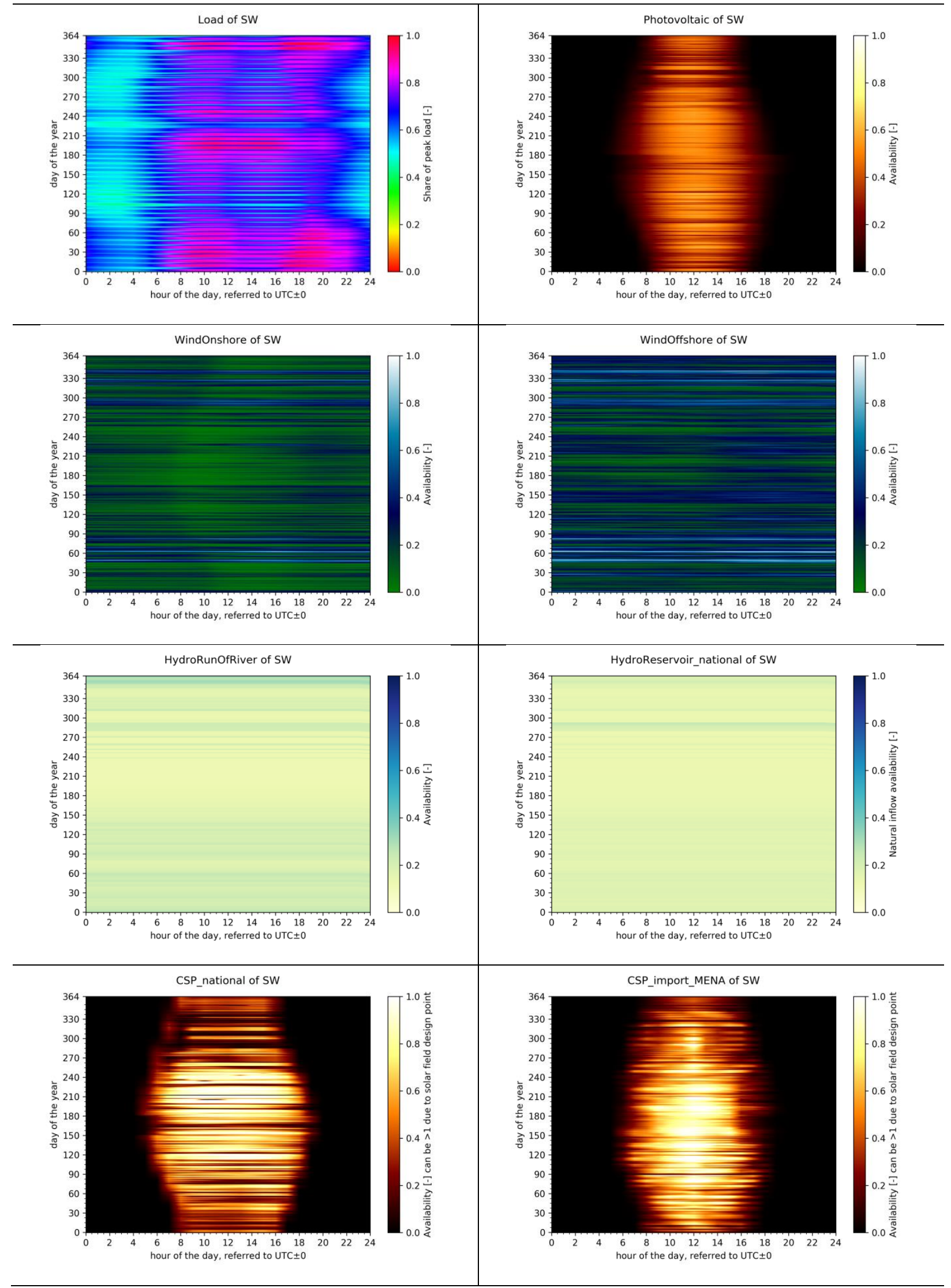

Figure 15: Load and technological time series of model region SW 
Post-print - Please quote as: Hess, D. The empirical probability of integrating CSP and its cost optimal configuration in a low carbon energy system of EUMENA. Solar Energy, 2018 (accepted)

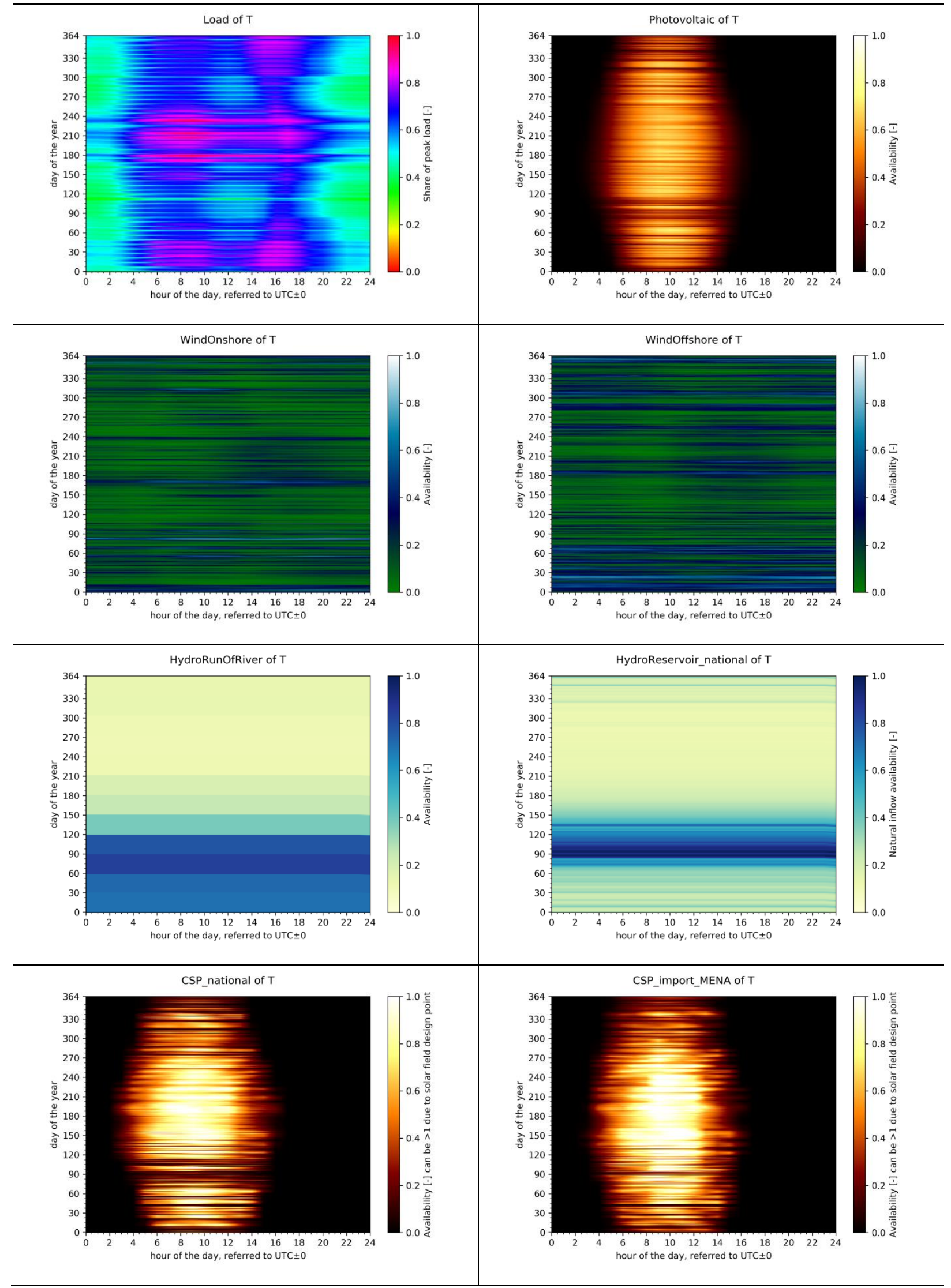

Figure 16: Load and technological time series of model region T 
Post-print - Please quote as: Hess, D. The empirical probability of integrating CSP and its cost optimal configuration in a low carbon energy system of EUMENA. Solar Energy, 2018 (accepted)

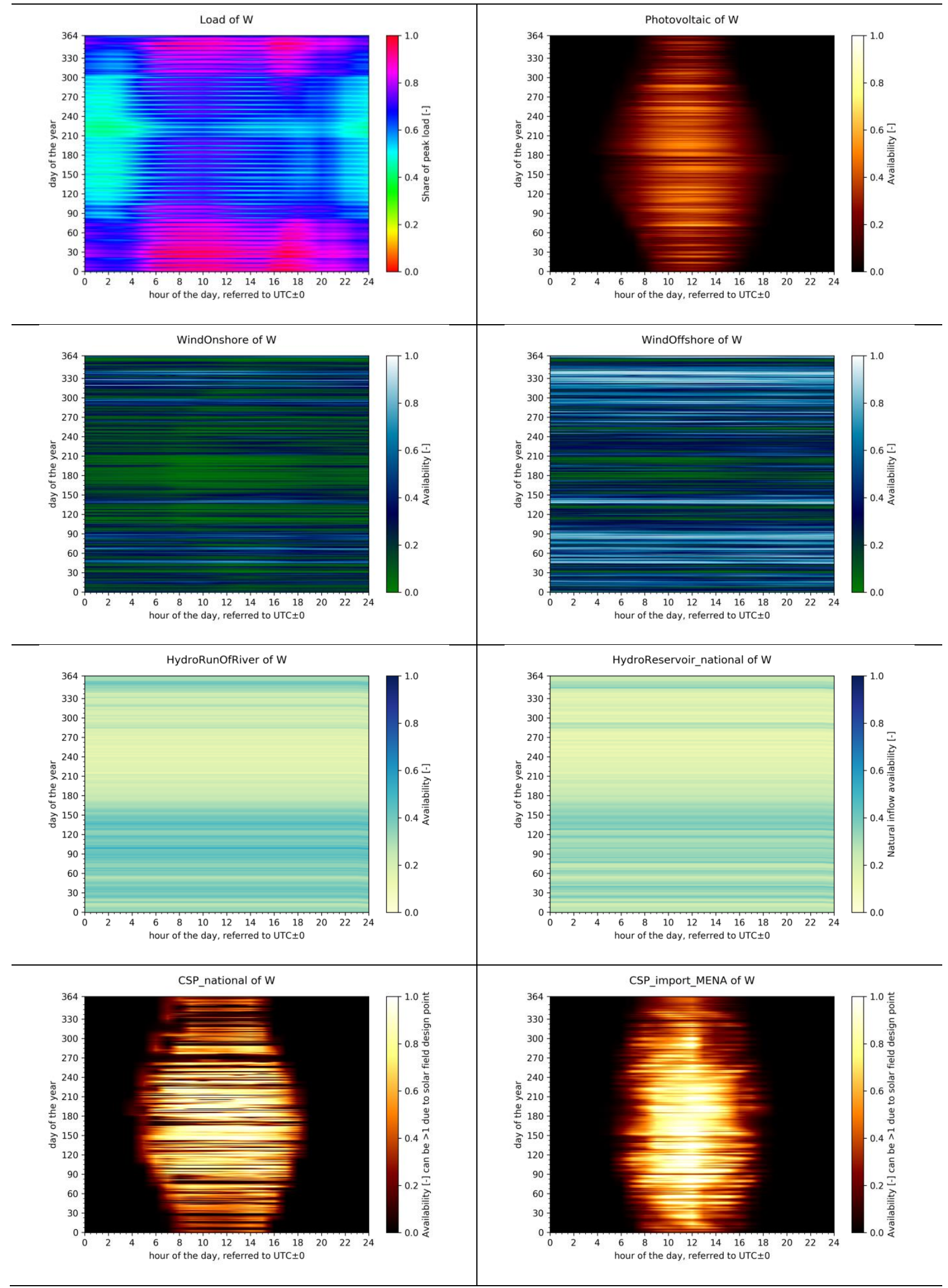

Figure 17: Load and technological time series of model region $\mathrm{W}$ 
Post-print - Please quote as: Hess, D. The empirical probability of integrating CSP and its cost optimal configuration in a low carbon energy system of EUMENA. Solar Energy, 2018 (accepted)

MENA:

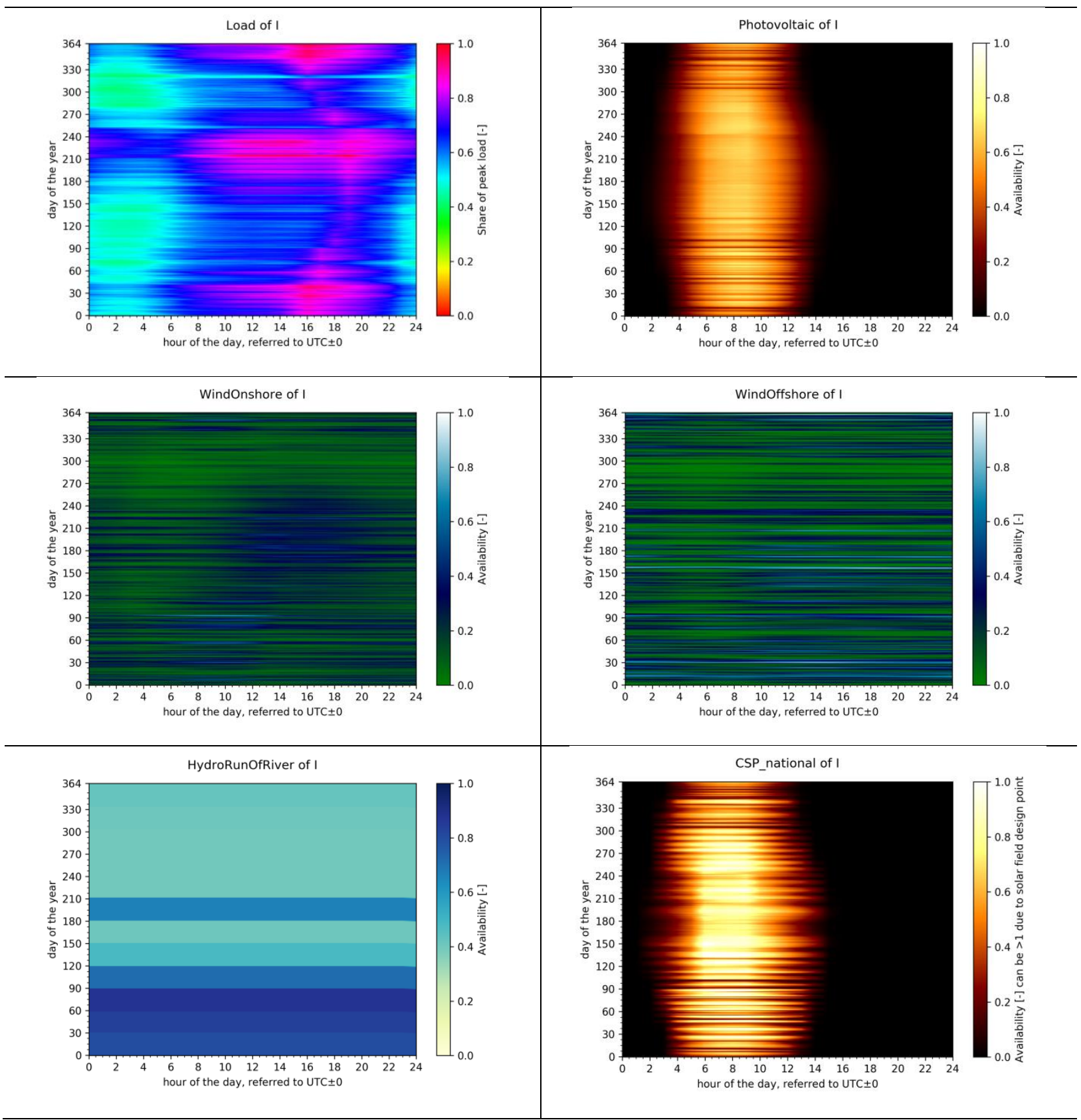

Figure 18: Load and technological time series of model region I 
Post-print - Please quote as: Hess, D. The empirical probability of integrating CSP and its cost optimal configuration in a low carbon energy system of EUMENA. Solar Energy, 2018 (accepted)

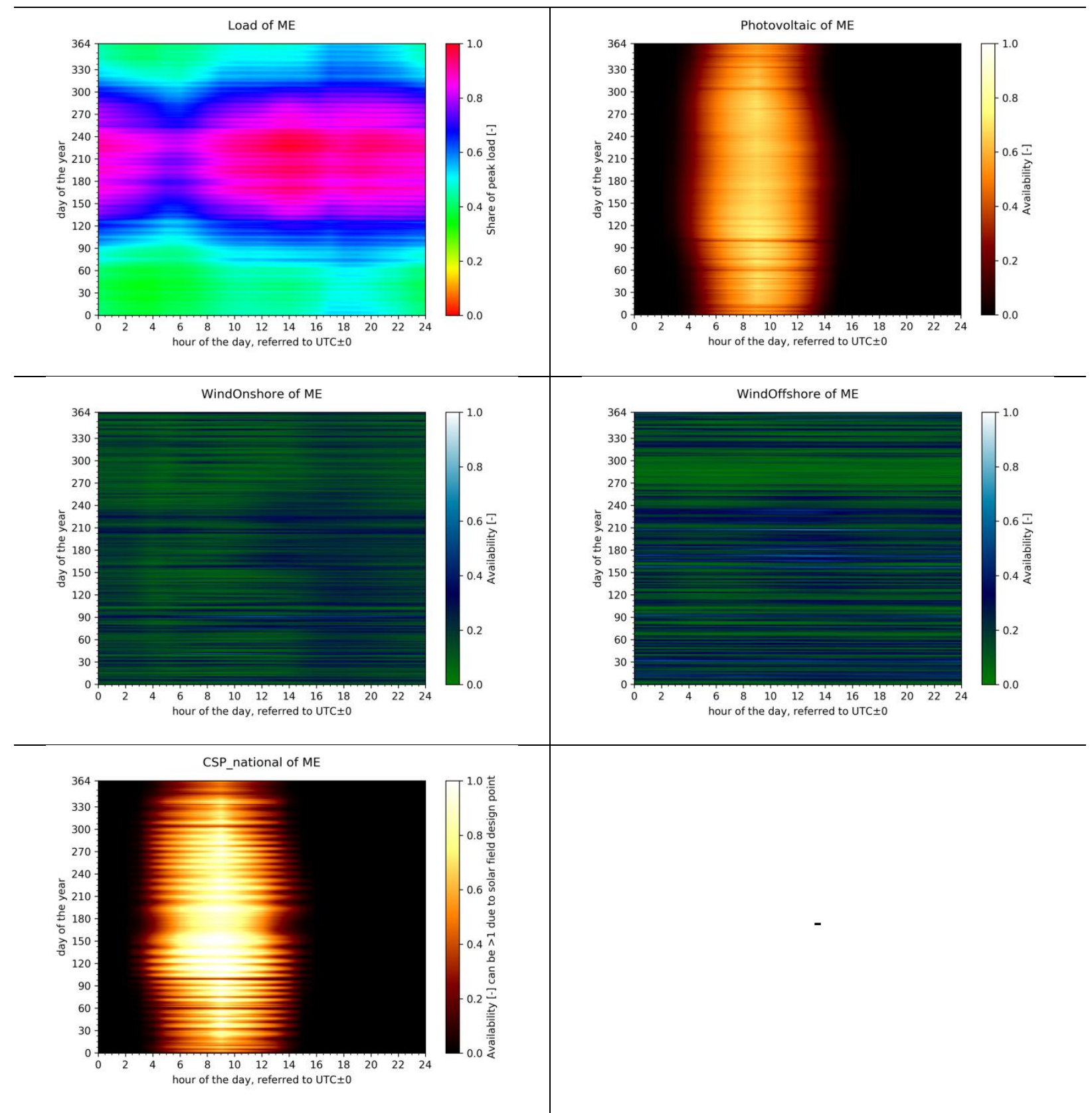

Figure 19: Load and technological time series of model region ME 
Post-print - Please quote as: Hess, D. The empirical probability of integrating CSP and its cost optimal configuration in a low carbon energy system of EUMENA. Solar Energy, 2018 (accepted)

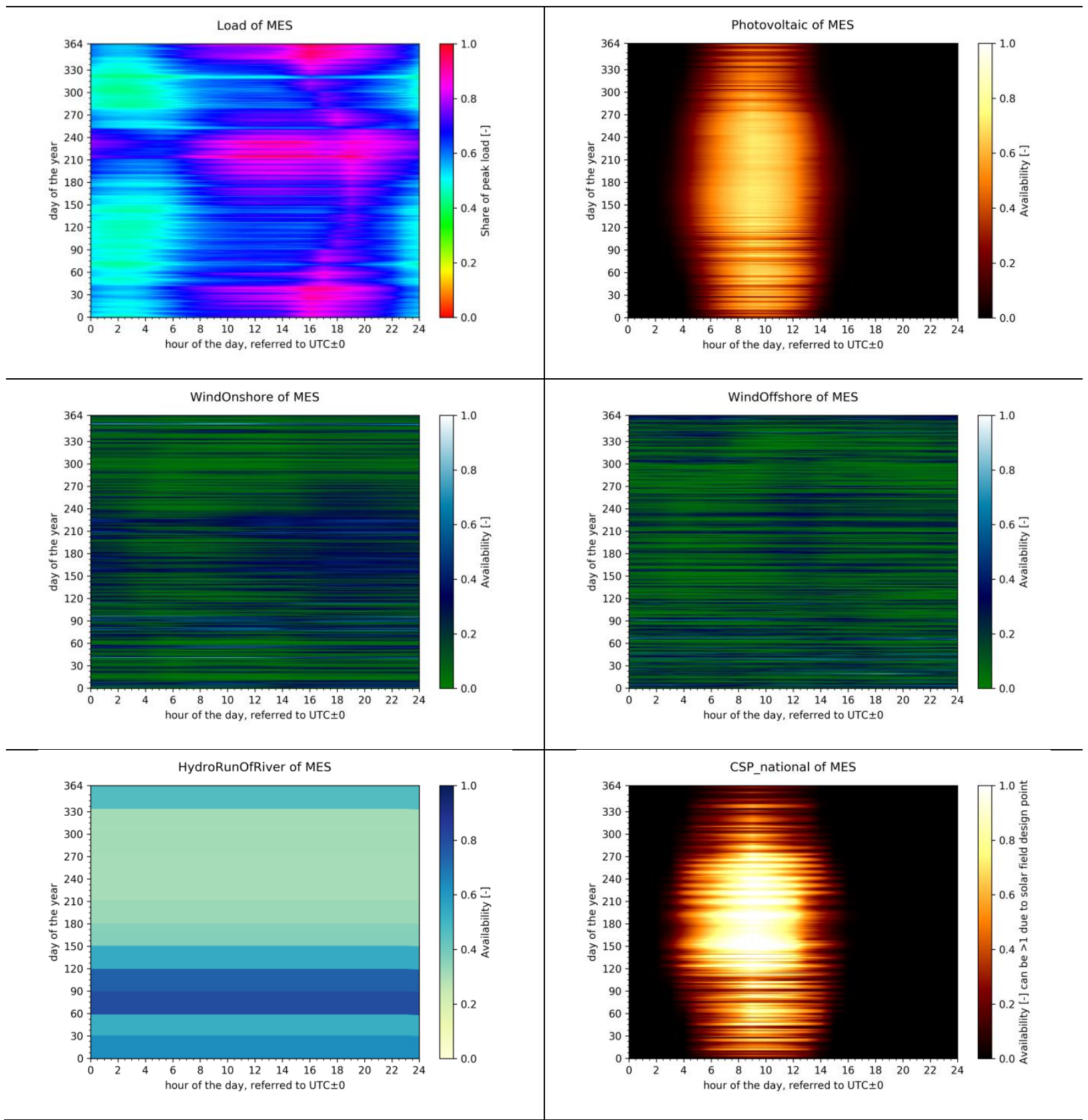

Figure 20: Load and technological time series of model region MES 
Post-print - Please quote as: Hess, D. The empirical probability of integrating CSP and its cost optimal configuration in a low carbon energy system of EUMENA. Solar Energy, 2018 (accepted)

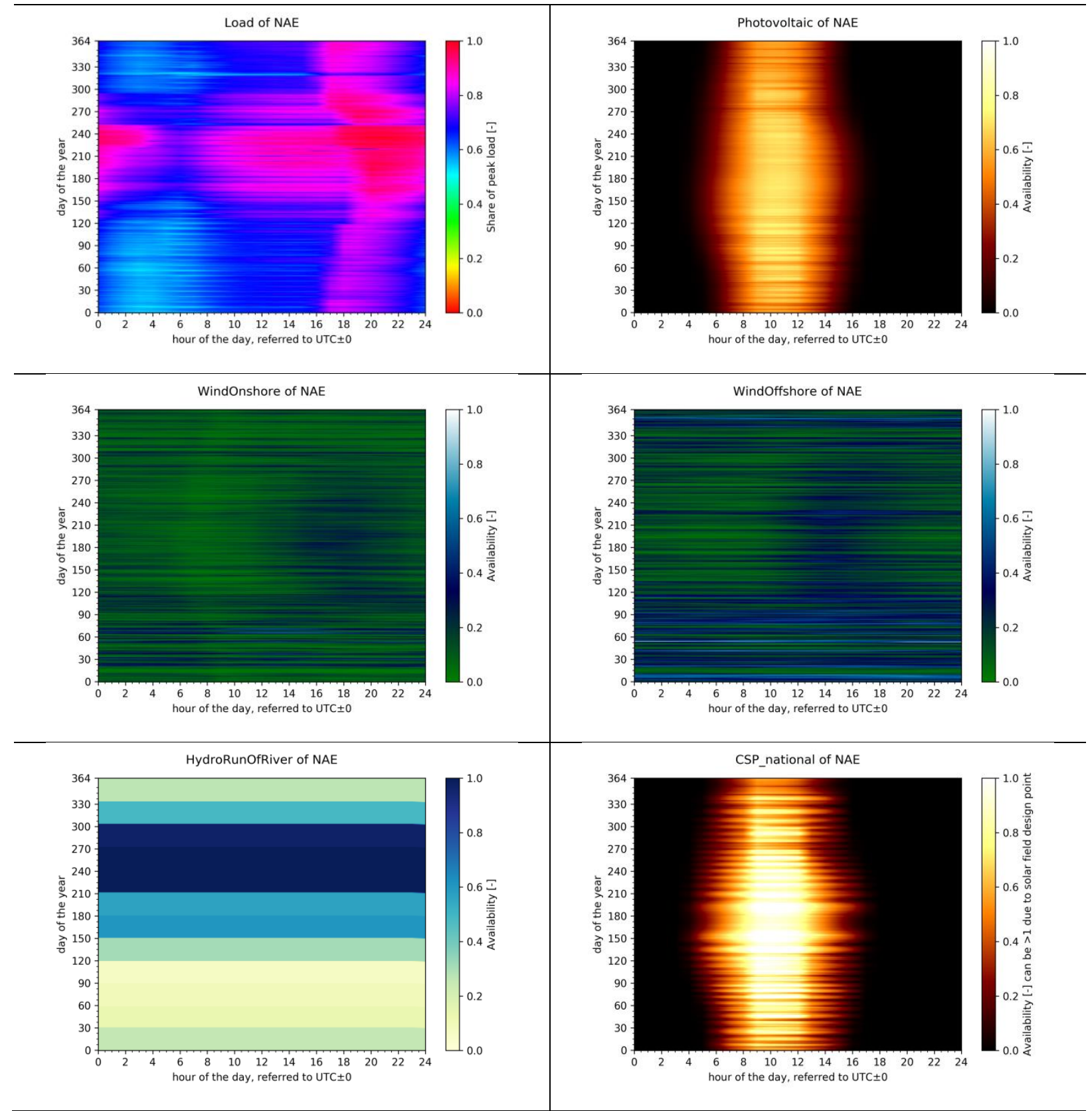

Figure 21: Load and technological time series of model region NAE 
Post-print - Please quote as: Hess, D. The empirical probability of integrating CSP and its cost optimal configuration in a low carbon energy system of EUMENA. Solar Energy, 2018 (accepted)

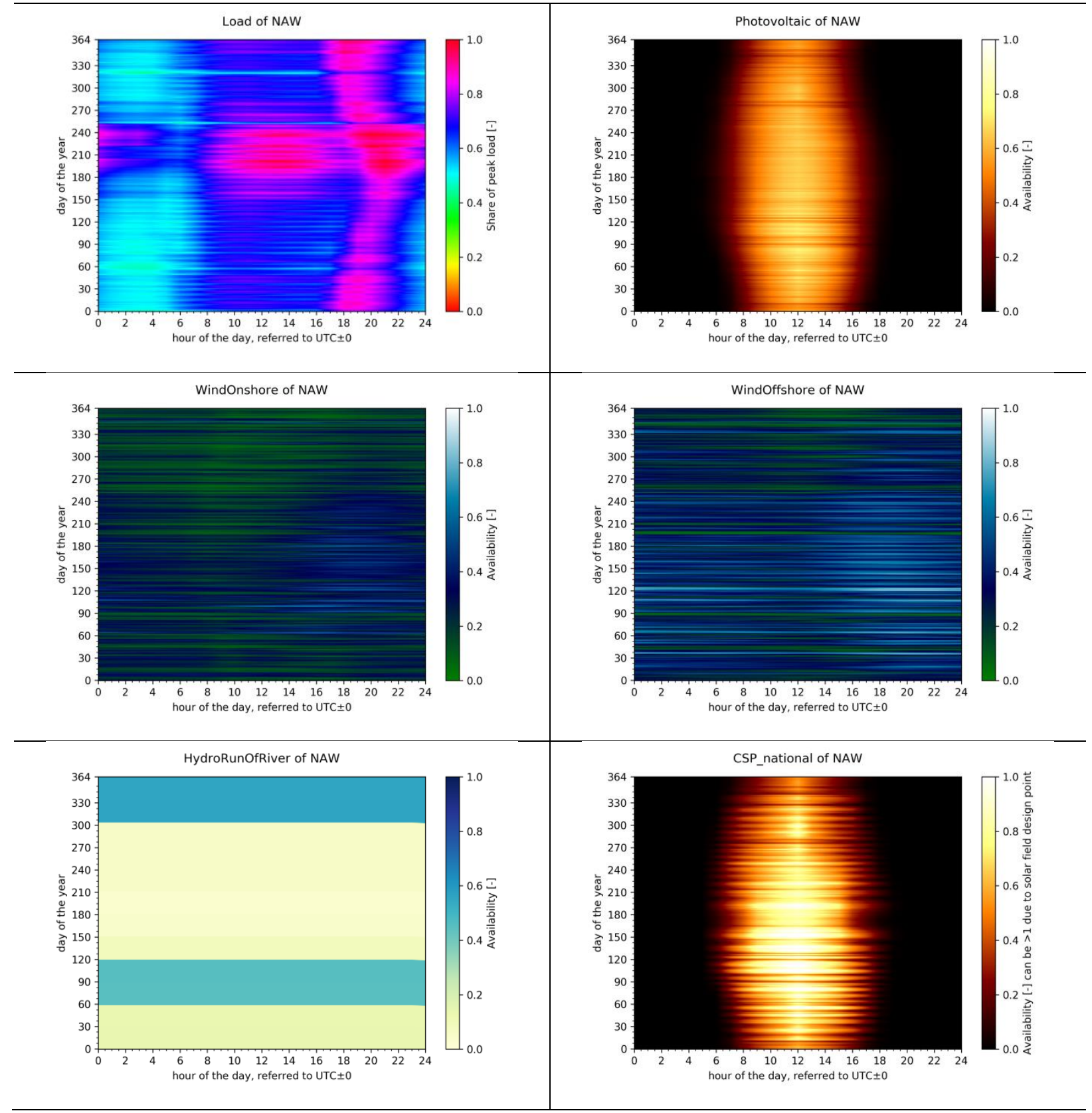

Figure 22: Load and technological time series of model region NAW

\subsubsection{Demand Side Management}

Regarding Demand Side Management (DSM), former studies have shown that the economic potential of DSM in Germany is approximately $10 \mathrm{GW}$ [27] [28]. DSM substitutes short time storages (e.g. lithium ion batteries) and cost-efficient gas turbines [27] [28]. Thus, DSM has only a small influence on system cost and operating behaviour of the power plant park in Germany [27] [28]. Therefore DSM is neglected in the analysis. 
Post-print - Please quote as: Hess, D. The empirical probability of integrating CSP and its cost optimal configuration in a low carbon energy system of EUMENA. Solar Energy, 2018 (accepted)

\subsubsection{Storages}

The model uses different types of storage: short-term (e.g. battery type, represented by parameters for lithium ion batteries), medium-term (e.g. compressed air and pump storages) and long-term storages (e.g. hydrogen storages). The representatives are chosen due to the optimization method with the target function of minimizing system cost. When modelling technologies with about the same cost, the optimizer always uses the cheapest technology. Other technologies with about the same characteristics are therefore excluded by the optimizer. Thus, only the used three types of storage are considered due to their different temporal commitment.

Power-to-Gas-to-Power (P2G2P) is modelled with an electrolysis (alkali in maximum cost sensitivity, PEMFC in minimum cost sensitivity), methanation, compressed and stored in a salt cavern or in the gas distribution grid and burned in gas turbines. Power capacity of electrolyser and turbine can be optimized separately.

\subsubsection{Security of supply}

To ensure security of supply, the capacity credit is introduced (see Table 12). The capacity credit defines revision and outage of the installed capacity of each technology as an empirical value. For security and reserve reasons, the total firm capacity (product of capacity credits and related power plant capacities) must be $100 \%$. So the total firm capacity is calculated referred to peak load at about $105 \%$. To ensure firm national capacity in Germany, gas turbines are installed to cover the total peak demand together with other national dispatchable capacities in case of any failure. Installation of back-up capacities raise new financing questions if these capacities were not used (e.g. apportionment financing). CSPHVDC is assumed with a capacity credit of $0 \%$ to model a possible total outage based on non-technical reasons. However, this dispatchable technology is able to ensure firm capacity due to its co-firing option. Thus, CSP-HVDC could substitute national gas turbines and reduce system cost if firm capacity abroad is accepted as such.

\subsubsection{Modelling of CSP-HVDC in REMix}

\subsubsection{CSP-HVDC}

A CSP-HVDC power plant is modelled with a solar field (SF), thermal energy storage (TES), power block (PB) with co-firing system (BUS), two HVDC converters and a HVDC transmission. Each of these components has its own techno-economic characteristics which 
Post-print - Please quote as: Hess, D. The empirical probability of integrating CSP and its cost optimal configuration in a low carbon energy system of EUMENA. Solar Energy, 2018 (accepted)

are listed in Table 12 and Table 17 and are considered by REMix. The following description is based on [13] and reveals the functioning of the CSP model with thermal storage and cofiring option in REMix.

The total solar field thermal capacity is composed of the exogenous capacity $Q_{\text {existcap }}$ and the model endogenous capacity $\boldsymbol{Q}_{\text {addedcap }}$ and is limited to the total potential calculated by REMix-EnDAT. The solar field thermal output $\boldsymbol{Q}_{S F}(t)$ arises from the overall capacity $\left(\boldsymbol{Q}_{\text {addedCap }}+Q_{\text {existCap }}\right)$ and the normalised hourly availability of the solar resource $s_{\text {gen }}(t)$ as thermal time series. This is described in Eq. (10).

$$
\boldsymbol{Q}_{S F}(t) \stackrel{!}{=}\left(\boldsymbol{Q}_{\text {addedCap }}+Q_{\text {existCap }}\right) \cdot s_{g e n}(t)
$$

The thermal balance of CSP plants includes the thermal output of a solar field $\boldsymbol{Q}_{S F}(t)$, backup unit $\boldsymbol{Q}_{B U S}(t)$, TES charging $\boldsymbol{Q}_{\text {charge }}(t)$ and discharging $\boldsymbol{Q}_{\text {discharge }}(t)$, the thermal curtailment of the solar field $\boldsymbol{Q}_{\text {curtail }}(t)$, the power generation of the power block $\boldsymbol{P}_{g e n}(t)$ according to Eq. (11) and the efficiency of the power block $\eta_{\text {generator }}$. The efficiency of the power block is the product of the thermal and electrical efficiency.

$$
\boldsymbol{Q}_{S F}(t)+\boldsymbol{Q}_{\text {BUS }}(t)+\left(\boldsymbol{Q}_{\text {discharge }}(t)-\boldsymbol{Q}_{\text {charge }}(t)\right)-\boldsymbol{Q}_{\text {curtail }}(t) \stackrel{!}{=} \frac{\boldsymbol{P}_{\text {gen }}(t)}{\eta_{\text {generator }}} \quad \forall t
$$

Hourly changes in TES energy level $\boldsymbol{U}_{\text {level }}(t)$ are described by the storage balance, which accounts for charging, discharging, and self-discharging in Eq.(12). An additional equation sets the storage level in the first and last time step to the same value, assuring that no energy is produced in the storage [13].

$$
\begin{gathered}
\boldsymbol{U}_{\text {level }}(t) \stackrel{!}{=} \boldsymbol{U}_{\text {level }}(t-1)+\left(\boldsymbol{Q}_{\text {charge }}(t) \cdot \eta_{\text {charge }}-\frac{\boldsymbol{Q}_{\text {discharge }}(t)}{\eta_{\text {discharge }}}\right) \cdot \Delta t-\frac{1}{2} \\
\cdot\left(\boldsymbol{U}_{\text {level }}(t)+\boldsymbol{U}_{\text {level }}(t-1)\right) \cdot \eta_{\text {self }}
\end{gathered}
$$

$\forall t$

[13]

The hourly output of the power block $\boldsymbol{P}_{g e n}(t)$ is limited by the available capacity. The storage level $\boldsymbol{U}_{\text {level }}(t)$ must be in all time steps lower than the overall TES capacity [13].

The novelty of modelling does not consist in the CSP model - developed by [11], [18] and [13] - but in the method of implementing CSP-HVDC in REMix. A CSP-HVDC power plant 
Post-print - Please quote as: Hess, D. The empirical probability of integrating CSP and its cost optimal configuration in a low carbon energy system of EUMENA. Solar Energy, 2018 (accepted)

transmits electricity via HVDC point-to-point transmission line directly to one offtaker in Europe. Thus, for this offtaker CSP is available apparently locally like home-grown renewable energies. Therefore CSP-HVDC is modelled as a power plant which has the solar resource of a MENA country and HVDC transmission losses - occurring with the transmission of CSP generated electricity to the consumer - but CSP from MENA is placed virtually in a European region. The gross capacity of the HVDC line $P_{H V D C \text {,gross }}$ is the same as the net capacity of the CSP power block $P_{P B, C S P, \text { net }}$ as described in Eq. (13).

$$
P_{P B, C S P, \text { net }}=P_{H V D C, \text { gross }}
$$

Transmission losses are assumed to increase linearly with an increasing distance.

\subsubsection{CSP sites, HVDC point-to-point transmission corridors and offtaker points}

The basis for the CSP-HVDC power plant modelling is built by an exemplary identification of 15 CSP sites (hotspots) in MENA and 82 potential offtakers in geographical Europe (Figure 26 and Figure 27). These production and offtaker centres define the starting and end point of a CSP-HVDC power plant in the model. CSP hotspots are chosen selecting good solar resource [3], short distance to Europe and diversified placement in different MENA countries. The CSP resource is taken within a $30 \mathrm{~km}$ radius of the hotspot. Offtakers are bigger EU cities that represent centres of demand.

The pathways of HVDC between these CSP hotspots and offtaker are calculated using a line laying algorithm [29]. This algorithm considers the geographical terrain with cost and minimizes cost to find a cost optimal pathway. Its spatial resolution is $1 \mathrm{~km} \times 1 \mathrm{~km}$.

The transmission pathway is calculated according to excluded areas (highest cost), preferred and unprivileged areas (lower or higher cost). Here two geographical categories are essential: The first category is independent from the direction of a pathway which is called isotropic friction image. The second category is dependant from the direction of the pathway and called anisotropic friction image (such as slope). With both categories cost-distance images of the CSP hotspots are calculated. Including the offtaker (demand centre) in the analysis a cost optimal pathway can be calculated with the cost-distance image. 
Post-print - Please quote as: Hess, D. The empirical probability of integrating CSP and its cost optimal configuration in a low carbon energy system of EUMENA. Solar Energy, 2018 (accepted)

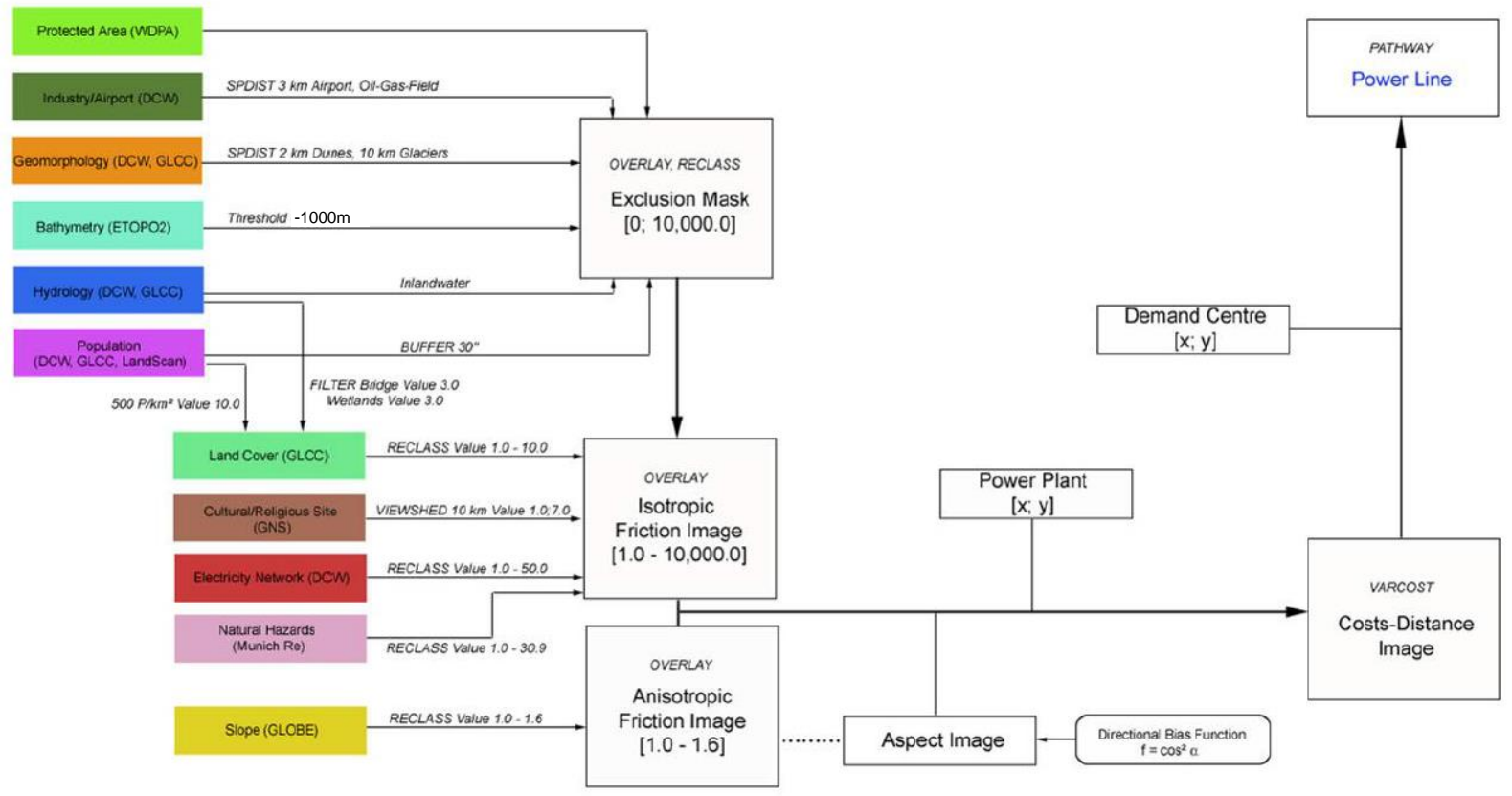

Figure 23: Line laying model based on [29]

The used isotropic friction images are exhibited in Figure 24 and Figure 25 showing two cost sensitivities:

- In Figure 24 a business as usual cost assumption is assumed which leads to predominant onshore pathways as shown in [29] and [3].

- In Figure 25 a dominant use of offshore pathways results. Here the isotropic friction image was calculated like in Figure 24 but with an addition of its highest sea cost value $(\sim 40)$ to the existing cost assumption of the land area.

Out of all possible combinations with 15 CSP sites and 82 potential offtakers (1230 possibilities) those CSP-HVDC plants are chosen which have a short distance to the consumer and at the same time a diversified solar resource from different CSP sites. Both figures illustrate the same connections between CSP hotspot and offtaker with different pathways. Evaluating CSP-HVDC in this paper with an energy system model presumes a reduction of this high-resolution infrastructure due to computational limits. Thus, average transmission lengths and average solar resource from selected CSP-HVDC are used each for one model region. The total average length to one model region is between $1200 \mathrm{~km}$ and $3800 \mathrm{~km}$ and is listed in Table 2. The average solar resource is shown by full load hours of the solar field in the appendix in Table 11. These solar resources of the CSP hotspots are assumed as relative conservative compared to the spatial average solar resources of a model region. 
Post-print - Please quote as: Hess, D. The empirical probability of integrating CSP and its cost optimal configuration in a low carbon energy system of EUMENA. Solar Energy, 2018 (accepted)

Figure 26 and Figure 27 illustrate a possible topology of CSP-HVDC. It is visible that in Figure 27 more straight pathways occur than in Figure 26 due to total higher cost. Thus, it can be assumed that Figure 27 represents sea cable and also underground cable. The CSP power plant sites and offtakters are exemplary and do neither represent real projects nor feasibility studies. 
Post-print - Please quote as: Hess, D. The empirical probability of integrating CSP and its cost optimal configuration in a low carbon energy system of EUMENA. Solar Energy, 2018 (accepted)

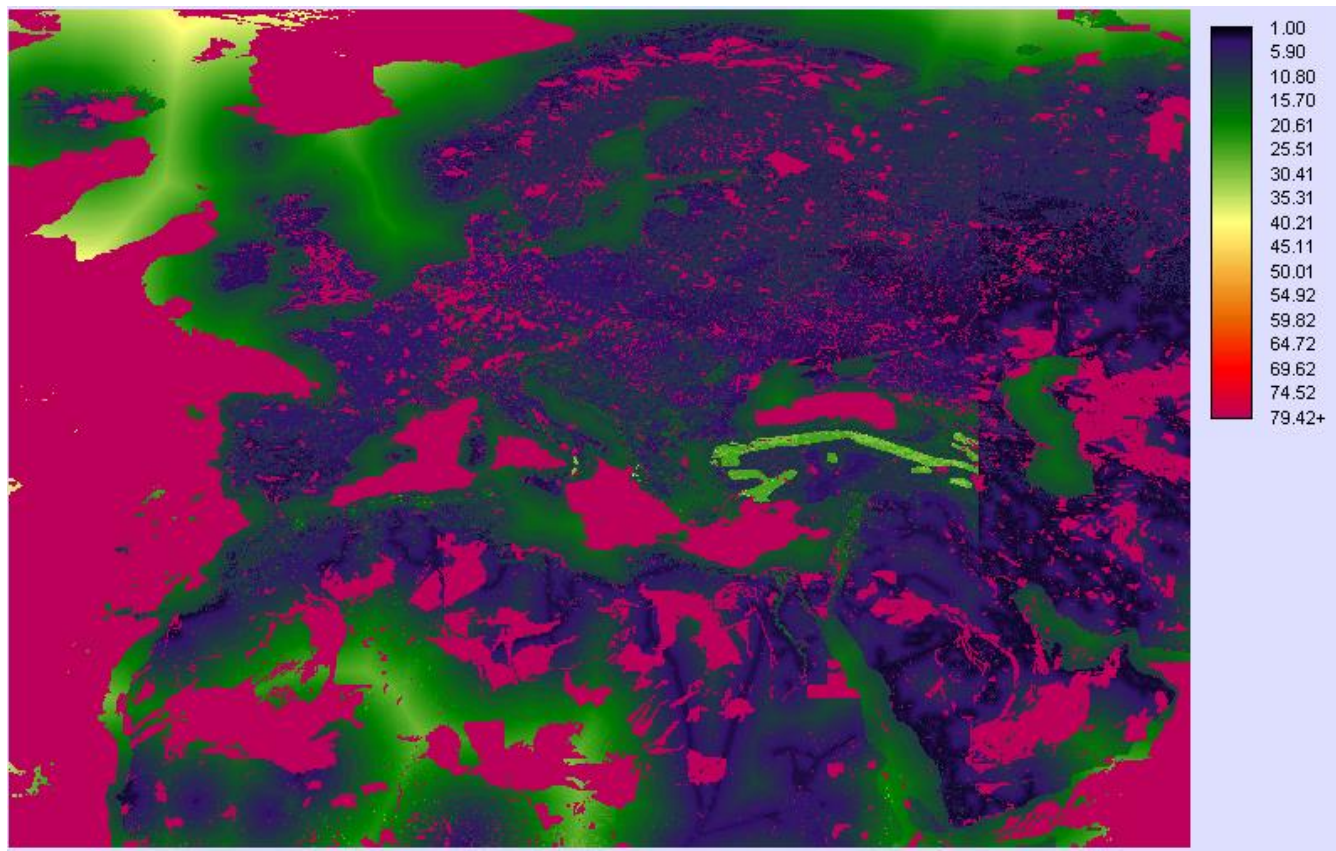

Figure 24: Isotropic friction image based on [29] (OHL case)

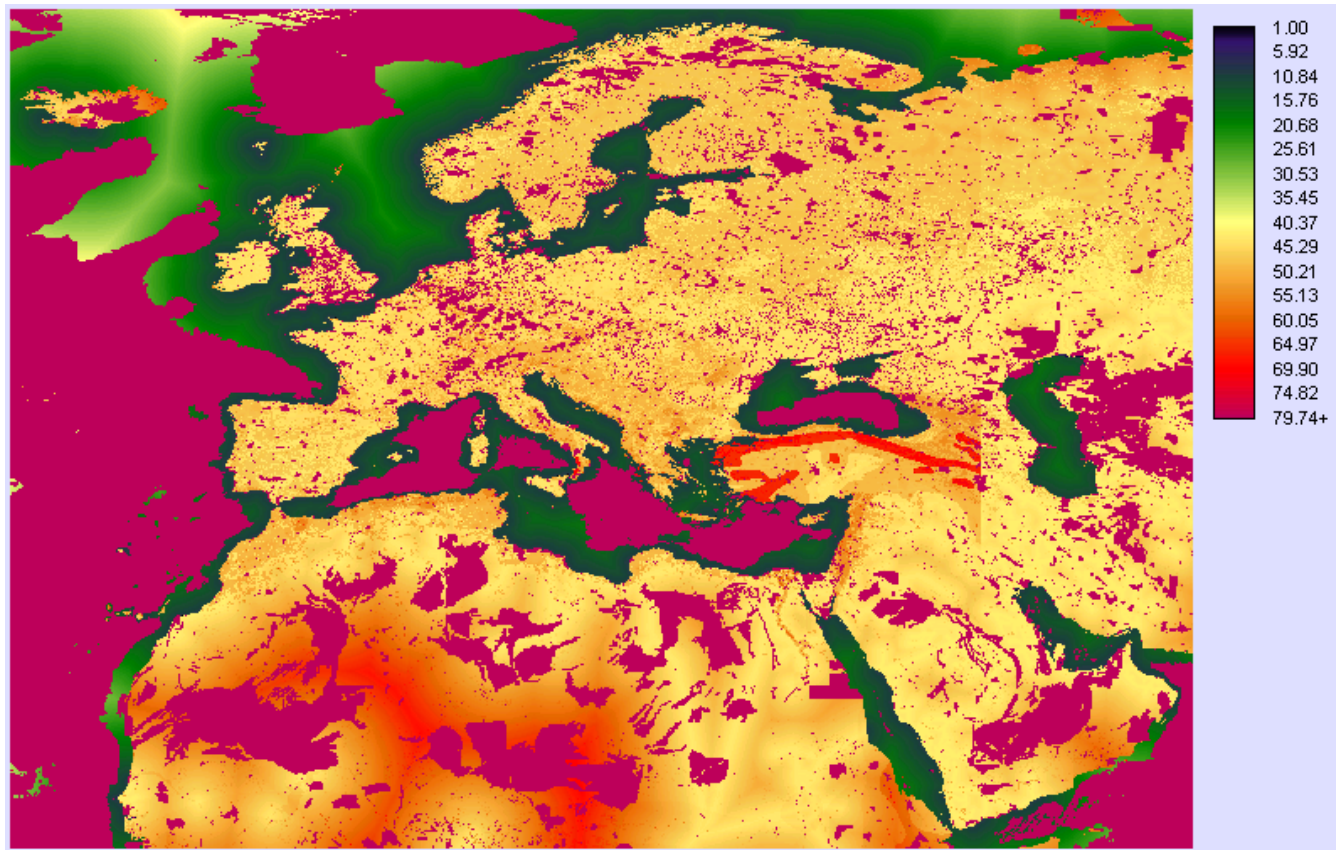

Figure 25: Isotropic friction image based on [29] with addition of highest sea cost value $(\sim 40)$ to all land cost values allowing the algorithm to use predominantly offshore pathways (sea cable and UGC case) 
Post-print - Please quote as: Hess, D. The empirical probability of integrating CSP and its cost optimal configuration in a low carbon energy system of EUMENA. Solar Energy, 2018 (accepted)

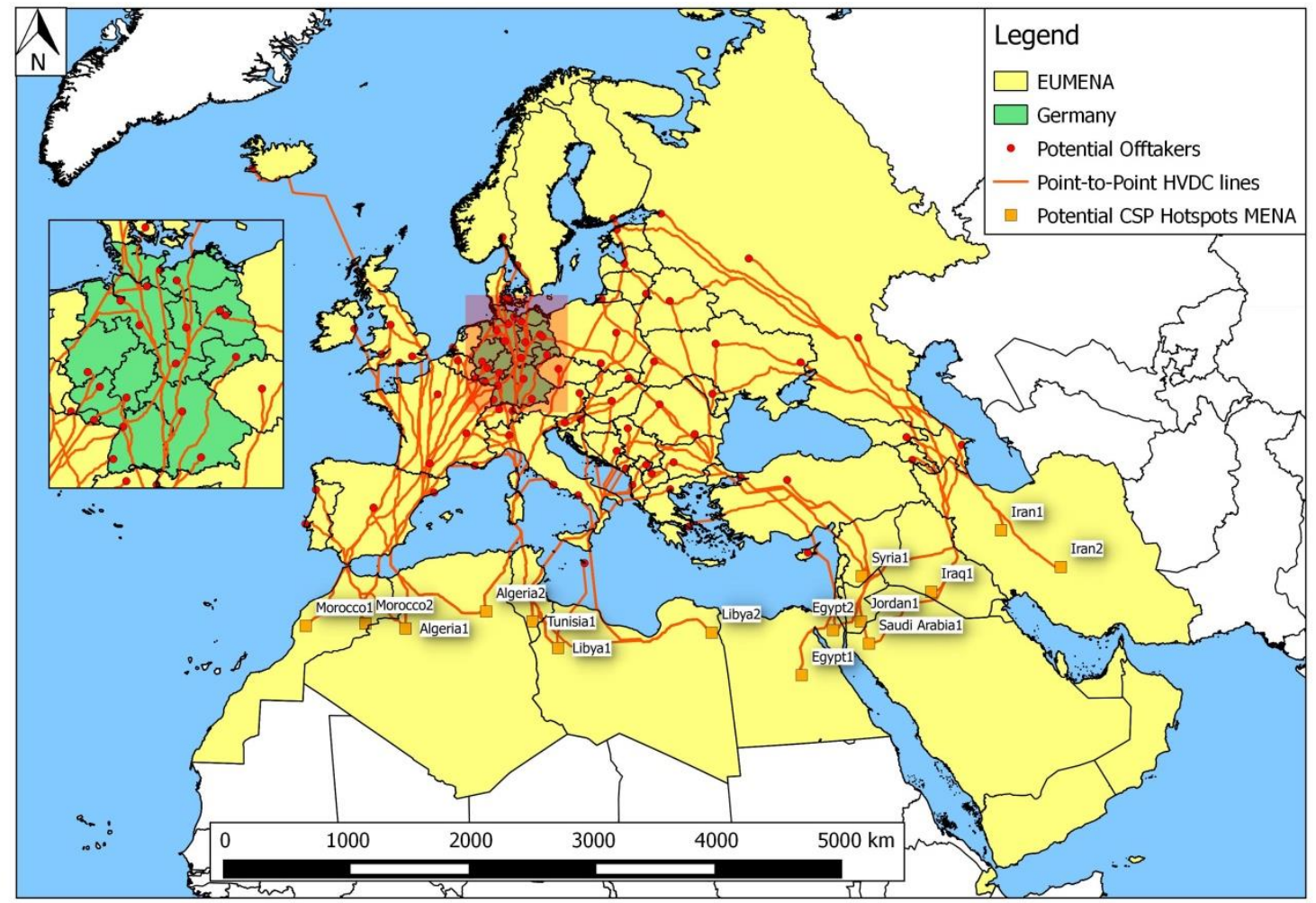

Figure 26: Point-to-point CSP-HVDC with potential CSP hotspots in MENA and potential offtakers in Europe - predominant onshore line configuration (OHL case)

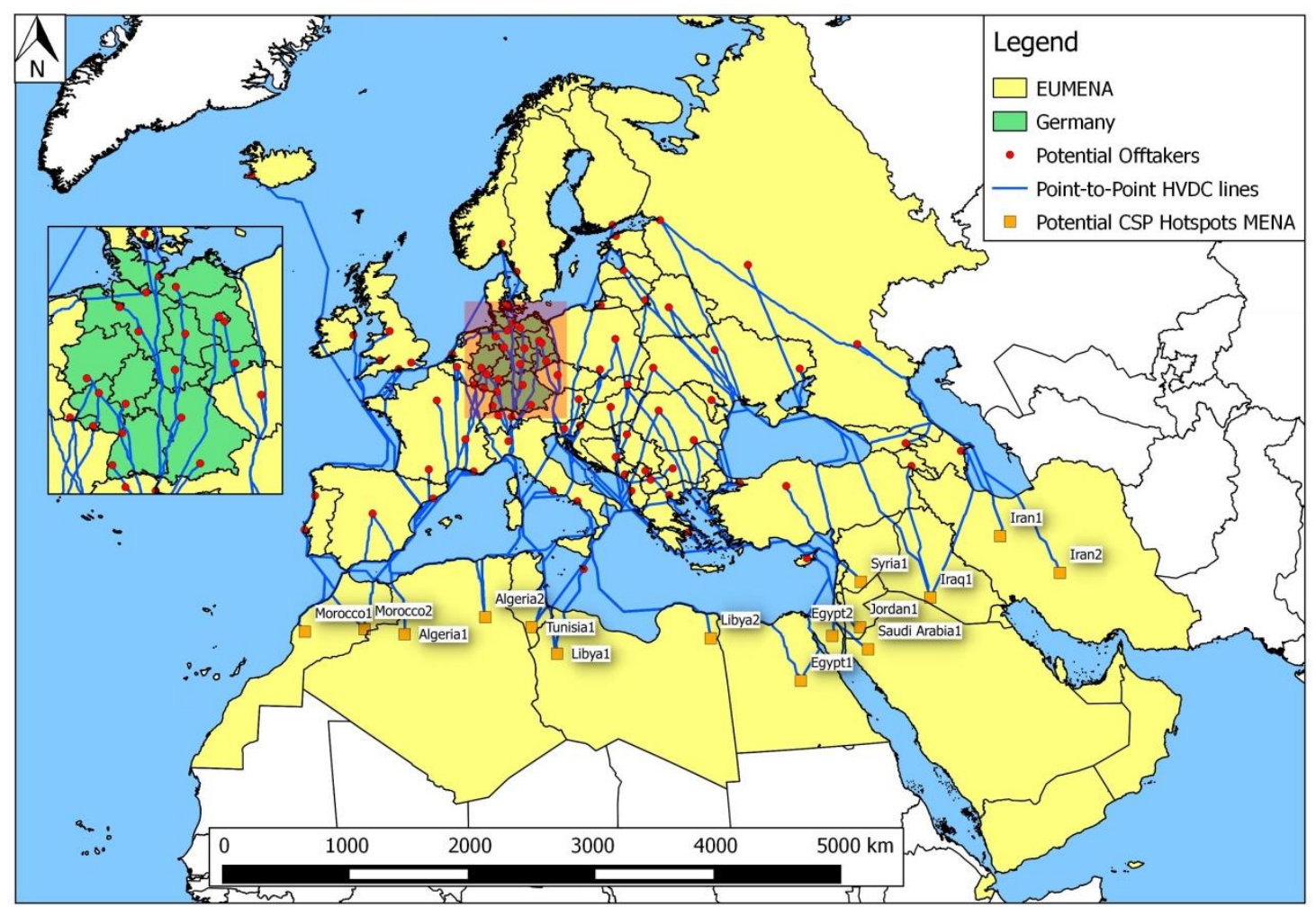

Figure 27: Point-to-point CSP-HVDC with potential CSP hotspots in MENA and potential offtakers in Europe - predominant offshore configuration (sea cable and UGC case) 
Post-print - Please quote as: Hess, D. The empirical probability of integrating CSP and its cost optimal configuration in a low carbon energy system of EUMENA. Solar Energy, 2018 (accepted)

For Germany a relatively high number of offtakers is included to identify precisely the average length of a specific point-to-point line.

\subsubsection{Supply technologies and their resource potentials}

Table 10 shows the model limitations by resource potential of the listed technologies. Other used technologies or technological components (e.g. storage size) have unlimited potentials.

Table 10: Limited resource potentials of used technologies

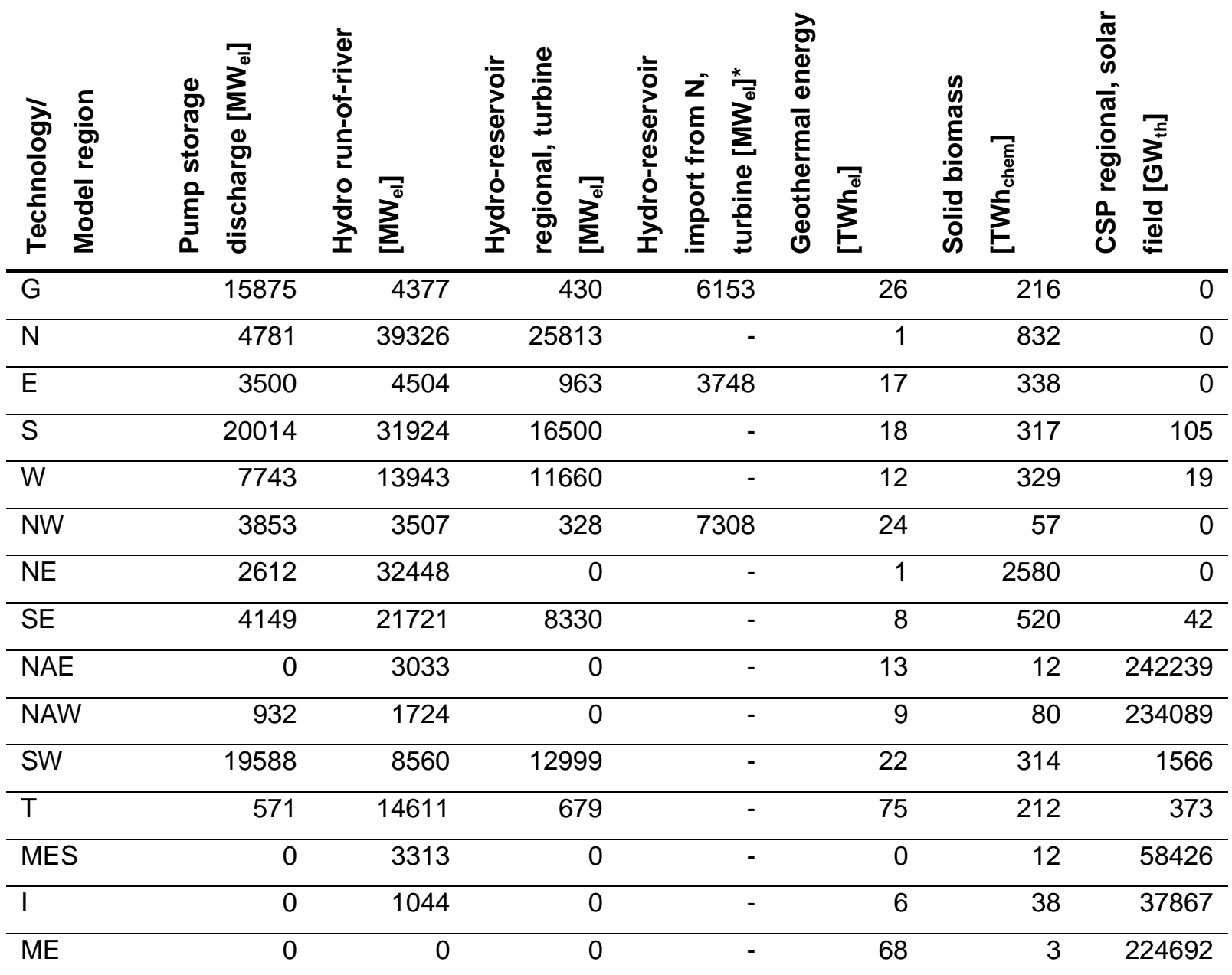

${ }^{*}$ The import potential of hydro reservoir from model region $\mathrm{N}$ to $\mathrm{G}, \mathrm{E}$ and $\mathrm{NW}$ is calculated with $40 \%$ of the available potential in $\mathrm{N}$ and distributed due to the electricity of the destination model regions. Thus, $60 \%$ of the original potential remains in model region $\mathrm{N}$.

Potential of pump storage discharge is taken from [30] "T2 realisable (5km)" with energy to power ratio of 7 and a reduced potential of $75.5 \%$. This reduced potential is achieved comparing the cost-efficient pump storage discharge potential in Germany of $15 \mathrm{GW}$ [31] to the study values with 20GW [30]. Potential of hydro run-of-river and CSP is taken from [11] 
Post-print - Please quote as: Hess, D. The empirical probability of integrating CSP and its cost optimal configuration in a low carbon energy system of EUMENA. Solar Energy, 2018 (accepted)

for Europe and from [12] for MENA. Potential of hydro-reservoir is taken from [32] using a power plant matching in Europe and for Turkey from [11]. Potential of geothermal energy is taken from [1], [2] and for Germany from [33]. Net primary production (NPP) potential of solid biomass is taken from model values of [34]. The assumed usable energy potential consists of $25 \%$ of total tree NPP and of $20 \%$ of total straw NPP of the year 2010 .

\subsubsection{Annual characteristic of load and renewable resources}

For a regional comparison of renewable resources and demand Table 11 shows peak load and average full load hours of model regions.

Table 11: Peak load and average resource full load hours of model regions

\begin{tabular}{|c|c|c|c|c|c|c|c|}
\hline \multirow[b]{2}{*}{$\begin{array}{l}\text { Model } \\
\text { region }\end{array}$} & \multirow[b]{2}{*}{$\begin{array}{l}\text { Peak } \\
\text { Load } \\
{[G W]}\end{array}$} & \multicolumn{6}{|c|}{ Average resource full load hours [h/y] } \\
\hline & & PV & $\begin{array}{c}\text { Wind } \\
\text { Onshore }\end{array}$ & $\begin{array}{c}\text { Wind } \\
\text { Offshore }\end{array}$ & $\begin{array}{l}\text { Hydro } \\
\text { Run Of } \\
\text { River }\end{array}$ & $\begin{array}{c}\text { CSP } \\
\text { solar } \\
\text { field } \\
\text { national }\end{array}$ & $\begin{array}{c}\text { CSP } \\
\text { solar } \\
\text { field } \\
\text { import }\end{array}$ \\
\hline $\bar{G}$ & 112 & 836 & 2107 & 4125 & 5015 & - & 1934 \\
\hline $\mathrm{N}$ & 99 & 867 & 2023 & 3810 & 4137 & - & 1980 \\
\hline $\mathrm{E}$ & 69 & 1016 & 1731 & 3207 & 2396 & - & 2011 \\
\hline S & 112 & 1139 & 1353 & 1917 & 3033 & 1914 & 1943 \\
\hline $\mathrm{W}$ & 155 & 1027 & 2110 & 3626 & 2543 & 1881 & 1926 \\
\hline NW & 134 & 789 & 3721 & 4309 & 3606 & - & 1916 \\
\hline $\mathrm{NE}$ & 170 & 1011 & 2251 & 3260 & 3220 & - & 1939 \\
\hline SE & 54 & 1118 & 1290 & 2265 & 2432 & 1938 & 1997 \\
\hline NAE & 182 & 1747 & 1257 & 1939 & 4219 & 2135 & - \\
\hline NAW & 112 & 1701 & 2179 & 3096 & 1925 & 2026 & - \\
\hline SW & 57 & 1309 & 1555 & 2418 & 1551 & 2034 & 1897 \\
\hline$T$ & 113 & 1494 & 1312 & 1767 & 3266 & 1847 & 1966 \\
\hline MES & 165 & 1620 & 1661 & 1400 & 4096 & 1881 & - \\
\hline I & 152 & 1671 & 1591 & 1725 & 4957 & 1972 & - \\
\hline $\mathrm{ME}$ & 170 & 1749 & 1577 & 1765 & - & 2105 & - \\
\hline
\end{tabular}

The average resource full load hours are a result of an aggregation of the spatial availability of the resource. Full load hours of CSP solar field import represent an average of selected 
Post-print - Please quote as: Hess, D. The empirical probability of integrating CSP and its cost optimal configuration in a low carbon energy system of EUMENA. Solar Energy, 2018 (accepted)

sites in EUMENA which leads to a more conservative approach than for CSP solar field national.

\subsection{Used techno-economic data}

The objective of the analysis is to model CSP-HVDC and CSP relative conservatively compared to other technologies. This facilitates a conservative examination of CSP-HVDC and CSP to analyse their value strictly avoiding an overestimation of this technology. Therefore the applied techno-economic data for other technologies are rather optimistic.

The bandwidth of cost assumptions $\left(€_{2015}\right)$ and technological characteristics in Table 12 to Table 18 are assumed from today's point of view and can differ from reality especially when projecting an energy system in the year 2050.

Table 12 to Table 18 include an exchange rate with $1 \$$ at the parity of $1.35 €$. Some values are based on a time value of money the year 2010 . Therefore an inflation rate of $10 \%$ is considered from 2010 to 2015 to calculate the time value of money of the year 2015 . The mean values are not listed in the tables but are calculated according to the average of max and min values. 
Post-print - Please quote as: Hess, D. The empirical probability of integrating CSP and its cost optimal configuration in a low carbon energy system of EUMENA. Solar Energy, 2018 (accepted)

Table 12: Cost and technology parameters for power plants in the year 2050 based on expert assumptions

\begin{tabular}{|c|c|c|c|c|c|c|c|c|c|c|}
\hline Technology & $\begin{array}{l}\text { Cost } \\
\text { sensi- } \\
\text { tivity } \\
\end{array}$ & $\begin{array}{c}\text { Specific investment } \\
{[k \in / M W e l]}\end{array}$ & $\begin{array}{l}\text { O\&M Fix [\%/y] } \\
\text { of investment }\end{array}$ & $\begin{array}{c}\text { O\&M Variable } \\
\text { [€/MWh] }\end{array}$ & $\begin{array}{l}\text { Fuel cost } \\
\text { [€/MWh] }\end{array}$ & $\begin{array}{l}\text { Amortisation } \\
\text { Time [y] }\end{array}$ & $\begin{array}{c}\text { Interest } \\
\text { Rate }\end{array}$ & $\begin{array}{c}\text { Efficiency [-] } \\
\text { net }\end{array}$ & Availability & Capacity Credit [-] \\
\hline \multirow[t]{2}{*}{ Photovoltaics } & $\max$ & 1150 & 0.04 & 0.00 & & 20 & $9 \%$ & \multirow{2}{*}{1} & \multirow{2}{*}{$98 \%$} & \multirow{2}{*}{0} \\
\hline & $\min$ & 597 & 1.10 & 0.00 & & 40 & $3 \%$ & & & \\
\hline \multirow[t]{2}{*}{ Wind Onshore } & $\max$ & 1272 & 2.10 & 4.33 & & 18 & $9 \%$ & \multirow{2}{*}{1} & \multirow{2}{*}{$95 \%$} & \multirow{2}{*}{0} \\
\hline & $\min$ & 769 & 1.61 & 2.44 & & 24 & $3 \%$ & & & \\
\hline \multirow[t]{2}{*}{ Wind Offshore } & $\max$ & 2275 & 3.64 & 13.87 & & 16 & $9 \%$ & \multirow{2}{*}{1} & \multirow{2}{*}{$95 \%$} & \multirow{2}{*}{0} \\
\hline & $\min$ & 1052 & 3.49 & 9.55 & & 22 & $3 \%$ & & & \\
\hline \multirow[t]{2}{*}{ Run-Of-River } & $\max$ & 5541 & 5.50 & 4.84 & & 40 & $9 \%$ & \multirow{2}{*}{1} & \multirow{2}{*}{$95 \%$} & \multirow{2}{*}{0} \\
\hline & $\min$ & 5541 & 2.75 & 2.44 & & 60 & $3 \%$ & & & \\
\hline \multirow{2}{*}{$\begin{array}{l}\text { Hydro } \\
\text { Reservoir* }\end{array}$} & $\max$ & 2113 & 5.00 & 1.00 & & 40 & $9 \%$ & \multirow{2}{*}{1} & \multirow{2}{*}{$98 \%$} & \multirow{2}{*}{0} \\
\hline & $\min$ & 1017 & 5.00 & 1.00 & & 30 & $3 \%$ & & & \\
\hline \multirow[t]{2}{*}{ Solid Biomass } & $\max$ & 3833 & 1.98 & 3.20 & 40.0 & 20 & $9 \%$ & \multirow{2}{*}{0.35} & \multirow{2}{*}{$90 \%$} & \multirow{2}{*}{0.9} \\
\hline & $\min$ & 1647 & 5.60 & 2.90 & 25.0 & 30 & $3 \%$ & & & \\
\hline \multirow[t]{2}{*}{ Geothermal } & $\max$ & 6797 & 3.00 & 0.10 & & 20 & $9 \%$ & \multirow{2}{*}{1} & \multirow{2}{*}{$90 \%$} & \multirow{2}{*}{0.9} \\
\hline & $\min$ & 3826 & 3.00 & 0.10 & & 30 & $3 \%$ & & & \\
\hline \multirow{2}{*}{$\begin{array}{l}\text { CSP power } \\
\text { block }\end{array}$} & $\max$ & 1098 & 2.50 & 2.22 & & 35 & $9 \%$ & \multirow[b]{2}{*}{0.37} & \multirow[b]{2}{*}{$95 \%$} & \multirow{2}{*}{$\begin{array}{c}\text { modelled with } 0 \text {, } \\
\text { however } 0.9 \text { is possible } \\
\text { accepting firm capacity } \\
\text { abroad }\end{array}$} \\
\hline & $\min$ & 857 & 2.50 & 2.22 & & 45 & $3 \%$ & & & \\
\hline \multirow[t]{2}{*}{ CSP solar field } & $\max$ & $356 \mathrm{k} € / \mathrm{MW}_{\text {thermal }}$ & 2.50 & & & 20 & $9 \%$ & & & \\
\hline & $\min$ & $166 \mathrm{k} \in / \mathrm{MW}_{\text {thermal }}$ & 2.50 & & & 30 & $3 \%$ & & $90 \%$ & - \\
\hline CSP thermal & $\max$ & $18 \mathrm{k} \in / \mathrm{MWh}$ & 2.50 & & & 20 & $9 \%$ & & & \\
\hline sturage & $\min$ & $11 \mathrm{k} € / \mathrm{MWh}$ & 2.50 & & & 30 & $3 \%$ & $\begin{array}{c}\text { self-discharge } \\
\text { rate }\end{array}$ & $95 \%$ & - \\
\hline
\end{tabular}

Sources: [35], [36], [37], [38], [39], [40], own assumptions 
Post-print - Please quote as: Hess, D. The empirical probability of integrating CSP and its cost optimal configuration in a low carbon energy system of EUMENA. Solar Energy, 2018 (accepted)

Table 13: Cost and technology parameters for storages in the year 2050

\begin{tabular}{|c|c|c|c|c|c|c|c|c|c|}
\hline 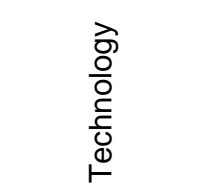 & 岕 & 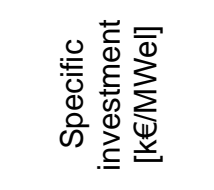 & 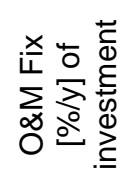 & $\sum_{\infty} \frac{\frac{0}{0}}{\frac{\pi}{0}} \sum_{>}^{\frac{T}{\pi}}$ & 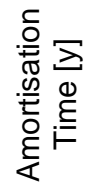 & 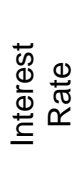 & 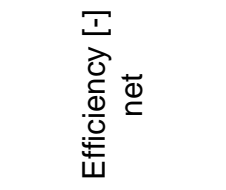 & 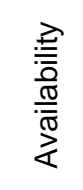 & 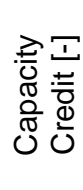 \\
\hline \multirow{2}{*}{$\begin{array}{l}\text { Pump } \\
\text { Storage } \\
\text { storage }\end{array}$} & $\max$ & $40 \mathrm{k} \in / \mathrm{MWh}$ & 2.80 & - & 30 & $9 \%$ & \multirow{2}{*}{$\begin{array}{c}0 \% / h \\
\text { self-discharge } \\
\text { rate }\end{array}$} & \multirow{6}{*}{$95 \%$} & \multirow[b]{2}{*}{ - } \\
\hline & $\min$ & $5 \mathrm{k} \in / \mathrm{MWh}$ & 1.86 & - & 40 & $3 \%$ & & & \\
\hline \multirow{2}{*}{$\begin{array}{l}\text { Pump } \\
\text { Storage } \\
\text { charge }\end{array}$} & $\max$ & 400 & 2.80 & 3.80 & 20 & $9 \%$ & \multirow{2}{*}{0.89} & & \multirow[b]{2}{*}{ - } \\
\hline & $\min$ & 180 & 1.86 & 3.80 & 30 & $3 \%$ & & & \\
\hline \multirow{2}{*}{$\begin{array}{l}\text { Pump } \\
\text { Storage } \\
\text { discharge }\end{array}$} & $\max$ & 400 & 2.80 & - & 20 & $9 \%$ & \multirow{2}{*}{0.90} & & \multirow{2}{*}{0} \\
\hline & $\min$ & 170 & 1.86 & - & 30 & $3 \%$ & & & \\
\hline \multirow{2}{*}{$\begin{array}{l}\text { Power-to- } \\
\text { Gas-to- } \\
\text { Power } \\
\text { (P2G2P) } \\
\text { Storage }\end{array}$} & $\max$ & $0.20 \mathrm{k} € / \mathrm{MWh}$ & 3.00 & - & 25 & $9 \%$ & \multirow[b]{2}{*}{$\begin{array}{c}0 \% / h \\
\text { self-discharge } \\
\text { rate }\end{array}$} & \multirow[b]{4}{*}{$95 \%$} & \multirow[b]{2}{*}{ - } \\
\hline & $\min$ & $0.20 \mathrm{k} € / \mathrm{MWh}$ & 2.42 & - & 35 & $3 \%$ & & & \\
\hline \multirow{2}{*}{$\begin{array}{l}\text { Power-to- } \\
\text { Gas-to- } \\
\text { Power } \\
\text { (P2G2P) } \\
\text { charge }\end{array}$} & $\max$ & $\begin{array}{c}1206=606 \\
\text { (alkali } \\
\text { electrolysis) } \\
+600 \\
\text { (methanation) }\end{array}$ & 3.00 & 2.30 & 15 & $9 \%$ & \multirow{2}{*}{$\begin{array}{c}0.70= \\
0.79 \\
\text { (methanation) } \\
\times 0.89 \\
\text { (compression) }\end{array}$} & & \multirow[b]{2}{*}{ - } \\
\hline & $\min$ & $\begin{array}{c}922=322 \\
\text { (PEM } \\
\text { electrolysis) } \\
+600 \\
\text { (methanation) }\end{array}$ & 2.42 & 1.64 & 20 & $3 \%$ & & & \\
\hline \multirow{2}{*}{$\begin{array}{l}\text { Power-to- } \\
\text { Gas-to- } \\
\text { Power } \\
\text { (P2G2P) } \\
\text { discharge } \\
\text { (gas turbine) }\end{array}$} & $\max$ & 713 & 3.00 & - & 25 & $9 \%$ & \multirow[b]{2}{*}{0.465} & & \multirow[b]{2}{*}{0.95} \\
\hline & $\min$ & 417 & 2.42 & - & 40 & $3 \%$ & & & \\
\hline \multirow{2}{*}{$\begin{array}{l}\text { Compressed } \\
\text { Air Storage } \\
\text { storage }\end{array}$} & $\max$ & $60 \mathrm{k} € / \mathrm{MWh}$ & 1.30 & - & 25 & $9 \%$ & \multirow{2}{*}{$\begin{array}{c}0.125 \% / h \\
\text { self-discharge } \\
\text { rate }\end{array}$} & \multirow{6}{*}{$95 \%$} & \multirow{2}{*}{ - } \\
\hline & $\min$ & $38 \mathrm{k} € / \mathrm{MWh}$ & 1.30 & - & 35 & $3 \%$ & & & \\
\hline \multirow{2}{*}{$\begin{array}{l}\text { Compressed } \\
\text { Air Storage } \\
\text { charge }\end{array}$} & $\max$ & 310 & 1.30 & 2.70 & 20 & $9 \%$ & \multirow{2}{*}{0.88} & & \multirow{2}{*}{-} \\
\hline & $\min$ & 200 & 1.30 & 0.10 & 30 & $3 \%$ & & & \\
\hline \multirow{2}{*}{$\begin{array}{l}\text { Compressed } \\
\text { Air Storage } \\
\text { discharge }\end{array}$} & $\max$ & 400 & 1.30 & - & 25 & $9 \%$ & \multirow{2}{*}{0.70} & & \multirow{2}{*}{0} \\
\hline & $\min$ & 260 & 1.30 & - & 35 & $3 \%$ & & & \\
\hline \multirow{2}{*}{$\begin{array}{l}\text { Lithium Ion } \\
\text { storage }\end{array}$} & $\max$ & $220 \mathrm{k} € / \mathrm{MWh}$ & 2.00 & - & 15 & $9 \%$ & \multirow{2}{*}{$\begin{array}{c}0.001 \% / h \\
\text { self-discharge } \\
\text { rate }\end{array}$} & & \\
\hline & $\min$ & $150 \mathrm{k} € / \mathrm{MWh}$ & 2.00 & - & 25 & $3 \%$ & & & - \\
\hline Lithium Ion & $\max$ & 25 & 2.00 & 0.22 & 15 & $9 \%$ & & & \\
\hline charge & $\min$ & 12.5 & 2.00 & 0.22 & 25 & $3 \%$ & 0.97 & $95 \%$ & - \\
\hline Lithium Ion & $\max$ & 25 & 2.00 & - & 15 & $9 \%$ & 07 & & 0 \\
\hline discharge & $\min$ & 12.5 & 2.00 & - & 25 & $3 \%$ & 0.97 & & 0 \\
\hline
\end{tabular}

Sources: [41], [42], [43], own assumptions 
Post-print - Please quote as: Hess, D. The empirical probability of integrating CSP and its cost optimal configuration in a low carbon energy system of EUMENA. Solar Energy, 2018 (accepted)

Table 14: Cost and technology parameters for carbon emitting and nuclear technologies in the year 2050

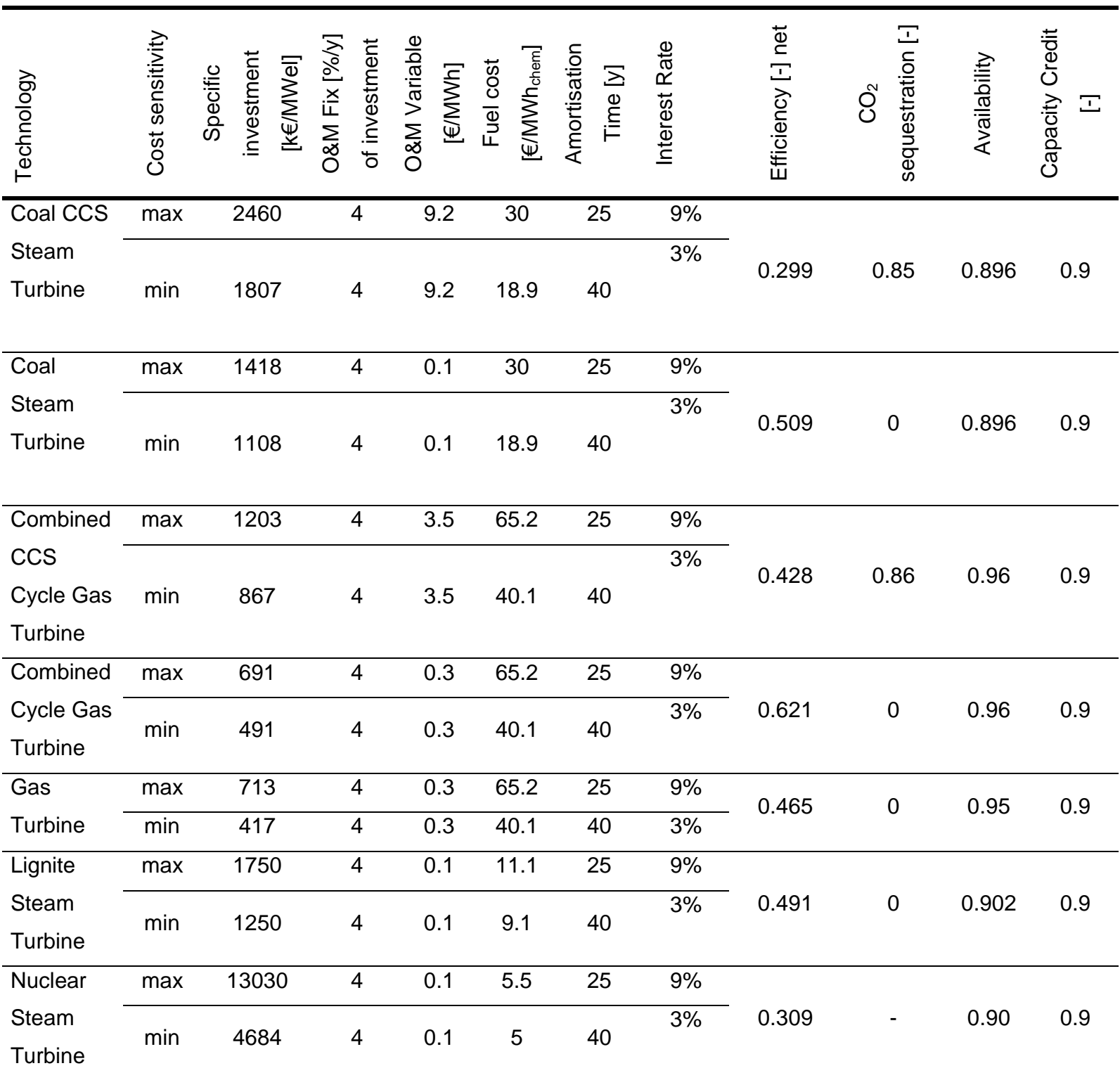

Sources: [40], [44], [45], [46], own assumptions, CCS O\&M Variable are based on cost for $\mathrm{CO}_{2}$ transport (3€/t) and CO2 storage $(4.45 € / t)[47]$ 
Post-print - Please quote as: Hess, D. The empirical probability of integrating CSP and its cost optimal configuration in a low carbon energy system of EUMENA. Solar Energy, 2018 (accepted)

Table 15: Specific $\mathrm{CO}_{2}$ emission

\begin{tabular}{lc}
\hline Fuel & $\mathrm{tCO}_{2} / \mathrm{MWh}_{\text {chem }}$ \\
\hline Coal & 0.3348 \\
\hline Lignite & 0.3996 \\
\hline Natural Gas & 0.2016 \\
\hline Nuclear & 0 \\
\hline Biomass & 0 \\
\hline Source: [40]
\end{tabular}

Table 16: $\mathrm{CO}_{2}$ certificate cost representing environmental impact

\begin{tabular}{lc}
\hline Cost sensitivity & $€ / \mathrm{tCO}_{2}$ \\
\hline $\max$ & 82.5 \\
\hline mean & 62.7 \\
\hline $\min$ & 49.5 \\
\hline
\end{tabular}

Source: [40]

Table 17: Techno-economic parameters of HVDC infrastructure

\begin{tabular}{llll}
\hline & DC & DC converter & Losses \\
\hline OHL & $786.000 € / \mathrm{km}$ & $\begin{array}{l}148.730 .000 € \\
\text { per station }\end{array}$ & $4.5 \% / 1000 \mathrm{~km}$ \\
\hline UGC & $2.271 .350 € / \mathrm{km}$ & $\begin{array}{l}148.730 .000 € \\
\text { per station }\end{array}$ & $3.5 \% / 1000 \mathrm{~km}$ \\
\hline Sea cable & $2.672 .000 € / \mathrm{km}$ & $\begin{array}{l}148.730 .000 € \\
\text { per station }\end{array}$ & $2.7 \% / 1000 \mathrm{~km}$ \\
\hline Specific Capacity & $1500 \mathrm{MW}$ & $1500 \mathrm{MW}$ & \\
\hline Specific Voltage & $600 \mathrm{kV}$ & &
\end{tabular}

Losses of converter station are assumed with $0.7 \%$. Sources: [48], [3], [49].

Table 18: Learning curve approach of CSP solar field, thermal storage and power block based on installed capacity and progress ratio

\begin{tabular}{|c|c|c|c|c|c|c|c|c|}
\hline 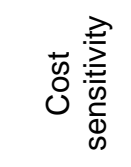 & 壱 & 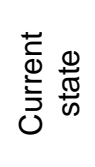 & $\stackrel{x}{\Sigma}$ & $\underset{⿱ 亠 凶}{\stackrel{\rightleftarrows}{\Sigma}}$ & $\underline{z}$ & $\stackrel{.=}{\vec{c}}$ & 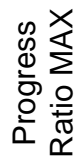 & 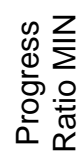 \\
\hline year & & 2015 & 2050 & 2050 & 2050 & & & \\
\hline $\begin{array}{l}\text { Installed } \\
\text { capacity }\end{array}$ & MW & 4,700 & 120,000 & 835,000 & $1,550,000$ & & & \\
\hline $\begin{array}{l}\text { Solar } \\
\text { Field }\end{array}$ & {$\left[\mathrm{k} \in / \mathrm{MW}_{\mathrm{th}}\right]$} & 647 & 355 & 260 & 166 & {$[-]$} & 0.88 & 0.85 \\
\hline $\begin{array}{l}\text { Thermal } \\
\text { Storage }\end{array}$ & {$\left[\mathrm{k} \in / \mathrm{MWh}_{\mathrm{th}}\right]$} & 50 & 19 & 15 & 11 & {$[-]$} & 0.80 & 0.83 \\
\hline $\begin{array}{l}\text { Power } \\
\text { Block }\end{array}$ & {$\left[\mathrm{k} \in / \mathrm{MW}_{\mathrm{el}}\right]$} & 1206 & 1098 & 978 & 857 & {$[-]$} & 0.98 & 0.96 \\
\hline
\end{tabular}

Sources: based on [50] and [3], [51], [52], [53] 
Post-print - Please quote as: Hess, D. The empirical probability of integrating CSP and its cost optimal configuration in a low carbon energy system of EUMENA. Solar Energy, 2018 (accepted)

\subsubsection{Node-internal transmission and distribution grid}

In a novel approach the region internal grid is modelled respecting the main grid expansion drivers: wind and photovoltaics feed-in power into the grid. Grid expansion related to a rising demand is considered independently. The model is capable of making conclusions of grid expansion and curtailment of PV and wind energy in an optimized energy system. The region internal grid model is explained in [14]. The model uses two parameters to quantify the grid: start point of grid expansion in relation to peak load and specific cost per feed-in power of photovoltaics and wind turbines. The used parameters for each model region, distribution and transmission grid are listed in Table 19. 
Post-print - Please quote as: Hess, D. The empirical probability of integrating CSP and its cost optimal configuration in a low carbon energy system of EUMENA. Solar Energy, 2018 (accepted)

Table 19: Used parameters for distribution and transmission grid inside a model region

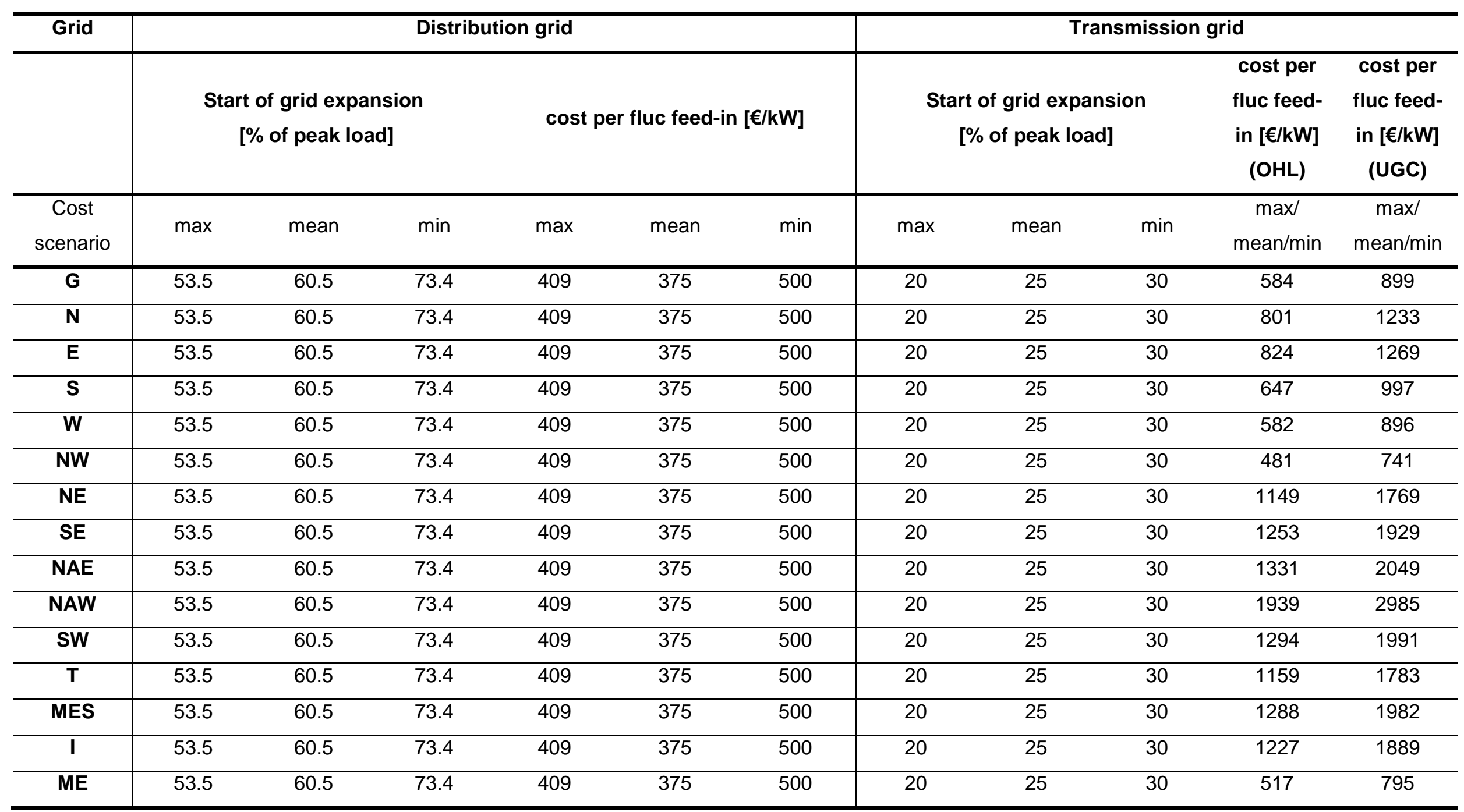


Post-print - Please quote as: Hess, D. The empirical probability of integrating CSP and its cost optimal configuration in a low carbon energy system of EUMENA. Solar Energy, 2018 (accepted)

\subsection{Configuration of CSP-HVDC and CSP as a result of the empirical probability analysis}

As additional results of the CSP-HVDC and CSP cost bandwidths, the technological configuration bandwidths are shown in Figure 28 by the solar multiple, in Figure 32 by the solar field capacity, in Figure 29 by the thermal energy storage, in Figure 30 by the electrical net generation and in Figure 31 by the electricity generation by co-firing. These results depend on the used cost sensitivities and show the difference between scenarios with 0 (first row of the figures $-\mathrm{a}, \mathrm{b}$ ) and $16 \mathrm{~g} \mathrm{CO}_{2} / \mathrm{kWh}_{\text {demand }}$ (second row of the figures $-\mathrm{b}, \mathrm{c}$ ) neglecting and including CCS (third row of the figures - e,f). The results show that high $\mathrm{CO}_{2}$ emission and the inclusion of CCS leads to lower CSP configuration values.

The results of sensitivity analysis show in Figure 28 the bandwidths of the solar multiple in the analysed regions with boxplots. In the left column the CSP-HVDC technology and in the right column the CSP technology is described. 
Post-print - Please quote as: Hess, D. The empirical probability of integrating CSP and its cost optimal configuration in a low carbon energy system of EUMENA. Solar Energy, 2018 (accepted)

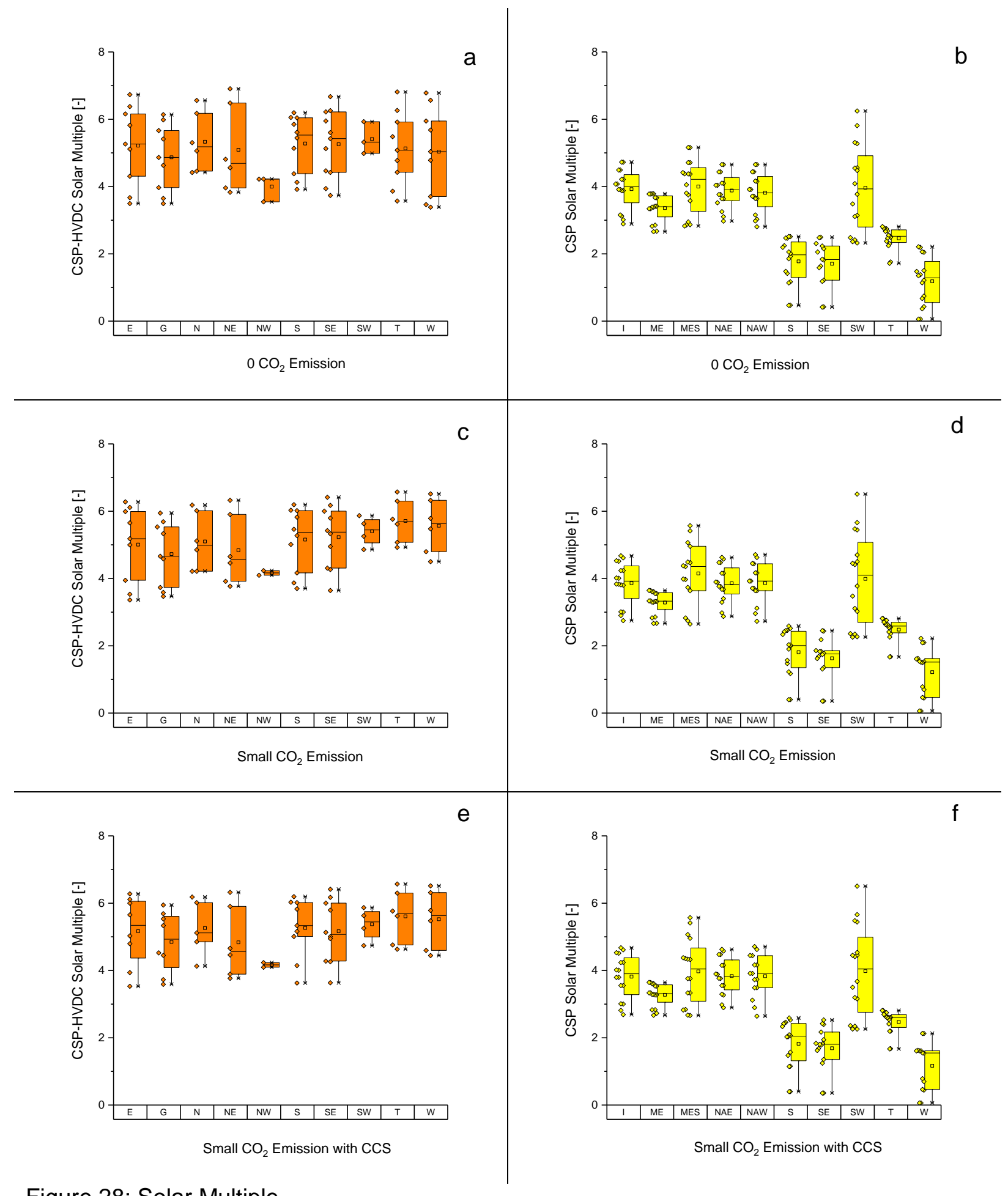

Figure 28: Solar Multiple 
Post-print - Please quote as: Hess, D. The empirical probability of integrating CSP and its cost optimal configuration in a low carbon energy system of EUMENA. Solar Energy, 2018 (accepted)

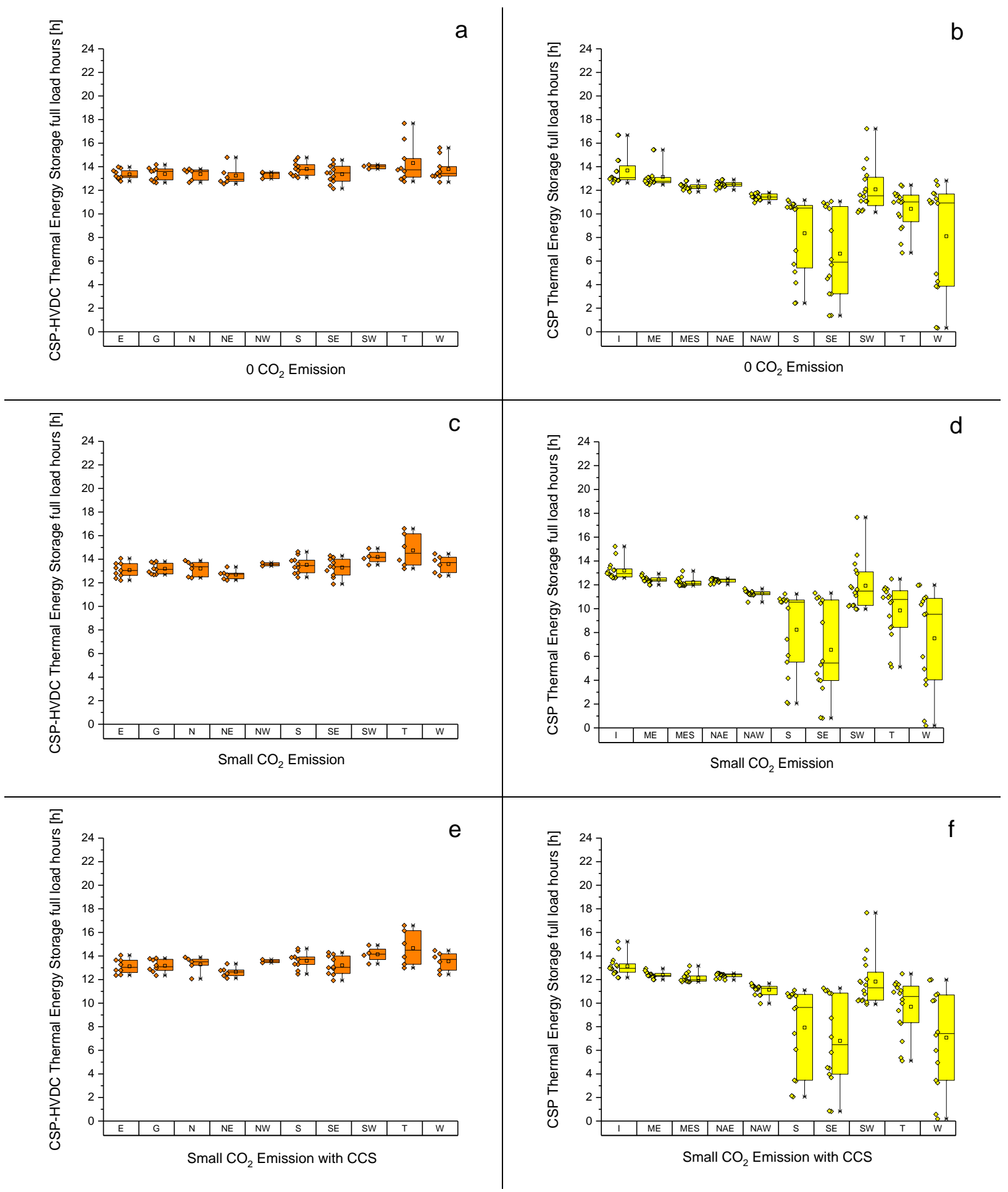

Figure 29: Thermal energy storage full load hours 
Post-print - Please quote as: Hess, D. The empirical probability of integrating CSP and its cost optimal configuration in a low carbon energy system of EUMENA. Solar Energy, 2018 (accepted)

Figure 30 shows the net electricity generation [TWh el $_{\text {l }}$ from CSP-HVDC and CSP. In the MENA region (regions I, ME, MES, NAE and NAW) the net electricity generation is relative high due to a high share of CSP. Also the use of the thermal energy storage in Figure 29 is high compared to other regions in MENA.

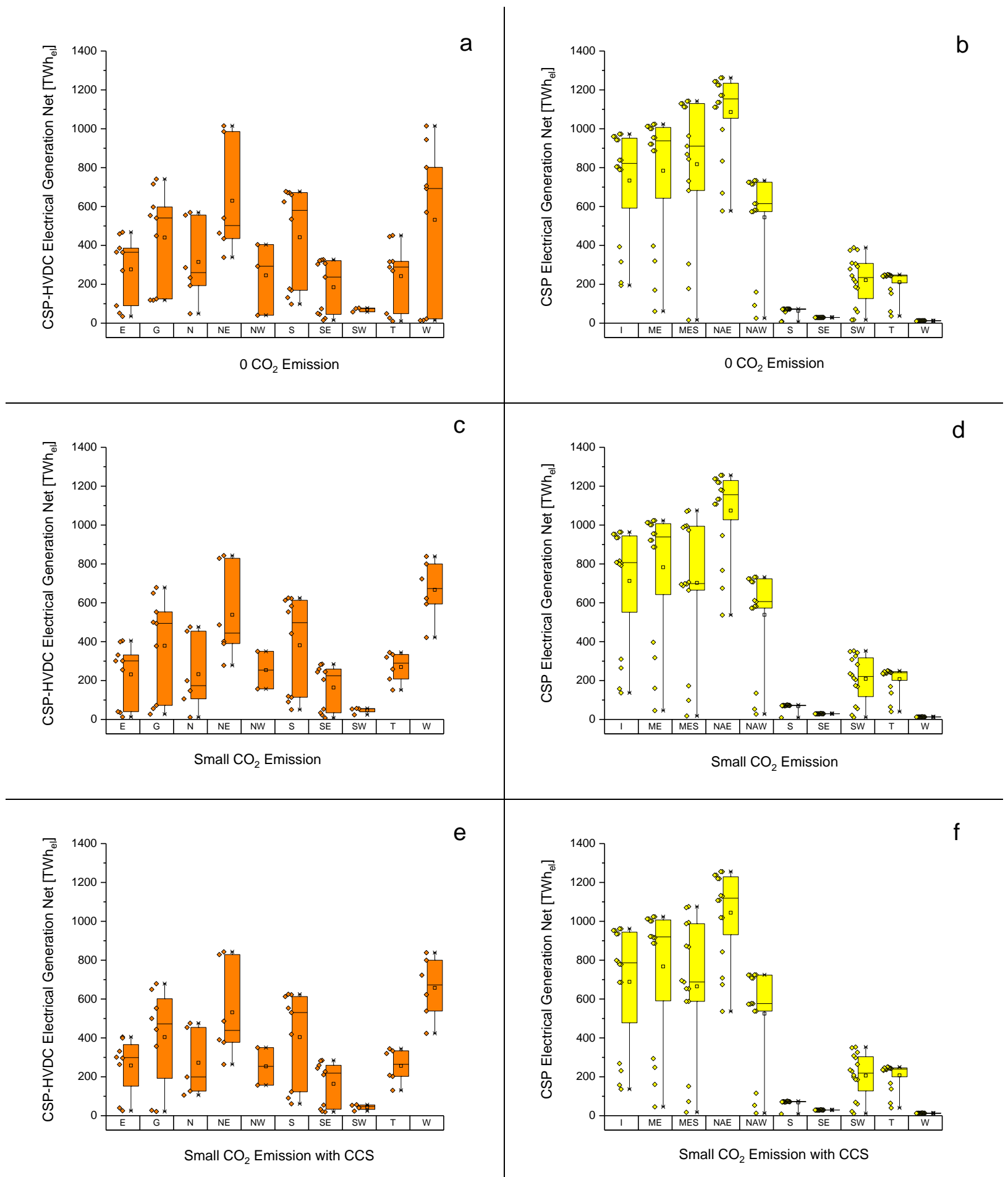

Figure 30: Electrical generation net of the CSP plant without transmission losses. 
Post-print - Please quote as: Hess, D. The empirical probability of integrating CSP and its cost optimal configuration in a low carbon energy system of EUMENA. Solar Energy, 2018 (accepted)

Figure 31 shows the co-firing with natural gas of the CSP-HVDC and CSP technologies. It can be seen in Figure 31d and $f$ that the electricity generation using co-firing compared to the net electrical generation is low (comparison of Figure 31 and Figure 30). However, some regions have a higher absolute co-firing value. This is not a result of different demand but a consequence of an hourly misfit of renewable energies and the demand curve. The integration of CCS technologies (here CSP has no CCS possibility) leads to a higher cofiring. Thus, it is more efficient to use the co-firing of CSP when CCS is integrated.

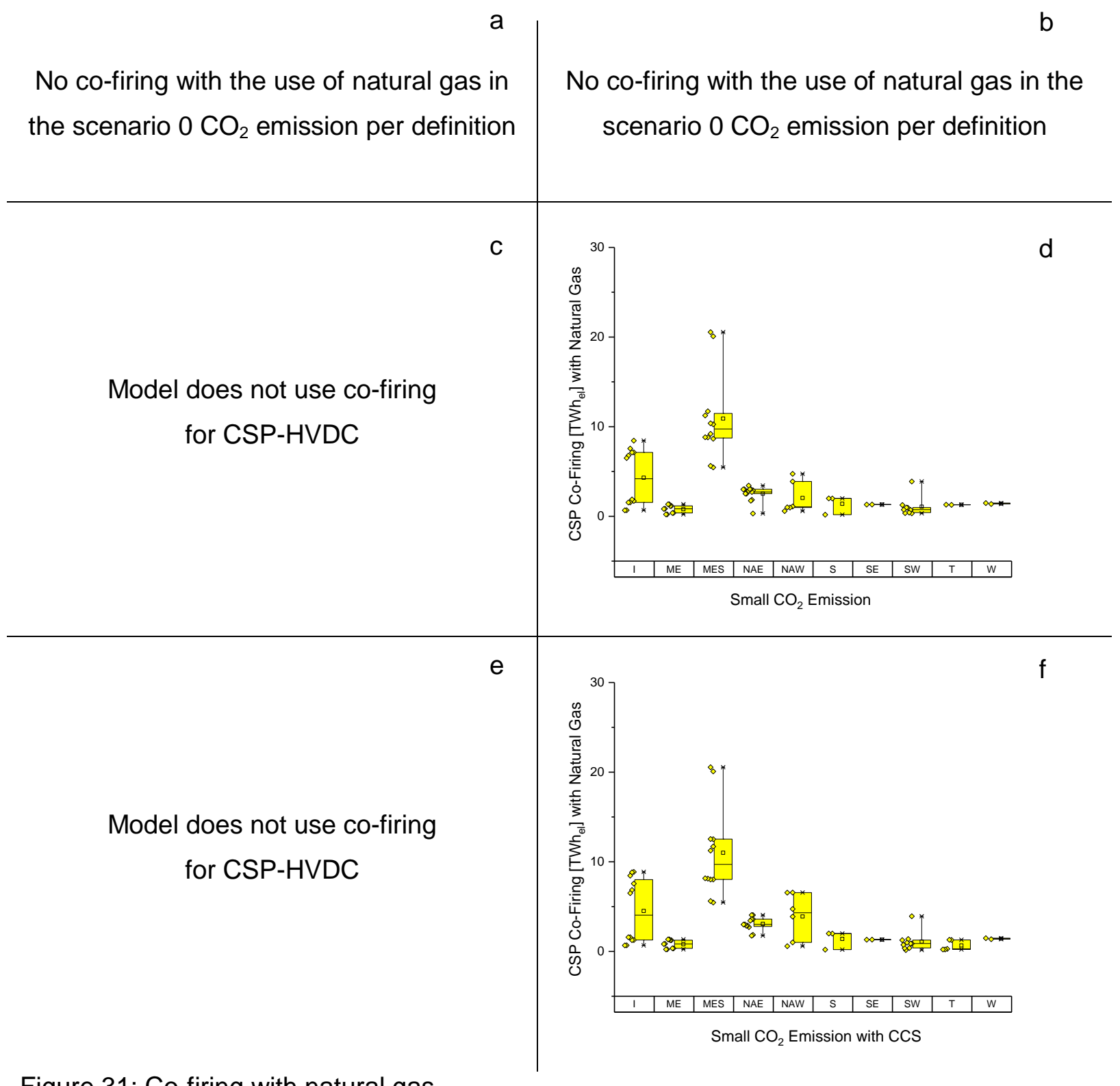

Figure 31: Co-firing with natural gas 
Post-print - Please quote as: Hess, D. The empirical probability of integrating CSP and its cost optimal configuration in a low carbon energy system of EUMENA. Solar Energy, 2018 (accepted)

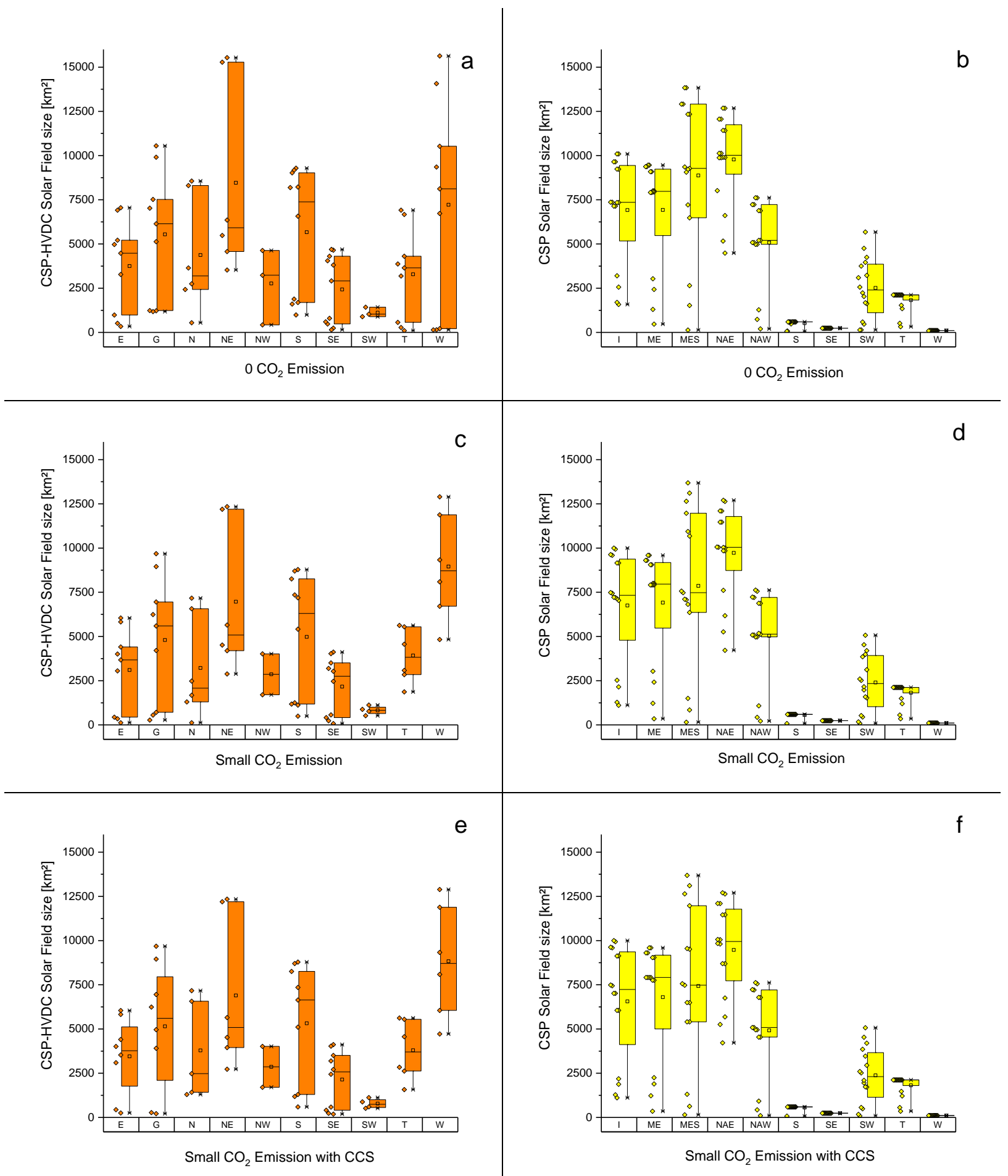

Figure 32: Solar field size - possible bandwidths of demand for land of CSP-HVDC and CSP 